U.S. Vepartment of the Interior / U.S. Geological Survey

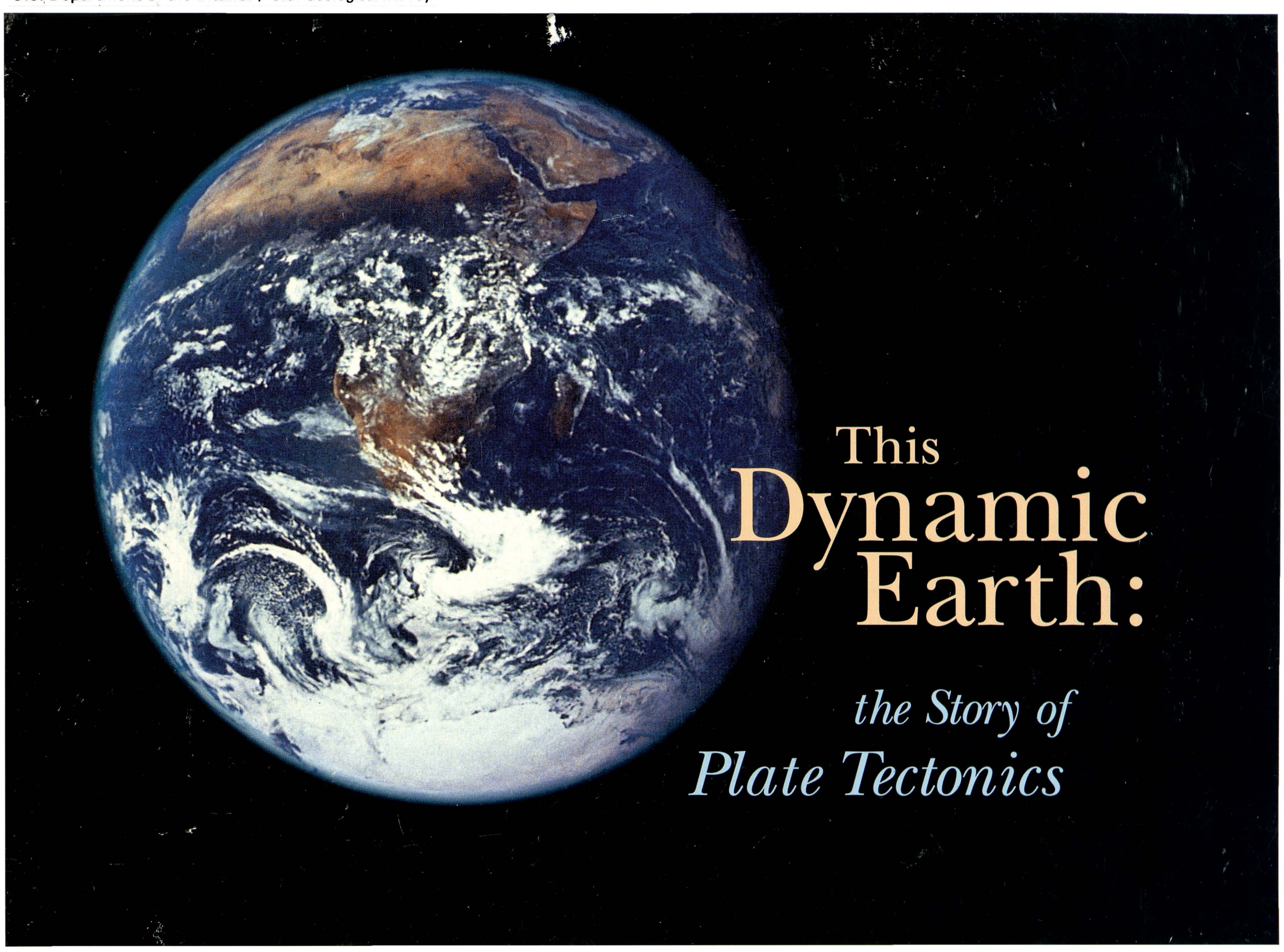




\section{Conversion of Units}

Metric units of measurement are used in this book, because they are the standard in virtually every country in the world except the United States. For readers who wish to convert measurements from metric units to English units, the conversion factors are listed below.

$\begin{array}{ccc}\text { Multiply } & \text { By } & \text { To obtain } \\ & \text { Length } & \\ \text { centimeter (cm) } & 0.39 & \text { inch } \\ \text { meter (m) } & 3.28 & \text { foot } \\ \text { meter }(\mathrm{m}) & 1.09 & \text { yard } \\ \text { kilometer }(\mathrm{km}) & 0.62 & \text { mile } \\ & & \\ & \text { Temperature } & \\ \text { degree Centigrade } & 1.80 \text { then } & \text { degree Fahrenheit } \\ \left({ }^{\circ} \mathrm{C}\right) & \text { add } 32 & \left({ }^{\circ} \mathrm{F}\right)\end{array}$

Front cover: View of planet Earth from the Apollo spacecraft. The Red Sea, which separates Saudi Arabia from the continent of Africa, is clearly visible at top. (Photograph courtesy of NASA.) 


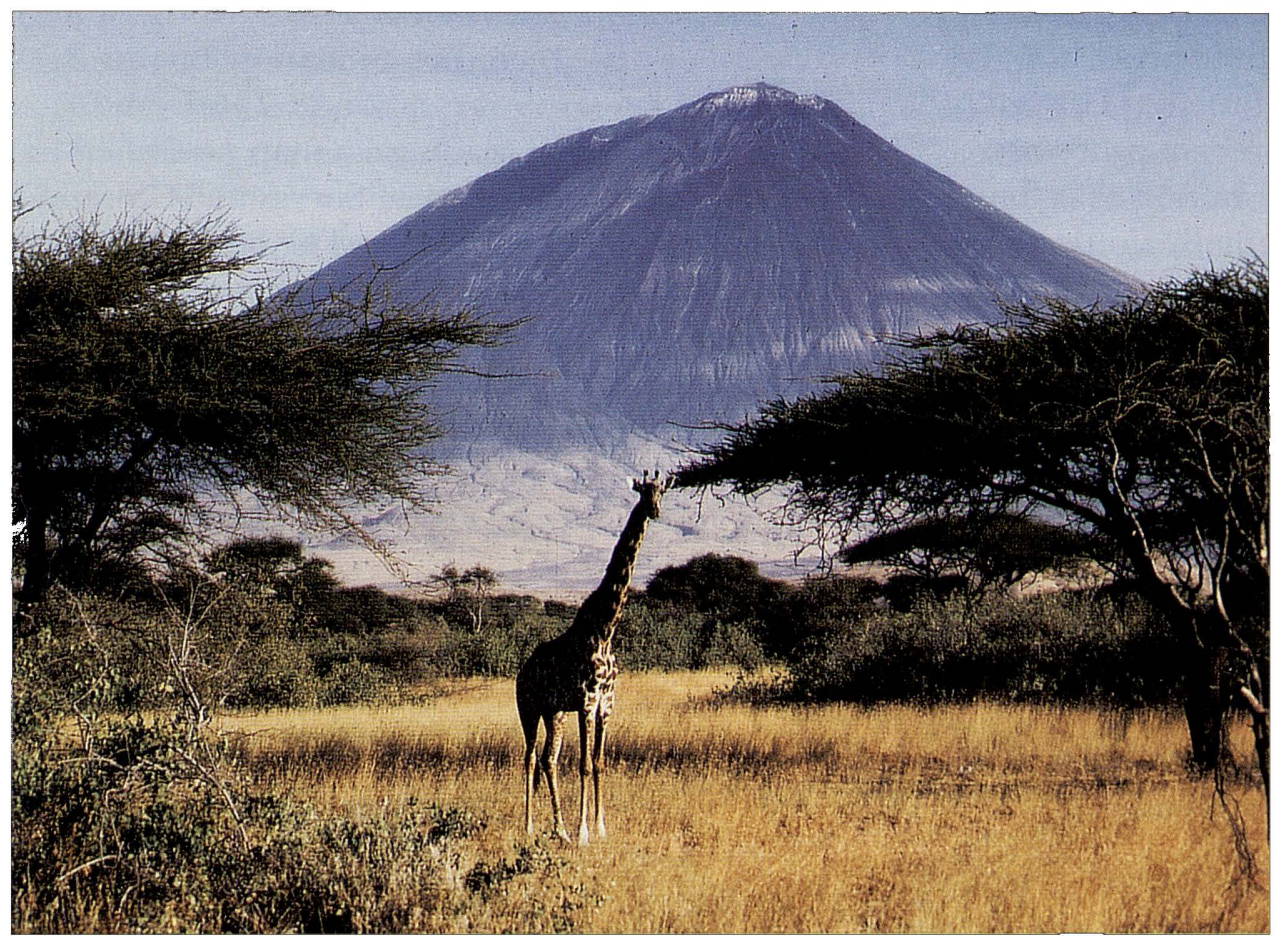

Oldoinyo Lengai, an active volcano in the East African Rift Zone, where Africa is being pulled apart by plate-tectonic processes. (Photograph by Jorg Keller, Albert-Ludwigs-Universität Freiburg, Germany.)

\section{This \\ Dynamic
Earth:}

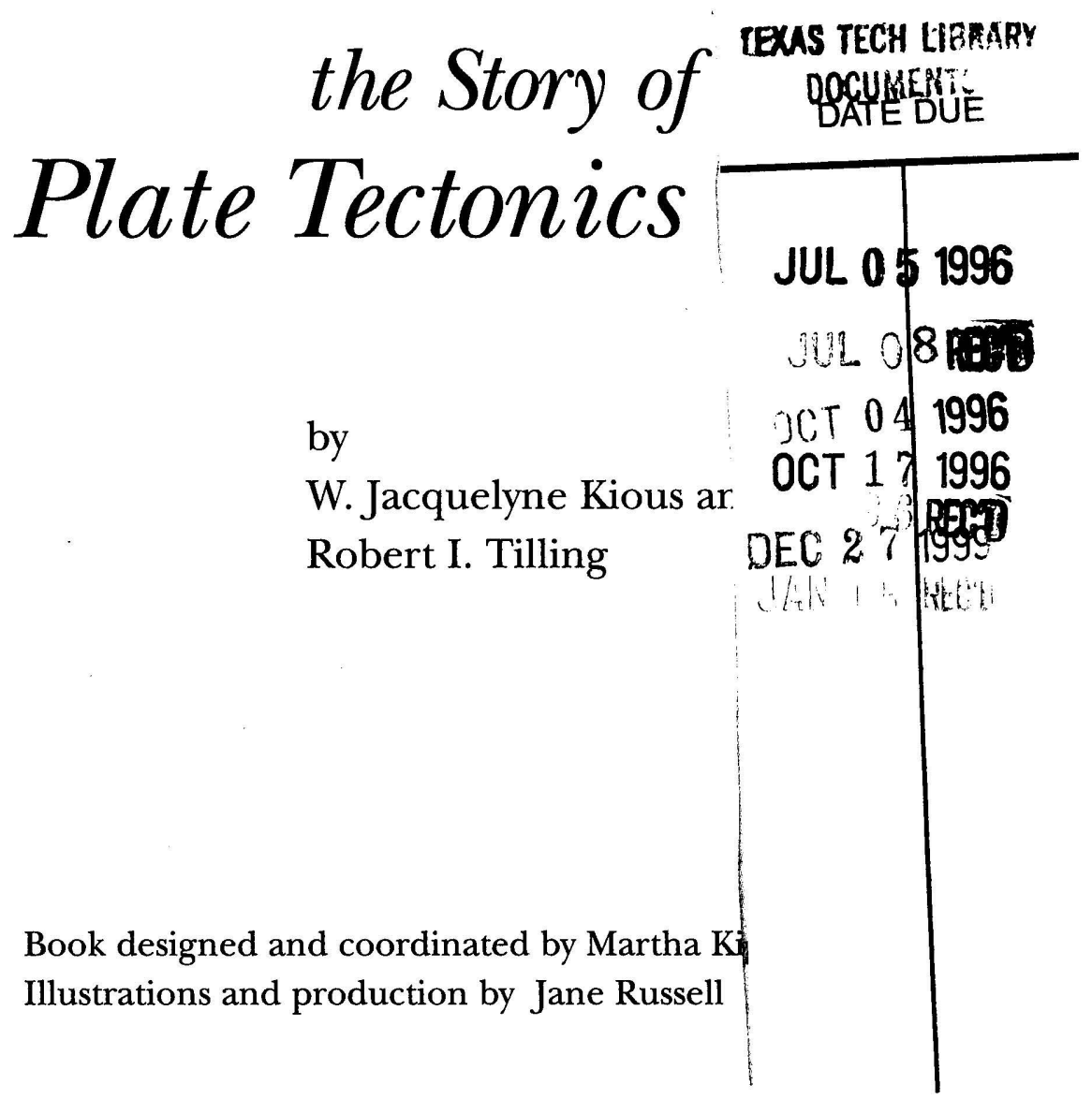

UPI 201-9509 PRINTED IN USA 


\section{Preface}

In the early 1960s, the emergence of the theory of plate tectonics started a revolution in the earth sciences. Since then, scientists have verified and refined this theory, and now have a much better understanding of how our planet has been shaped by plate-tectonic processes. We now know that, directly or indirectly, plate tectonics influences nearly all geologic processes, past and present. Indeed, the notion that the entire Earth's surface is continually shifting has profoundly changed the way we view our world.

People benefit from, and are at the mercy of, the forces and consequences of plate tectonics. With little or no warning, an earthquake or volcanic eruption can unleash bursts of energy far more powerful than anything we can generate. While we have no control over plate-tectonic processes, we now have the knowledge to learn from them. The more we know about plate tectonics, the better we can appreciate the grandeur and beauty of the land upon which we live, as well as the occasional violent displays of the Earth's awesome power.

This booklet gives a brief introduction to the concept of plate tectonics and complements the visual and written information in This Dynamic Planet (see Further reading), a map published in 1994 by the U.S. Geological Survey (USGS) and the Smithsonian Institution. The booklet highlights some of the people and discoveries that advanced the development of the theory and traces its progress since its proposal. Although the general idea of plate tectonics is now widely accepted, many aspects still continue to confound and challenge scientists. The earthscience revolution launched by the theory of plate tectonics is not finished.

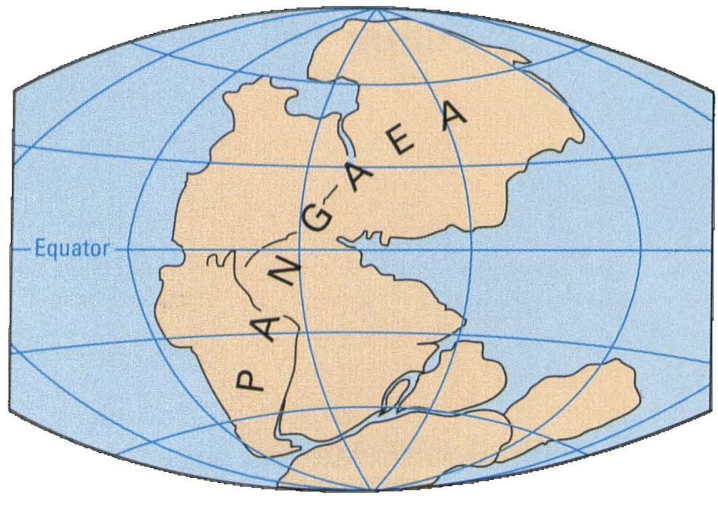

PERMIAN 225 million years ago
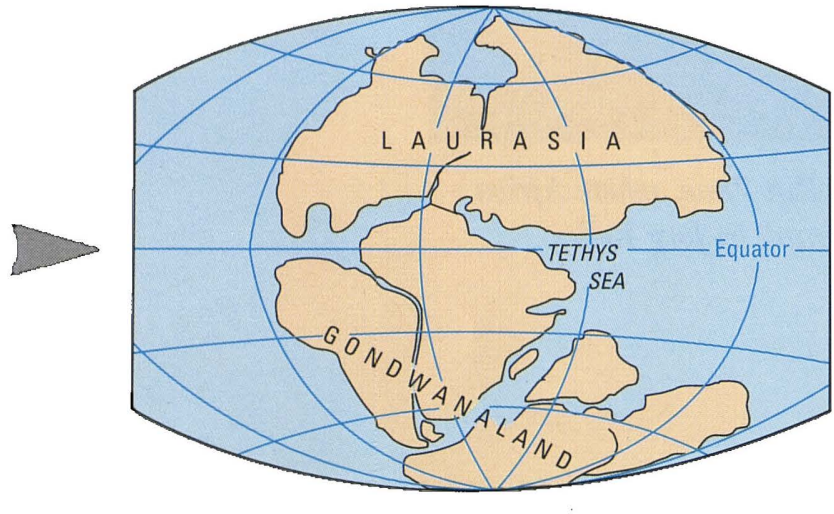

TRIASSIC

200 million years ago

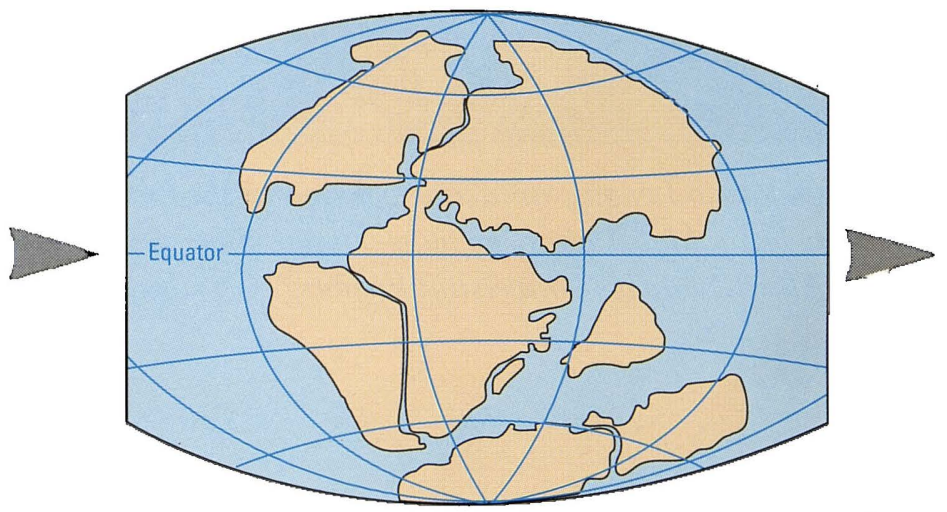

JURASSIC

135 million years ago 


\section{Historical perspective}

In geologic terms, a plate is a large, rigid slab of solid rock. The word tectonics comes from the Greek root "to build." Putting these two words together, we get the term plate tectonics, which refers to how the Earth's surface is built of plates. The theory of plate tectonics states that the Earth's outermost layer is fragmented into a dozen or more large and small plates that are moving relative to one another as they ride atop hotter, more mobile material. Before the advent of plate tectonics, however, some people already believed that the present-day continents were the fragmented pieces of preexisting larger landmasses ("supercontinents"). The diagrams below show the break-up of the supercontinent Pangaea (meaning "all lands" in Greek), which figured prominently in the theory of continental drift (p. 5) - the forerunner to the theory of plate tectonics.

Plate tectonics is a relatively new scientific concept, introduced some 30 years ago, but it has revolutionized our understanding of the dynamic planet upon which we live. The theory has unified the study of the Earth by drawing together many branches of the earth sciences, from paleontology (the study of fossils) to seismology (the study of earthquakes). It has provided explanations to questions that scientists had speculated upon for centuries-such as why earthquakes and volcanic eruptions occur in very

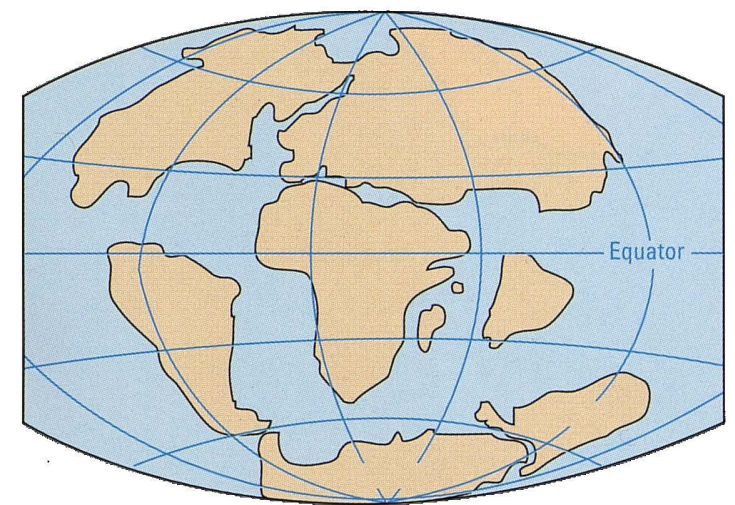

CRETACEOUS
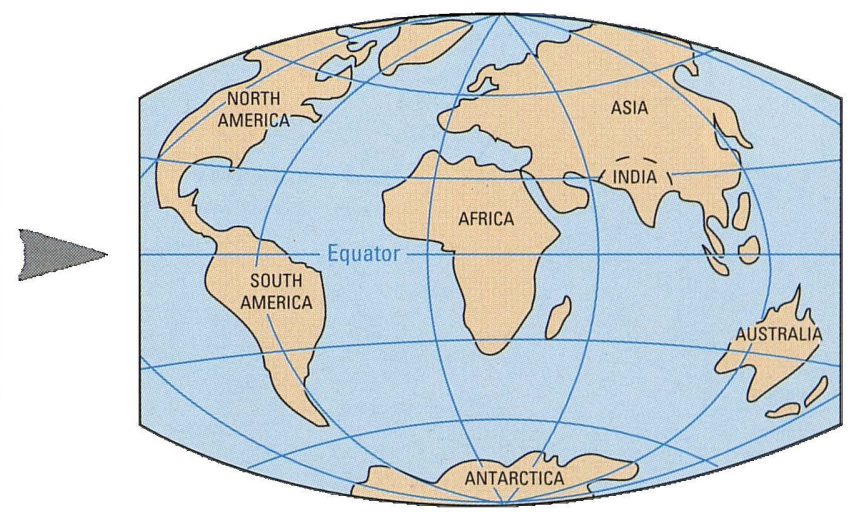

PRESENT DAY
According to the continental drift theory, the supercontinent Pangaea began to break up about 225-200 million years ago, eventually fragmenting into the continents as we know them today.

65 million years ago 


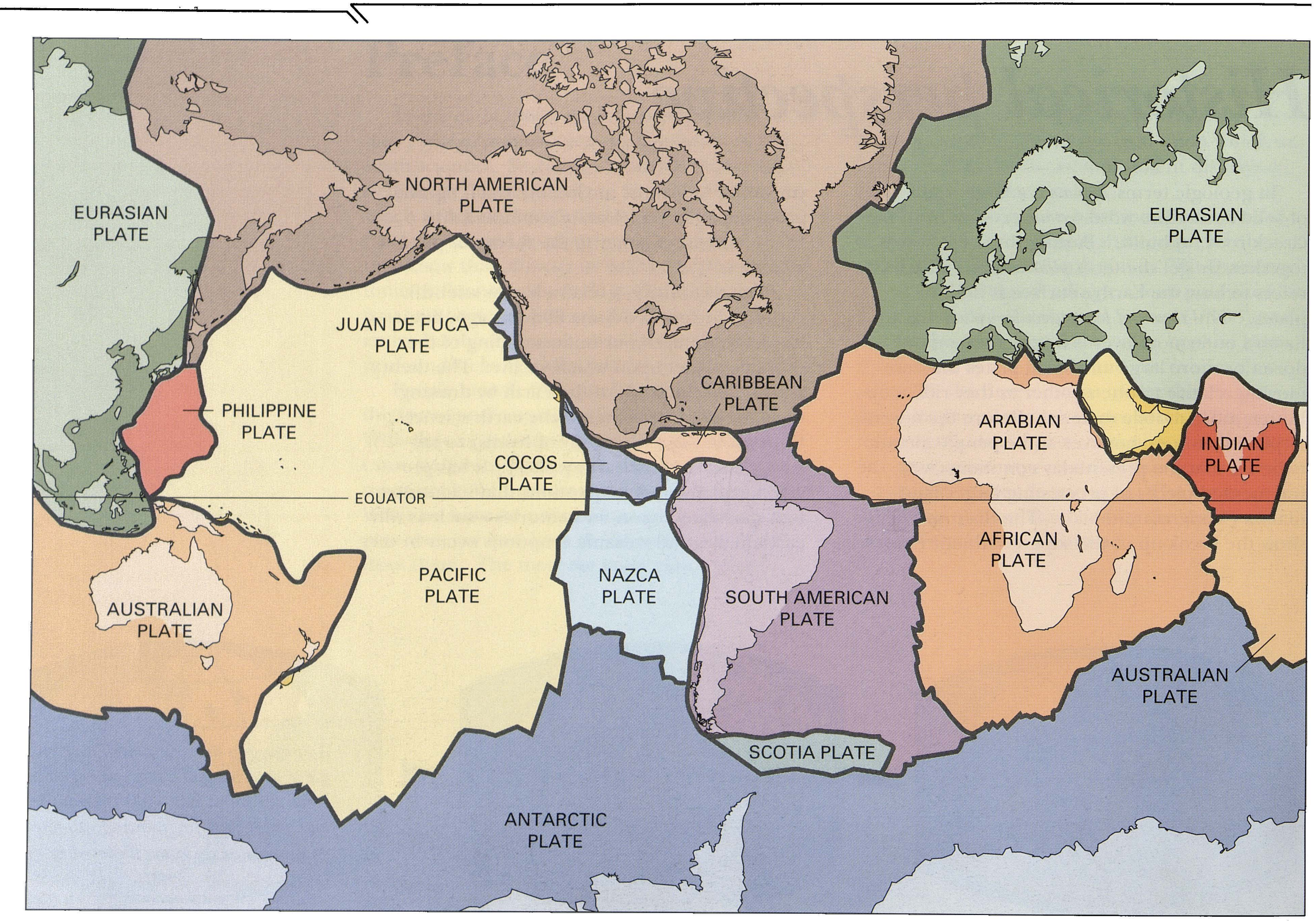

The layer of the Earth we live on is broken into a dozen or so rigid slabs (called tectonic plates by geologists) that are moving relative to one another. 
specific areas around the world, and how and why great mountain ranges like the Alps and Himalayas formed.

Why is the Earth so restless? What causes the ground to shake violently, volcanoes to erupt with explosive force, and great mountain ranges to rise to incredible heights? Scientists, philosophers, and theologians have wrestled with questions such as these for centuries. Until the 1700s, most Europeans thought that a Biblical Flood played a major role in shaping the Earth's surface. This way of thinking was known as "catastrophism," and geology (the study of the Earth)

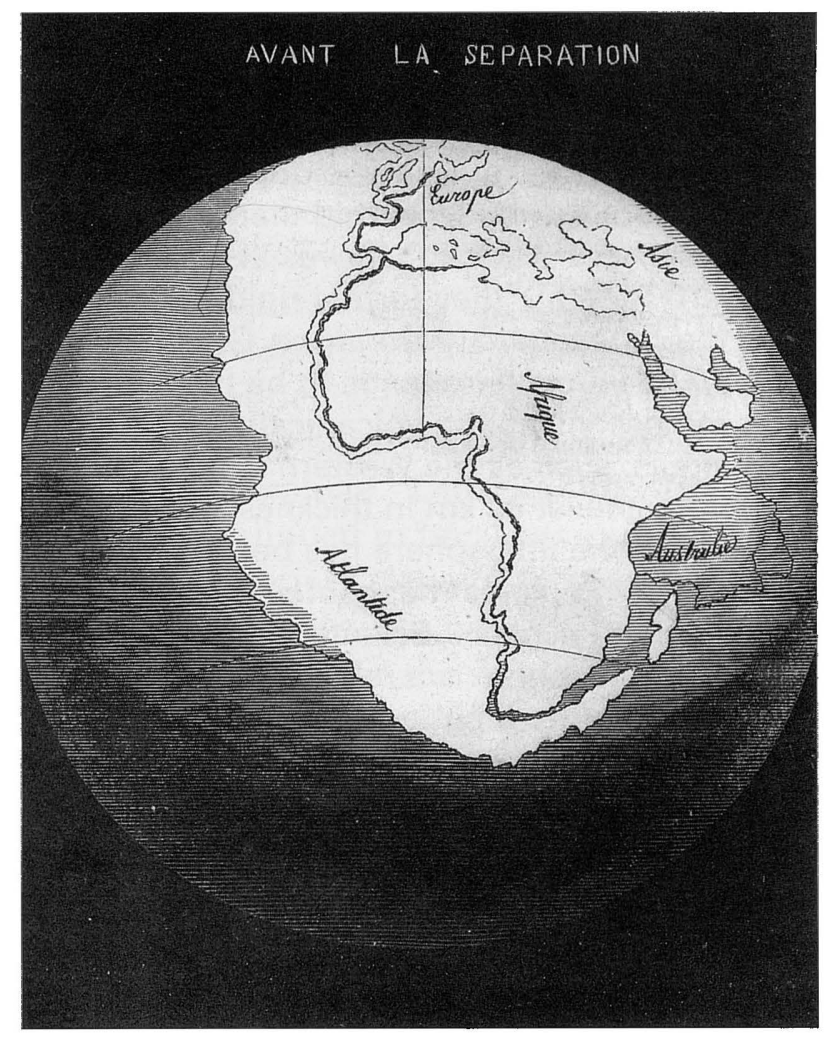

was based on the belief that all earthly changes were sudden and caused by a series of catastrophes. However, by the mid-19th century, catastrophism gave way to "uniformitarianism," a new way of thinking centered around the "Uniformitarian Principle" proposed in 1785 by James Hutton, a Scottish geologist. This principle is commonly stated as follows: The present is the key to the past. Those holding this viewpoint assume that the geologic forces and processes-gradual as well as catastrophic-acting on the Earth today are the same as those that have acted in the geologic past.

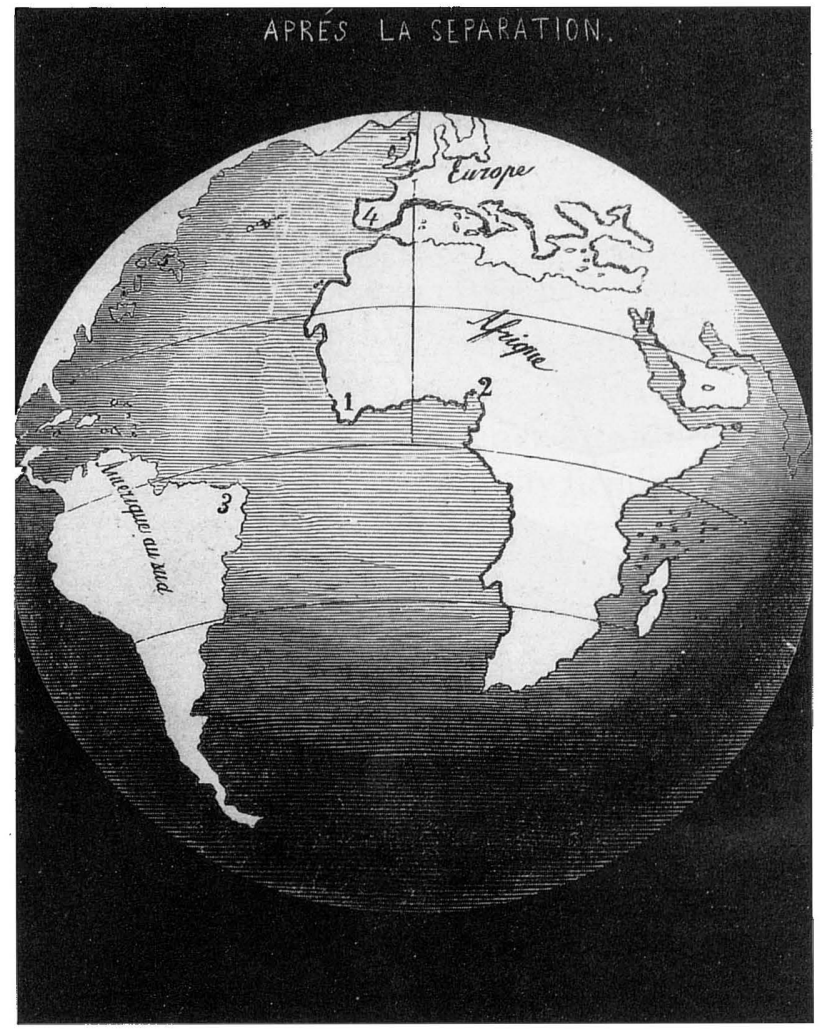

In 1858, geographer Antonio SniderPellegrini made these two maps showing his version of how the American and African continents may once have fit together, then later separated. Left: The formerly joined continents before (avant) their separation. Right: The continents after (aprés) the separation. (Reproductions of the original maps courtesy of University of California, Berkeley.) 


\section{Inside the Earth}

The size of the Earth-about 12,750 kilometers $(\mathrm{km})$ in diameter-was known by the ancient Greeks, but it was not until the turn of the 20th century that scientists determined that our planet is made up of three main layers: crust, mantle, and core. This layered structure can be compared to that of a boiled egg. The crust, the outermost layer, is rigid and very thin compared with the other two. Beneath the oceans, the crust varies little in thickness, generally extending only to about $5 \mathrm{~km}$. The thickness of the crust beneath continents is much more variable but averages about $30 \mathrm{~km}$; under large mountain ranges, such as the Alps or the Sierra Nevada, however, the
Cutaway views showing the internal view drawn to scale demonstrates that the Earth's crust literally is only skin deep. Below right: A view not drawn to scale to show the Earth's three main layers (crust, mantle, and core) in more detail (see text). base of the crust can be as deep as $100 \mathrm{~km}$. Like the shell of an egg, the Earth's crust is brittle and can break.

Below the crust is the mantle, a dense, hot layer of semi-solid rock approximately $2,900 \mathrm{~km}$ thick. The mantle, which contains more iron, magnesium, and calcium than the crust, is hotter and denser because temperature and pressure inside the Earth increase with depth. As a comparison, the mantle might be thought of as the white of a boiled egg. At the center of the Earth lies the core, which is nearly twice as dense as the mantle because its composition is metallic (iron-nickel alloy) rather than stony. Unlike the yolk of an egg, however, the Earth's core is actually made up of two distinct parts: a 2,200 kmthick liquid outer core and a 1,250 km-thick solid inner core. As the Earth rotates; the liquid outer core spins, creating the Earth's magnetic field.

Not surprisingly, the Earth's internal structure influences plate tectonics. The upper part of the mantle is cooler and more rigid than the deep mantle; in many ways, it behaves like the overlying crust. Together they form a rigid layer of rock called the lithosphere (from lithos, Greek for stone). The lithosphere tends to be thinnest under the oceans and in volcanically active continental areas, such as the Western United States. Averaging at least $80 \mathrm{~km}$ in thickness over much of the Earth, the lithosphere has been broken up into the moving plates that contain the world's continents and oceans. Scientists believe that below the lithosphere is a relatively narrow, mobile zone in the mantle called the asthenosphere (from asthenes, Greek for weak). This zone is composed of hot, semi-solid material, which can soften and flow after being subjected to high temperature and pressure over geologic time. The rigid lithosphere is thought to "float" or move about on the slowly flowing asthenosphere. 
The belief that continents have not always been fixed in their present positions was suspected long before the 20th century; this notion was first suggested as early as 1596 by the Dutch map maker Abraham Ortelius in his work Thesaurus Geographicus. Ortelius suggested that the Americas were "torn away from Europe and Africa...by earthquakes and floods" and went on to say:

"The vestiges of the rupture reveal themselves, if someone brings forward a map of the world and considers carefully the coasts of the three [continents]." Ortelius' idea surfaced again in the 19th century. However, it was not until 1912 that the idea of moving continents was seriously considered as a full-blown scientific theory-called Continental Drift-introduced in two articles published by a 32-year-old German meteorologist named Alfred Lothar Wegener. He contended that, around 200 million years ago, the supercontinent Pangaea began to split apart. Alexander Du Toit, Professor of Geology at Johannesburg University and one of Wegener's staunchest supporters, proposed that Pangaea first broke into two large continental landmasses, Laurasia in the northern hemisphere and Gondwanaland in the southern hemisphere. Laurasia and Gondwanaland then continued to break apart into the various smaller continents that exist today.

Wegener's theory was based in part on what appeared to him to be the remarkable fit of the South American and African continents, first noted by Abraham Ortelius three centuries earlier. Wegener was also intrigued by the occurrences of unusual geologic structures and of plant and animal fossils found on the matching coastlines of South America and Africa, which are now widely separated by the Atlantic Ocean.
He reasoned that it was physically impossible for most of these organisms to have swum or have been transported across the vast oceans. To him, the presence of identical fossil species along the coastal parts of Africa and South America was the most compelling evidence that the two continents were once joined.

In Wegener's mind, the drifting of continents after the break-up of Pangaea explained not only the matching fossil occurrences but also the evidence of dramatic climate changes on some continents. For example, the discovery of fossils of tropical plants (in the form of coal deposits) in Antarctica led to the conclusion that this frozen land previously must have been situated closer to the equator, in a more temperate climate where lush, swampy vegetation could grow. Other mismatches of geology and climate included distinctive fossil ferns (Glossopteris) discovered in nowpolar regions, and the occurrence of glacial deposits in present-day arid Africa, such as the Vaal River valley of South Africa.

The theory of continental drift would become the spark that ignited a new way of viewing the Earth. But at the time Wegener introduced his theory, the scientific community firmly believed the continents and oceans to be permanent features on the Earth's surface. Not surprisingly, his proposal was not well received, even though it seemed to agree with the scientific information available at the time. A fatal weakness in Wegener's theory was that it could not satisfactorily answer the most fundamental question raised by his critics: What kind of forces could be strong enough to move such large masses of solid rock over such great distances? Wegener suggested that the continents simply plowed 


\section{What is a tectomic plate?}

A tectonic plate (also called lithospheric plate) is a massive, irregularly shaped slab of solid rock, generally composed of both continental and oceanic lithosphere. Plate size can vary greatly, from a few hundred to thousands of kilometers across; the Pacific and Antarctic Plates are among the largest. Plate thickness also varies greatly, ranging from less than $15 \mathrm{~km}$ for young oceanic lithosphere to about $200 \mathrm{~km}$ or more for ancient continental lithosphere (for example; the interior parts of North and South America).

How do these massive slabs of solid rock float despite their tremendous weight? The answer lies in the composition of the rocks. Continental crust is composed of granitic rocks which are made up of relatively lightweight minerals such as quartz and feldspar. By contrast, oceanic crust is composed of basaltic rocks, which are much denser and heavier. The variations in plate thickness are nature's way of partly compensating for the imbalance in the weight and density of the two types of crust. Because continental rocks are much lighter, the crust under the continents is much thicker (as much as $100 \mathrm{~km}$ ) whereas the crust under the oceans is generally only about 5 $\mathrm{km}$ thick. Like icebergs, only the tips of which are visible above water, continents have deep "roots" to support their elevations.
Most of the boundaries between individual plates cannot be seen, because they are hidden beneath the oceans. Yet oceanic plate boundaries can be mapped accurately from outer space by measurements from GEOSAT satellites. Earthquake and volcanic activity is concentrated near these boundaries. Tectonic plates probably developed very early in the Earth's 4.6-billionyear history, and they have been drifting about on the surface ever since-like slow-moving bumper cars repeatedly clustering together and then separating.

Like many features on the Earth's surface, plates change over time. Those composed partly or entirely of oceanic lithosphere can sink under another plate, usually a lighter, mostly continental plate, and eventually disappear completely. This process is happening now off the coast of Oregon and Washington. The small Juan de Fuca Plate, a remnant of the formerly much larger oceanic Farallon Plate, will someday be entirely consumed as it continues to sink beneath the North American Plate.

These four diagrams illustrate the shrinking of the formerly very large Farallon Plate, as it was progressively consumed beneath the North American and Caribbean Plates, leaving only the present-day Juan de Fuca, Rivera, and Cocos Plates as small remnants (see text). Large solid arrows show the present-day sense of relative movement between the Pacific and North American Plates. (Modified from USGS Professional Paper

1515). 


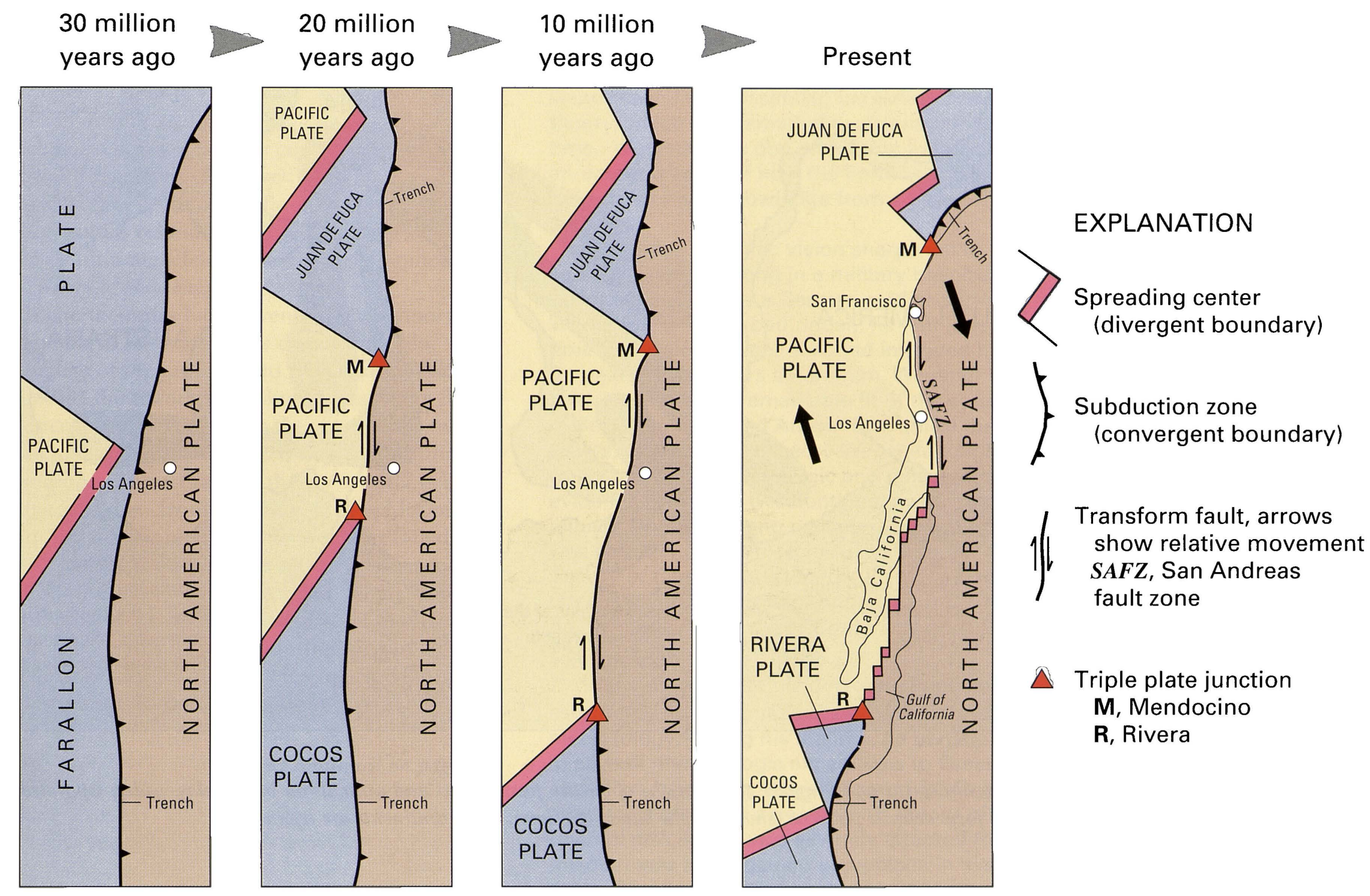




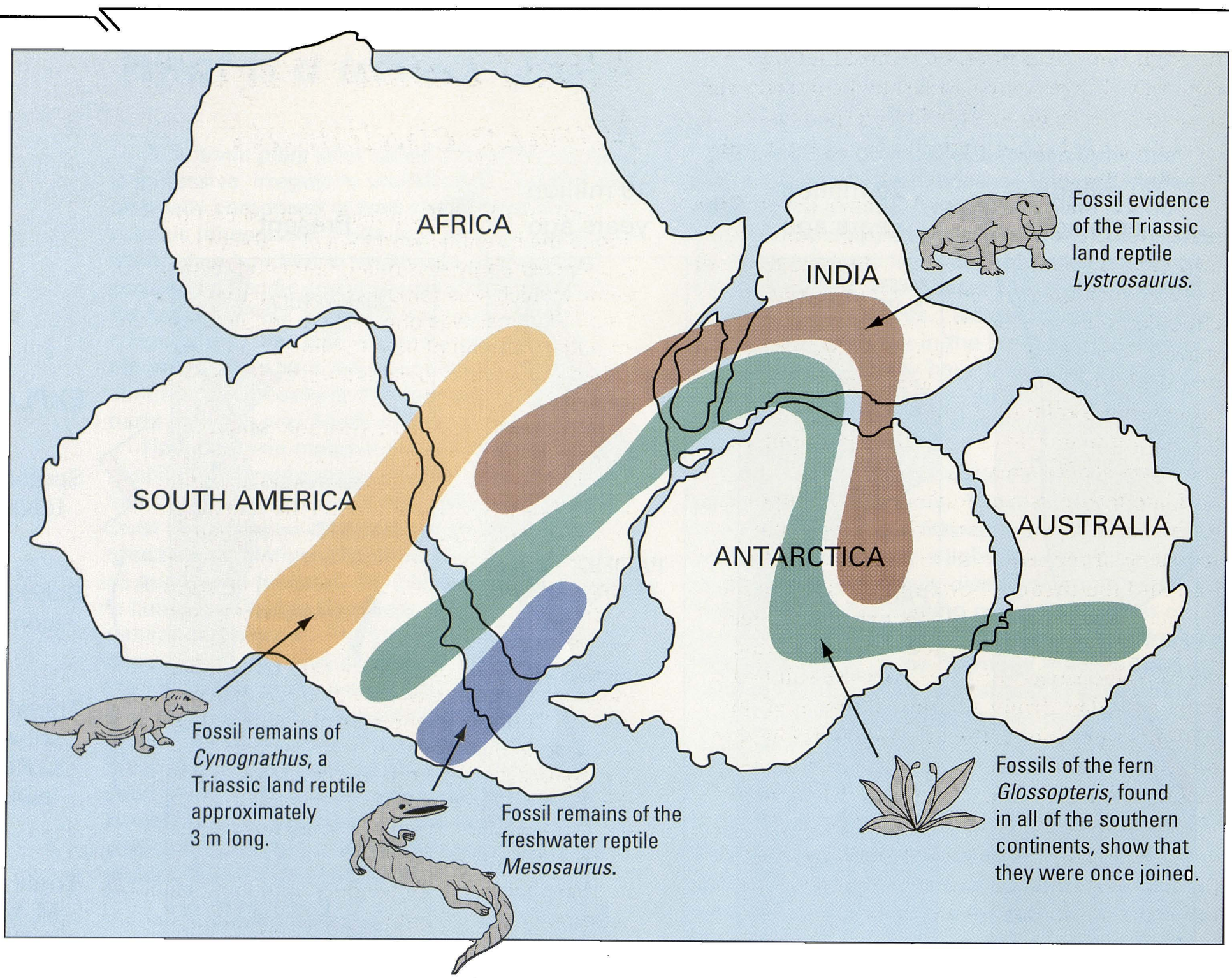

As noted by Snider-Pellegrini and Wegener, the locations of certain fossil plants and animals on present-day, widely separated continents would form definite patterns (shown by the bands of colors), if the continents are rejoined. 
through the ocean floor, but Harold Jeffreys, a noted English geophysicist, argued correctly that it was physically impossible for a large mass of solid rock to plow through the ocean floor without breaking up.

Undaunted by rejection, Wegener devoted the rest of his life to doggedly pursuing additional evidence to defend his theory. He froze to death in 1930 during an expedition crossing the Greenland ice cap, but the controversy he spawned raged on. However, after his death, new evidence from ocean-floor exploration and other studies rekindled interest in Wegener's theory, ultimately leading to the development of the theory of plate tectonics.

Plate tectonics has proven to be as important to the earth sciences as the discovery of the structure of the atom was to physics and chemistry and the theory of evolution was to the life sciences. Even though the theory of plate tectonics is now widely accepted by the scientific community, aspects of the theory are still being debated today. Ironically, one of the chief outstanding questions is the one Wegener failed to resolve: What is the nature of the forces propelling the plates? Scientists also debate how plate tectonics may have operated (if at all) earlier in the Earth's history and whether similar processes operate, or have ever operated, on other planets in our solar system.

(text continued on page 14)

\section{Alfred Lothar Wegener: Moving continents}

Perhaps Alfred Wegener's greatest contribution to the scientific world was his ability to weave seemingly dissimilar, unrelated facts into a theory, which was remarkably visionary for the time. Wegener was one of the first to realize that an understanding of how the Earth works required input and knowledge from all the earth sciences.

Wegener's scientific vision sharpened in 1914 as he was recuperating in a military hospital from an injury suffered as a German soldier during World War I. While bed-ridden, he had ample time to develop an idea that had intrigued him for years. Like others before him, Wegener had been struck by the remarkable fit of the coastlines of South America and Africa. But, unlike the others, to support his theory Wegener sought out many other lines of geologic and paleontologic evidence that these two continents were once joined. During his long convalescence, Wegener was able to fully develop his ideas into the

Theory of Continental Drift, detailed in a book titled Die Entstehung der Kontinente und Ozeane (in German, The Origin of Continents and Oceans) published in 1915.

Wegener obtained his doctorate in planetary astronomy in 1905 but soon became interested in meteorology; during his lifetime, he participated in several meteorologic expeditions to Greenland. Tenacious by nature, Wegener spent much of his adult life vigorously defending his theory of continental drift, which was severely attacked from the start and never gained acceptance in his lifetime. Despite overwhelming criticism from most leading geologists, who regarded him as a mere 


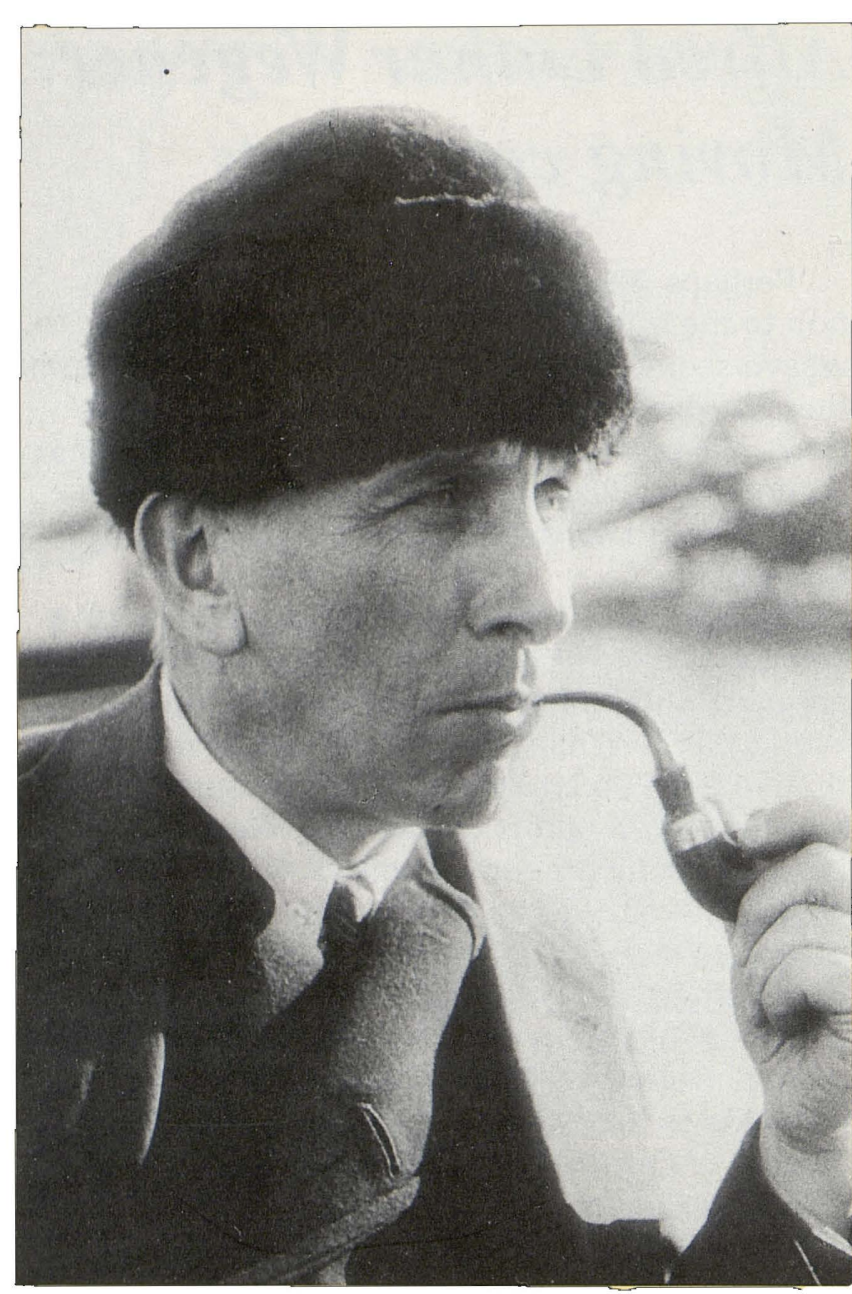

Alfred Lothar Wegener (1880-1930), the-originator of the theory of continental drift. (Photograph courtesy of the Alfred Wegener Institute for Polar and Marine Research, Bremerhaven, Germany.) meteorologist and outsider meddling in their field, Wegener did not back down but worked even harder to strengthen his theory.

A couple of years before his death, Wegener finally achieved one of his lifetime goals: an academic position. After a long but unsuccessful search for a university position in his native Germany, he accepted a professorship at the University of Graz in Austria. Wegener's frustration and long delay in gaining a university post perhaps stemmed from his broad scientific interests. As noted by Johannes Georgi, Wegener's longtime friend and colleague, "One heard time and again that he had been turned down for a certain chair because he was interested also, and perhaps to a greater degree, in matters that lay outside its terms of reference-as if such a man would not have been worthy of any chair in the wide realm of world science."

Ironically, shortly after achieving his academic goal, Wegener died on a meteorologic expedition to Greenland. Georgi had asked Wegener to coordinate an expedition to establish a winter weather station to study the jet stream (storm track) in the upper atmosphere. Wegener reluctantly agreed. After many delays due to severe weather, Wegener and 14 others set out for the winter station in September of 1930 with 15 sledges and 4,000 pounds of supplies. The extreme cold turned back all but one of the 13 Greenlanders, but Wegener was determined to push on to the station, where he knew the supplies were desperately needed by Georgi and the other researchers. Travelling under frigid conditions, with temperatures as low as minus $54^{\circ} \mathrm{C}$, Wegener reached the station five weeks later. Wanting to return home as soon as possible, he insisted upon starting back to the base camp the very next morning. But he never made it; his body was found the next summer. 
Wegener was still an energetic, brilliant researcher when he died at the age of 50. A year before his untimely death, the fourth revised edition (1929) of his classic book was published; in this edition, he had already made the significant observation that shallower oceans were geologically younger. Had he not died in 1930, Wegener doubtless would have pounced upon the new Atlantic bathymetric data just acquired by the German research vessel Meteor in the late 1920s. These data showed the existence of a central valley along much of the crest of the Mid-Atlantic Ridge. Given his fertile mind, Wegener just possibly might have recognized the shallow MidAtlantic Ridge as a geologically young feature resulting from thermal expansion, and the central valley as a rift valley resulting from stretching of the oceanic crust. From stretched, young crust in the middle of the ocean to seafloor spreading and plate tectonics would have been short mental leaps for a big thinker like Wegener. This conjectural scenario by Dr. Peter R. Vogt (U.S. Naval Research Laboratory, Washington, D.C.), an acknowledged expert on plate tectonics, implies that "Wegener probably would have been part of the plate-tectonics revolution, if not the actual instigator, had he lived longer." In any case, many of Wegener's ideas clearly served as the catalyst and framework for the development of the theory of plate tectonics three decades later.

Alfred Wegener (left) and an Inuit guide on 1 November 1930 during his final meteorological expedition in Greenland. This is one of the last photographs of Wegener, who died later during the expedition (see text). (Photograph courtesy of the Alfred Wegener Institute for Polar and Marine Research, Bremerhaven, Germany.)

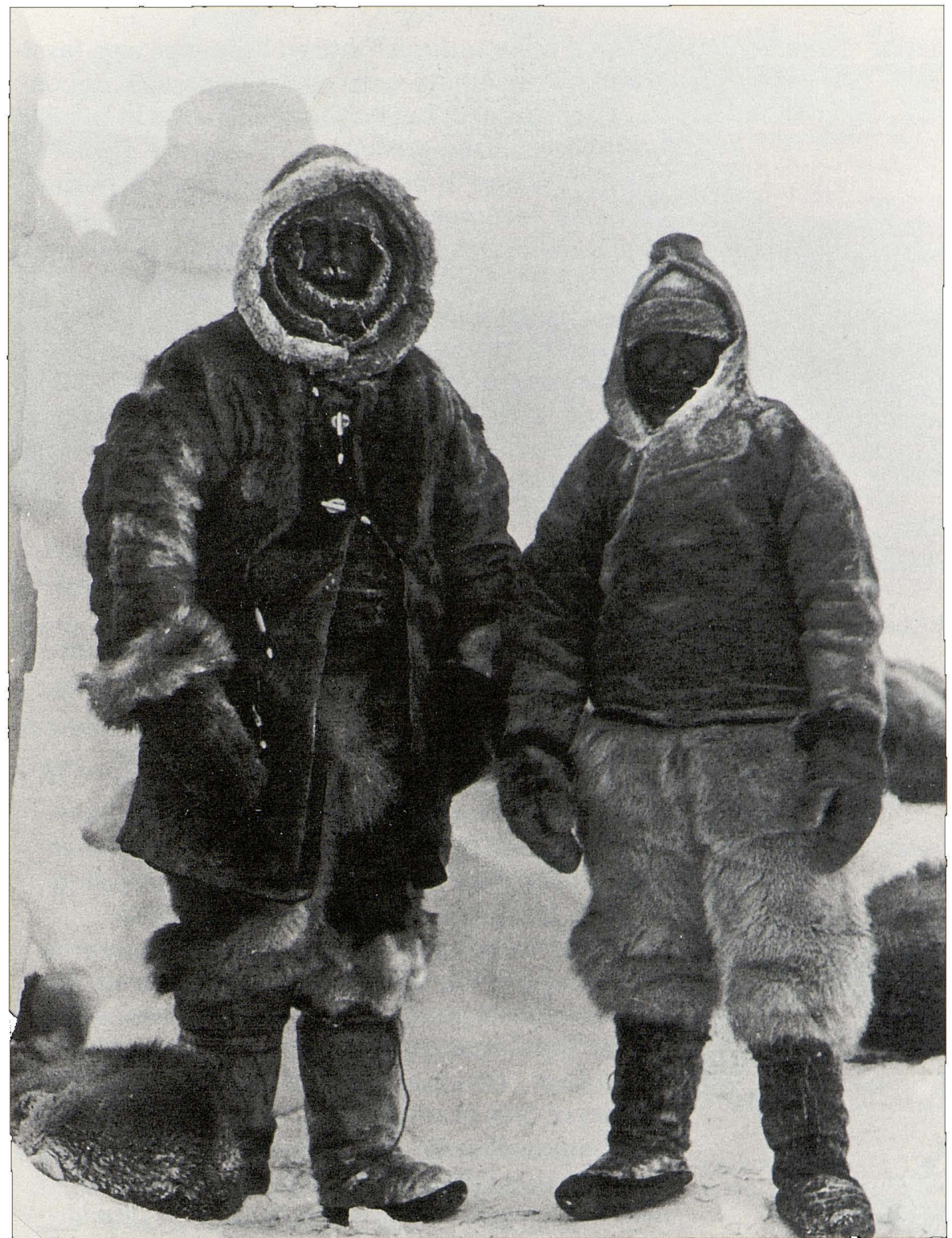




\section{Polar dinosaurs in Australia?}

As a meteorologist, Alfred Wegener was fascinated by questions such as: Why do coal deposits, a relic of lush ancient forests, occur in the icy barrenness of Antarctica? And why are glacial deposits found in now sweltering tropical Africa? Wegener reasoned that such anomalies could be explained if these two present-day continentstogether with South America, India, and Australia-originally were part of a supercontinent that extended from the equator to the South Pole and encompassed a wide range of climatic and geologic environments. The break-up of Pangaea and subsequent movement of the individual continents to their present positions formed the basis for Wegener's continental drift theory.

Recently, paleontologists (specialists in studies of fossils) have carefully studied some wellpreserved dinosaur remains unearthed at Dinosaur Cove, at the southeastern tip of mainland Australia. Dinosaurs found in most other parts of the world are believed to have lived in temperate or tropical regions, but these Australian species, popularly called "polar" dinosaurs, seemed well adapted to cooler temperature conditions. They apparently had keen night vision and were warm-blooded, enabling them to forage for food during long winter nights, at freezing or sub-freezing temperatures.

The last of the dinosaurs became extinct during a period of sharp global cooling toward the end of the Cretaceous period (about 65 million years ago). One current theory contends that the impact of one or more large comets or asteroids was responsible for the cooling trend ("impact winter") that killed off the dinosaurs; another theory attributes the sudden cooling to global climate change brought on by a series of huge volcanic eruptions over a short period of time ("volcanic winter"). The discovery of the polar dinosaurs clearly suggests that they survived the volcanic winter that apparently killed other dinosaur species. This then raises an intriguing question: Why did they become extinct if they were well adapted to a cold climate? Paleontologists do not have the answers. Regardless, this recently acquired paleontologic evidence convincingly demonstrates that Australia has drifted north toward the equator during the past 100 million years. At the time when the Australian polar dinosaurs thrived, their habitat was much farther south, well within the Antarctic Circle.

In 1991, paleontologists discovered the Cryolophosaurus ellito, a previously unknown dinosaur species and the only one found on the continent of Antarctica. Cryolophosaurus fossils were found at Mount Kirkpatrick, located only 600 $\mathrm{km}$ from the present-day South Pole. This newly discovered carnivorous dinosaur probably was similar in appearance to the Allosaurus (see artwork), except for a distinctive bony crest on its head, another meat-eating species found at Dinosaur Cove, Australia. Studies show that the Cryolophosaurus lived about 200 millions years ago, when Antarctica was still part of Gondwanaland and had a climate similar to that of Pacific Northwest-mild enough to support large planteating animal life, upon which the Cryolophosaurus preyed. With the break-up of Gondwanaland, Allosaurus and Cryolophosaurus parted company, as Australia drifted northward toward the equator and Antarctica drifted southward to the South Pole.

Had the Australian polar dinosaurs and the Cryolophosaurus been discovered while he was alive, the embattled Alfred Wegener would have been delighted! 


\section{Developing the theory}

Continental drift was hotly debated off and on for decades following Wegener's death before it was largely dismissed as being eccentric, preposterous, and improbable. However, beginning in the 1950s, a wealth of new evidence emerged to revive the debate about Wegener's provocative ideas and their implications. In particular, four major scientific developments spurred the formulation of the plate-tectonics theory: (1) demonstration of the ruggedness and youth of the ocean floor; (2) confirmation of repeated reversals of the Earth magnetic field in the geologic past; (3) emergence of the seafloor-spreading hypothesis and associated recycling of oceanic crust; and (4) precise documentation that the world's earthquake and volcanic activity is concentrated along oceanic trenches and submarine mountain ranges.

\section{Ocean floor mapping}

About two thirds of the Earth's surface lies beneath the oceans. Before the 19th century, the depths of the open ocean were largely a matter of speculation, and most people thought that the ocean floor was relatively flat and featureless. However, as early as the 16th century, a few intrepid navigators, by taking soundings with hand lines, found that the open ocean can differ considerably in depth, showing that the ocean floor was not as flat as generally believed. Oceanic exploration during the next centuries dramatically improved our knowledge of the ocean floor. We now know that most of the geologic processes occurring on land are linked, directly or indirectly, to the dynamics of the ocean floor.

"Modern" measurements of ocean depths greatly increased in the 19th century, when deepsea line soundings (bathymetric surveys) were routinely made in the Atlantic and Caribbean. In 1855, a bathymetric chart published by U.S. Navy Lieutenant Matthew Maury revealed the first evidence of underwater mountains in the central Atlantic (which he called "Middle Ground").

This was later confirmed by survey ships laying the trans-Atlantic telegraph cable. Our picture of the ocean floor greatly sharpened after World War I (1914-18), when echo-sounding devicesprimitive sonar systems-began to measure ocean depth by recording the time it took for a sound signal (commonly an electrically generated "ping") from the ship to bounce off the ocean floor and return. Time graphs of the returned signals revealed that the ocean floor was much more rugged than previously thought. Such echo-sounding measurements clearly demonstrated the continuity and roughness of the submarine mountain chain in the central Atlantic (later called the Mid-Atlantic Ridge) suggested by the earlier bathymetric measurements.

In 1947, seismologists on the U.S. research ship Atlantis found that the sediment layer on the floor of the Atlantic was much thinner than 


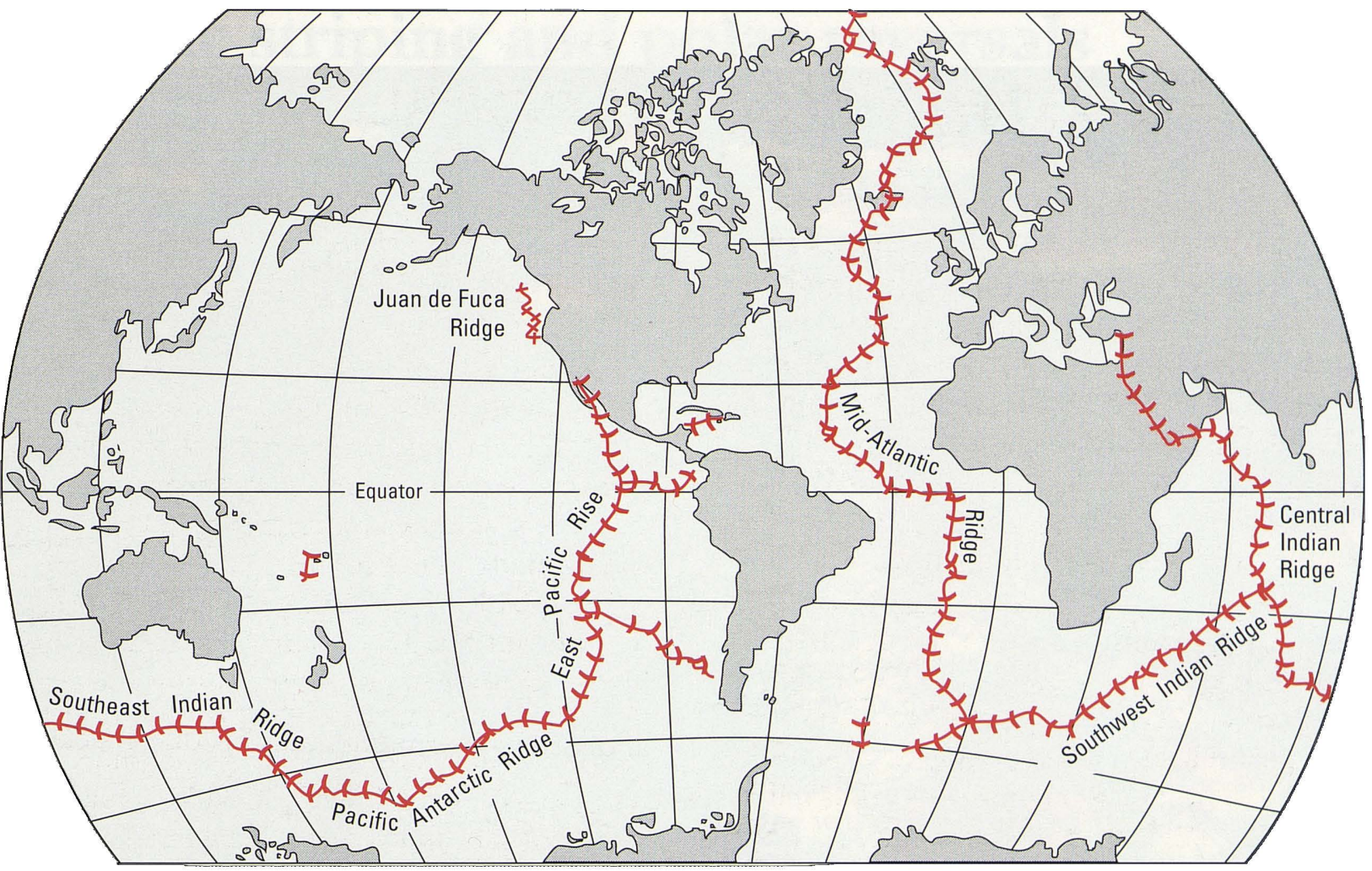

originally thought. Scientists had previously believed that the oceans have existed for at least 4 billion years, so therefore the sediment layer should have been very thick. Why then was there so little accumulation of sedimentary rock and debris on the ocean floor? The answer to this question, which came after further exploration, would prove to be vital to advancing the concept of plate tectonics.

In the 1950 s, oceanic exploration greatly expanded. Data gathered by oceanographic surveys conducted by many nations led to the discovery that a great mountain range on the ocean floor virtually encircled the Earth. Called the global mid-ocean ridge, this immense submarine mountain chain-more than 50,000 kilometers $(\mathrm{km})$ long and, in places, more than $800 \mathrm{~km}$ across-zig-zags between the continents, winding its way around the globe like the seam on a baseball. Rising an average of about 4,500 meters (m) above the sea floor, the mid-ocean ridge overshadows all the mountains in the United States except for Mount McKinley (Denali) in Alaska $(6,194 \mathrm{~m})$. Though hidden beneath the ocean surface, the global mid-ocean ridge system is the most prominent topographic feature on the surface of our planet.
The mid-ocean ridge (shown in red) winds its way between the continents much like the seam on a baseball. 
$\sqrt{1}$

Computer-generated detailed topographic map of a segment of the Mid-Oceanic Ridge. "Warm" colors (yellow to red) indicate the ridge rising above the seafloor, and the "cool" colors (green to blue) represent lower elevations. This image (at latitude $9^{\circ}$ north) is of a small part of the East Pacific Rise. (Imagery courtesy of Stacey Tighe, University of Rhode Island.)

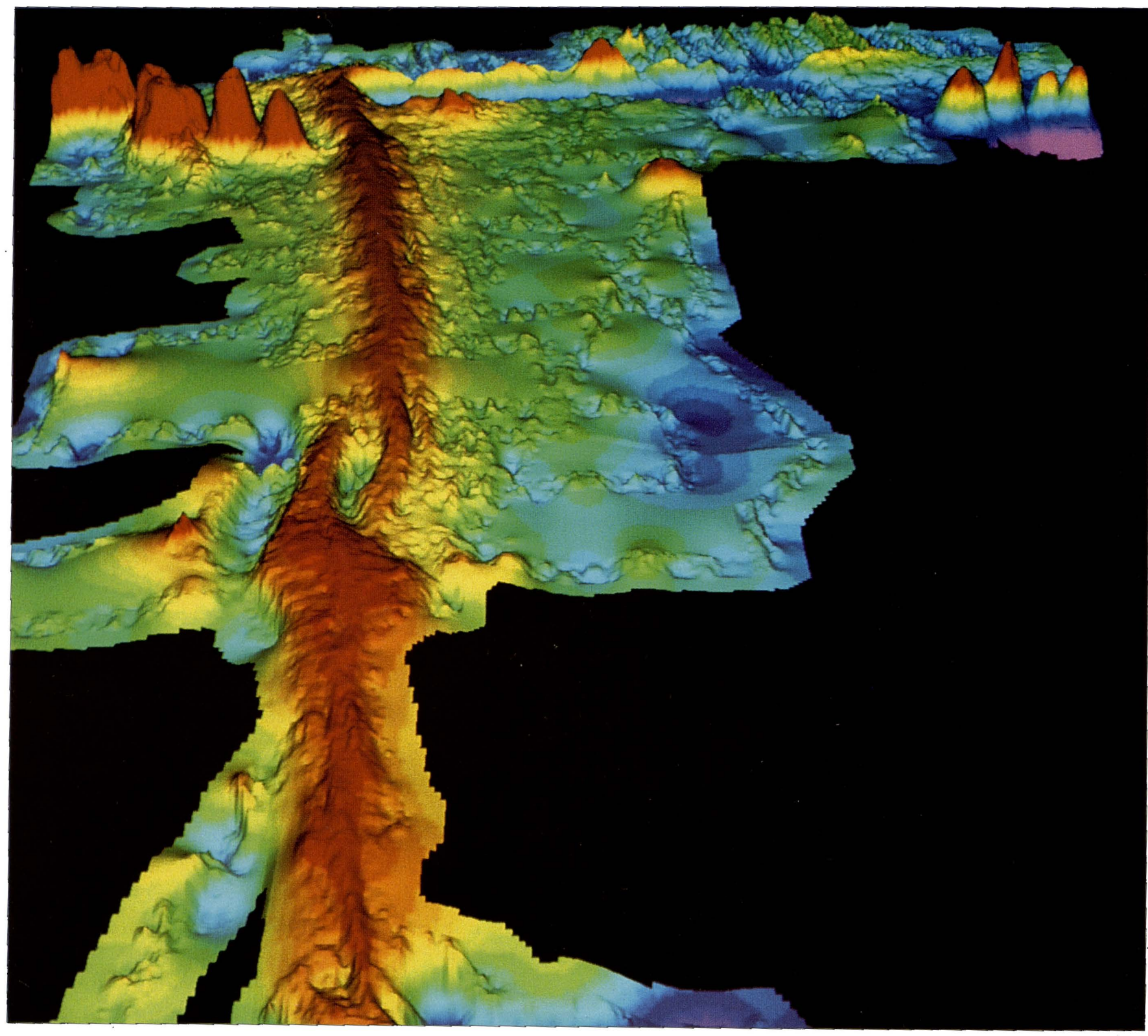




\section{Magnetic striping and polar reversals}

Beginning in the 1950 s, scientists, using magnetic instruments (magnetometers) adapted from airborne devices developed during World War II to detect submarines, began recognizing odd magnetic variations across the ocean floor. This finding, though unexpected, was not entirely surprising because it was known that basalt-the iron-rich, volcanic rock making up the ocean floor-contains a strongly magnetic mineral (magnetite) and can locally distort compass readings. This distortion was recognized by Icelandic mariners as early as the late 18th century. More important, because the presence of magnetite gives the basalt measurable magnetic properties, these newly discovered magnetic variations provided another means to study the deep ocean floor.

Early in the 20th century, paleomagnetists (those who study the Earth's ancient magnetic field) - such as Bernard Brunhes in France (in 1906) and Motonari Matuyama in Japan (in the 1920s) - recognized that rocks generally belong to two groups according to their magnetic properties. One group has so-called normal polarity, characterized by the magnetic minerals in the rock having the same polarity as that of the Earth's present magnetic field. This would result in the north end of the rock's "compass needle" pointing toward magnetic north. The other group, however, has reversed polarity, indicated by a polarity alignment opposite to that of the Earth's present magnetic field. In this case, the north end of the rock's compass needle would point south. How could this be? This answer lies in the magnetite in volcanic rock.
Grains of magnetite-behaving like little magnets-can align themselves with the orientation of the Earth's magnetic field. When magma (molten rock containing minerals and gases) cools to form solid volcanic rock, the alignment of the magnetite grains is "locked in," recording the Earth's magnetic orientation or polarity (normal or reversed) at the time of cooling.

As more and more of the seafloor was mapped during the 1950 s, the magnetic variations turned out not to be random or isolated occurrences, but instead revealed recognizable patterns. When these magnetic patterns were mapped over a wide region, the ocean floor showed a zebra-like pattern. Alternating stripes of magnetically different rock were laid out in rows on either side of the mid-ocean ridge: one stripe with normal polarity and the adjoining stripe with reversed polarity. The overall pattern, defined by these alternating bands of normally and reversely polarized rock, became known as magnetic striping.

(text continued on page 21) 

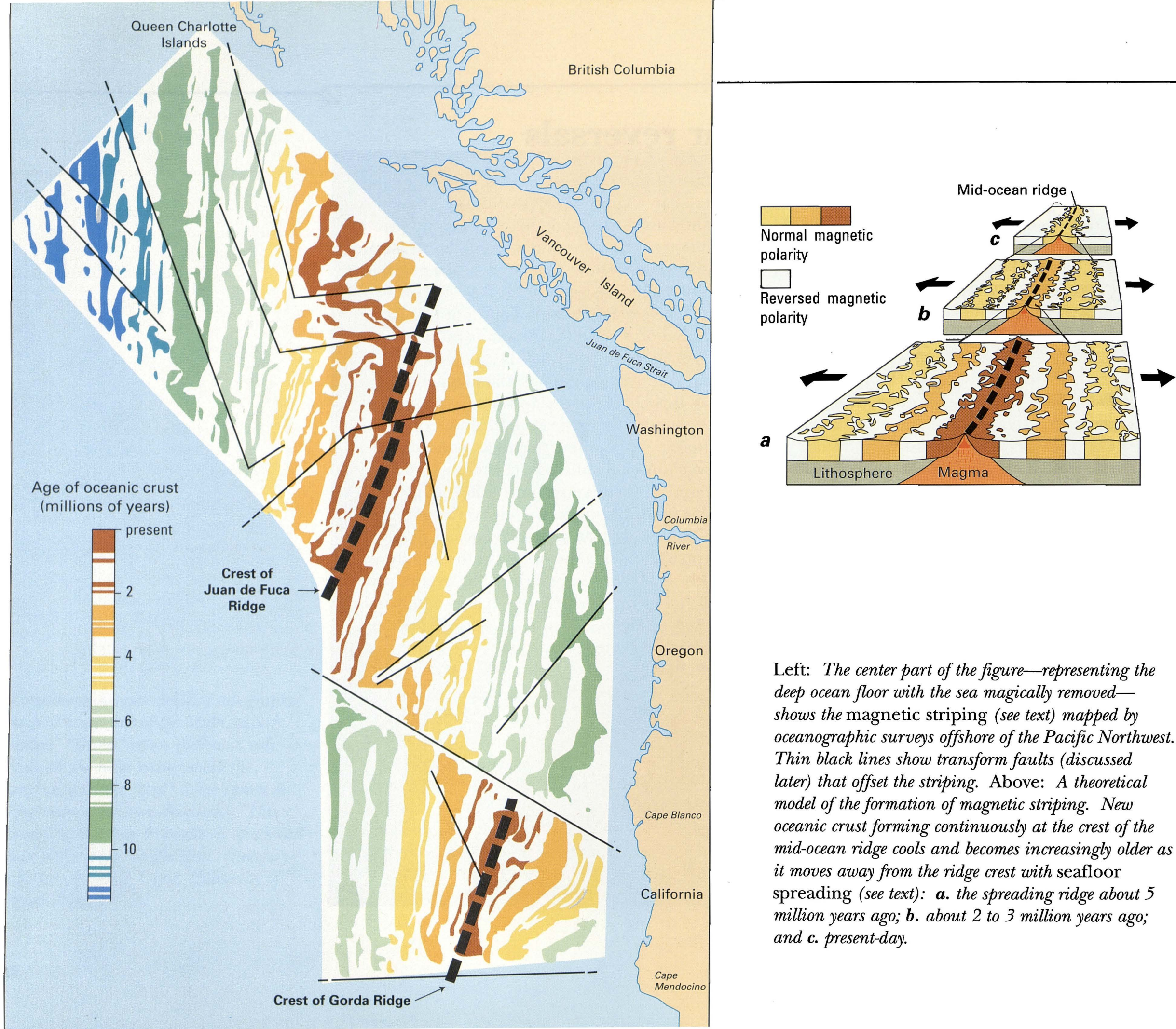

Left: The center part of the figure-representing the deep ocean floor with the sea magically removedshows the magnetic striping (see text) mapped by oceanographic surveys offshore of the Pacific Northwest. Thin black lines show transform faults (discussed later) that offset the striping. Above: A theoretical model of the formation of magnetic striping. New oceanic crust forming continuously at the crest of the mid-ocean ridge cools and becomes increasingly older as it moves away from the ridge crest with seafloor spreading (see text): a. the spreading ridge about 5 million years ago; $b$. about 2 to 3 million years ago; and c. present-day. 


\section{Magnetic stripes and isotopic clocks}

Oceanographic exploration in the 1950s led to a much better understanding of the ocean floor. Among the new findings was the discovery of zebra stripe-like magnetic patterns for the rocks of the ocean floor. These patterns were unlike any seen for continental rocks. Obviously, the ocean floor had a story to tell, but what?

In 1962, scientists of the U.S. Naval Oceanographic Office prepared a report summarizing available information on the magnetic stripes mapped for the volcanic rocks making up the ocean floor. After digesting the data in this

report, along with other information, two young British geologists, Frederick Vine and Drummond

Matthews, and also Lawrence Morley of the

Canadian Geological Survey, suspected that the

magnetic pattern was no accident. In 1963, they hypothesized that the magnetic striping was produced by repeated reversals of the Earth's magnetic field, not as earlier thought, by changes in intensity of the magnetic field or by other causes. Field reversals had already been demonstrated
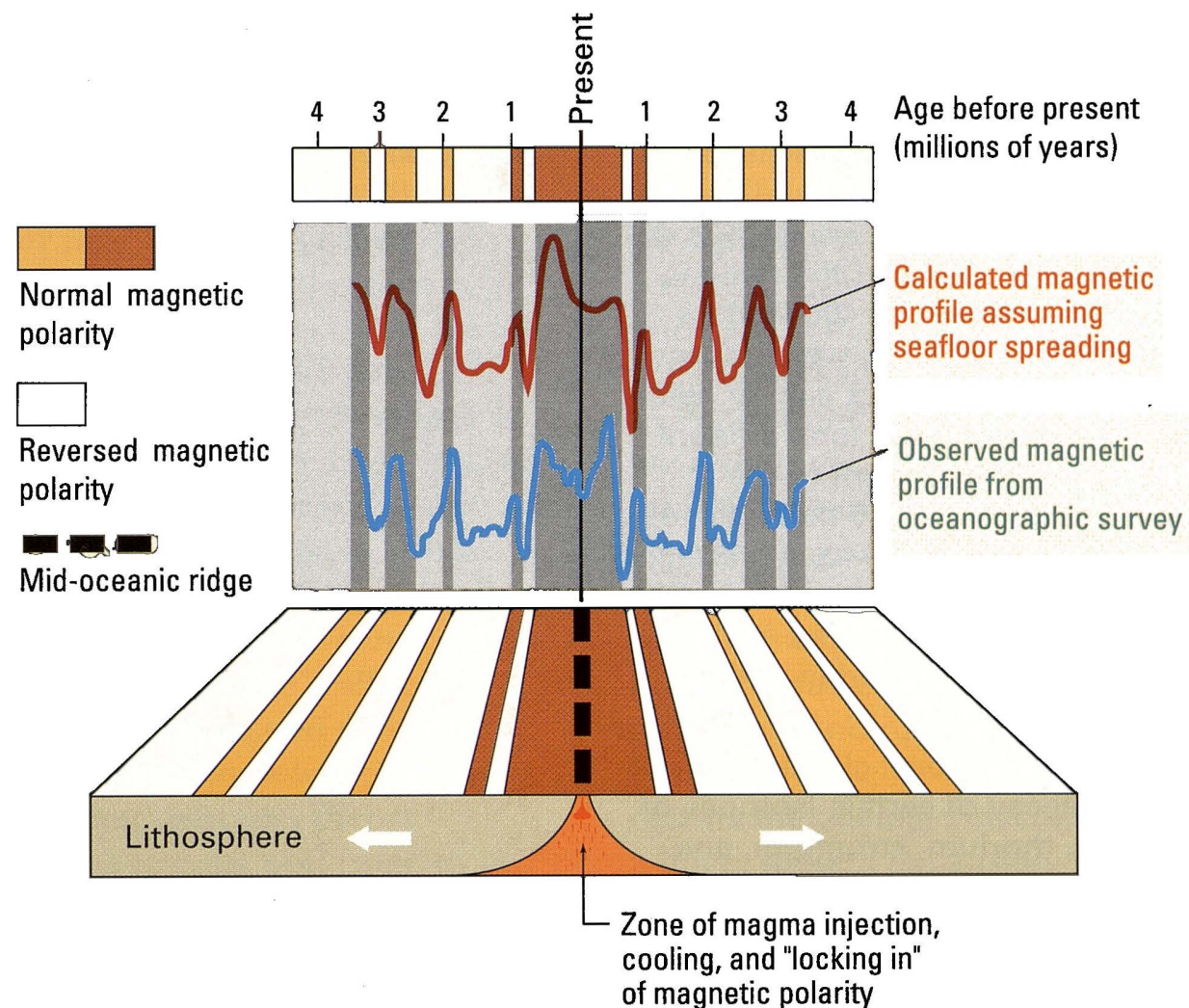

An observed magnetic profile (blue) for the ocean floor across the East Pacific Rise is matched quite well by a calculated profile (red) based on the Earth's magnetic reversals for the past 4 million years and an assumed constant rate of movement of ocean floor away from a hypothetical spreading center (bottom). The remarkable similarity of these two profiles provided one of the clinching arguments in support of the seafloor spreading hypothesis. 
for magnetic rocks on the continents, and a logical next step was to see if these continental magnetic reversals might be correlated in geologic time with the oceanic magnetic striping. About the same time as these exciting discoveries were being made on the ocean floor, new techniques for determining the geologic ages of rocks ("dating") were also developing rapidly.

A team of U.S. Geological Survey scientistsgeophysicists Allan Cox and Richard Doell, and isotope geochemist Brent Dalrymple-reconstructed the history of magnetic reversals for the past 4 million years using a dating technique based on the isotopes of the chemical elements potassium and argon. The potassium-argon technique-like other "isotopic clocks" - works because certain elements, such as potassium, contain unstable, parent radioactive isotopes that decay at a steady rate over geologic time to produce daughter isotopes. The rate of decay is expressed in terms of an element's "half-life," the time it takes for half of the radioactive isotope of the element to decay. The decay of the radioactive potassium isotope (potassium-40) yields a stable daughter isotope (argon-40), which does not decay further. The age of a rock can be determined ("dated") by measuring the total amount of potassium in the rock, the amount of the remaining radioactive potassium- 40 that has not decayed, and the amount of argon-40. Potassium is found in common rock-forming minerals, and because the potassium- 40 isotope has a half-life of 1,310 million years, it can be used in dating rocks millions of years old.

Other commonly used isotopic clocks are based on radioactive decay of certain isotopes of the elements uranium, thorium, strontium, and rubidium. However, it was the potassium-argon dating method that unlocked the riddle of the magnetic striping on the ocean floor and provid- ed convincing evidence for the seafloor spreading hypothesis. Cox and his colleagues used this method to date continental volcanic rocks from around the world. They also measured the magnetic orientation of these same rocks, allowing them to assign ages to the Earth's recent magnetic reversals. In 1966, Vine and Matthews-and also Morley working independently-compared these known ages of magnetic reversals with the magnetic striping pattern found on the ocean floor. Assuming that the ocean floor moved away from the spreading center at a rate of several centimeters per year, they found there was a remarkable correlation between the ages of the Earth's magnetic reversals and the striping pattern. Following their break-through discovery, similar studies were repeated for other spreading centers. Eventually, scientists were able to date and correlate the magnetic striping patterns for nearly all of the ocean floor, parts of which are as old as 180 million years. 


\section{Seafloor spreading and recycling of oceanic crust}

The discovery of magnetic striping naturally prompted more questions: How does the magnetic striping pattern form? And why are the stripes symmetrical around the crests of the midocean ridges? These questions could not be answered without also knowing the significance of these ridges. In 1961, scientists began to theorize that mid-ocean ridges mark structurally weak zones where the ocean floor was being ripped in two lengthwise along the ridge crest. New magma from deep within the Earth rises easily through these weak zones and eventually erupts along the crest of the ridges to create new oceanic crust. This process, later called seafloor spreading, operating over many millions of years has built the $50,000 \mathrm{~km}$-long system of mid-ocean ridges. This hypothesis was supported by several lines of evidence: (1) at or near the crest of the ridge, the rocks are very young, and they become progressively older away from the ridge crest; (2) the youngest rocks at the ridge crest always have present-day (normal) polarity; and (3) stripes of rock parallel to the ridge crest alternated in magnetic polarity (normal-reversed-normal, etc.), suggesting that the Earth's magnetic field has flip-flopped many times. By explaining both the zebra-like magnetic striping and the construction of the mid-ocean ridge system, the seafloor spreading hypothesis quickly gained converts and represented another major advance in the development of the plate-tectonics theory. Furthermore, the oceanic crust now came to be appreciated as a natural "tape recording" of the history of the reversals in the Earth's magnetic field.
Additional evidence of seafloor spreading came from an unexpected source: petroleum exploration. In the years following World War II, continental oil reserves were being depleted rapidly and the search for offshore oil was on. To conduct offshore exploration, oil companies built ships equipped with a special drilling rig and the capacity to carry many kilometers of drill pipe. This basic idea later was adapted in constructing a research vessel, named the Glomar Challenger, designed specifically for marine geology studies, including the collection of drillcore samples from the deep ocean floor. In 1968, the vessel embarked on a year-long scientific expedition, criss-crossing the Mid-Atlantic Ridge between South America and Africa and drilling core samples at specific locations. When the ages of the samples were determined by paleontologic and isotopic dating studies, they provided the clinching evidence that proved the seafloor spreading hypothesis.

A profound consequence of seafloor spreading is that new crust was, and is now, being continually created along the oceanic ridges. This idea found great favor with some scientists who claimed that the shifting of the continents can be simply explained by a large increase in size of the Earth since its formation. However, this socalled "expanding Earth" hypothesis was unsatisfactory because its supporters could offer no convincing geologic mechanism to produce such a huge, sudden expansion. Most geologists believe that the Earth has changed little, if at all, in size since its formation 4.6 billion years ago, raising a key question: how can new crust be 

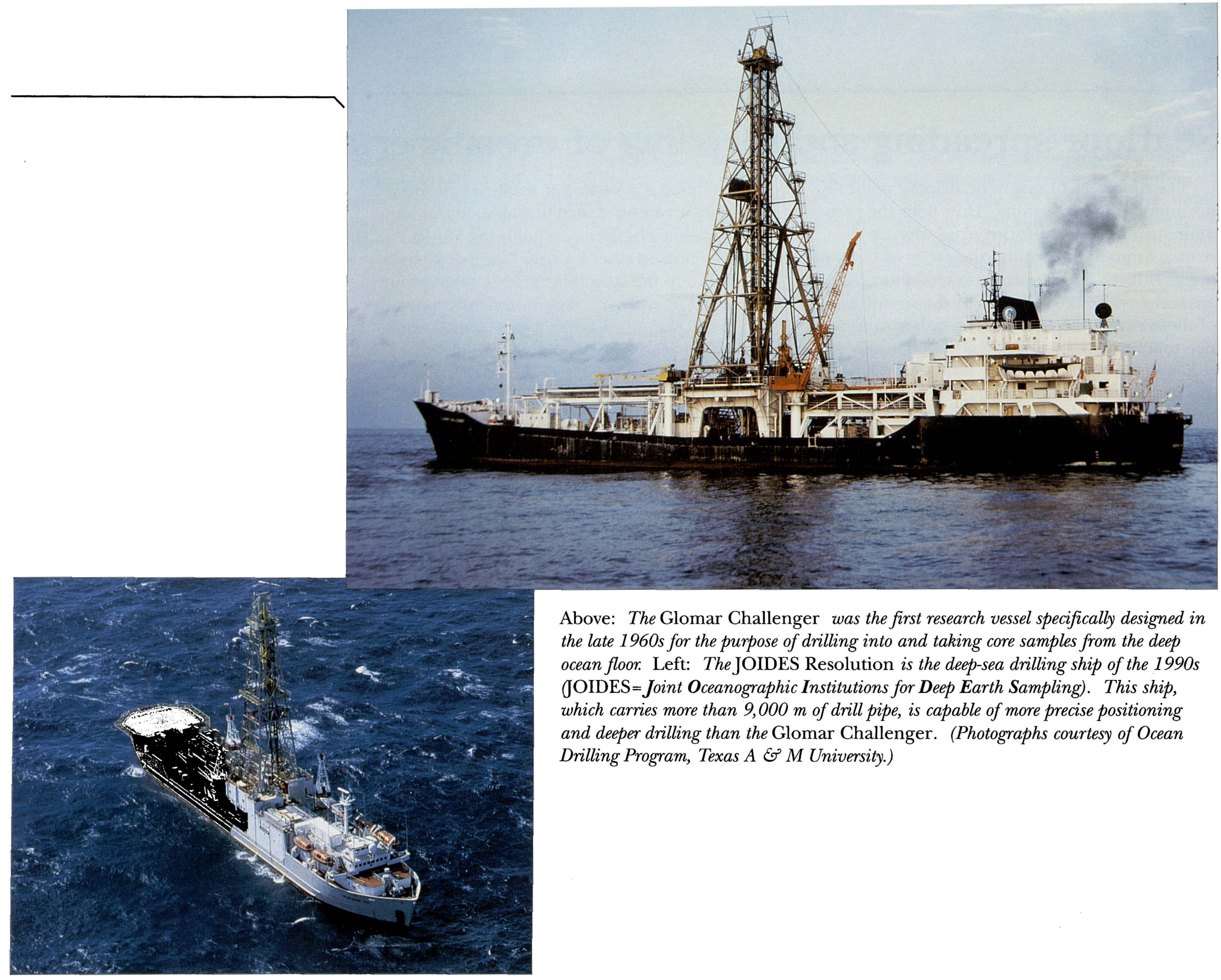

Above: The Glomar Challenger was the first research vessel specifically designed in the late 1960s for the purpose of drilling into and taking core samples from the deep ocean floor. Left: The JOIDES Resolution is the deep-sea drilling ship of the 1990s (JOIDES = Joint Oceanographic Institutions for Deep Earth Sampling). This ship, which carries more than 9,000 $m$ of drill pipe, is capable of more precise positioning and deeper drilling than the Glomar Challenger. (Photographs courtesy of Ocean Drilling Program, Texas A $\mathcal{E} M$ University.) 
continuously added along the oceanic ridges without increasing the size of the Earth?

This question particularly intrigued Harry $\mathrm{H}$. Hess, a Princeton University geologist and a Naval Reserve Rear Admiral, and Robert S. Dietz, a scientist with the U.S. Coast and Geodetic Survey who first coined the term seafloor spreading. Dietz and Hess were among the small handful who really understood the broad implications of sea floor spreading. If the Earth's crust was expanding along the oceanic ridges, Hess reasoned, it must be shrinking elsewhere. He suggested that new oceanic crust continuously spread away from the ridges in a conveyor belt-like motion. Many millions of years later, the oceanic crust eventually descends into the oceanic trenches-very deep, narrow canyons along the rim of the Pacific Ocean basin.

According to Hess, the Atlantic Ocean was expanding while the Pacific Ocean was shrinking. As old oceanic crust was consumed in the trenches, new magma rose and erupted along the spreading ridges to form new crust. In effect, the ocean basins were perpetually being "recycled," with the creation of new crust and the destruction of old oceanic lithosphere occurring simultaneously. Thus, Hess' ideas neatly explained why the Earth does not get bigger with sea floor spreading, why there is so little sediment accumulation on the ocean floor, and why oceanic rocks are much younger than continental rocks.

(text continued on page 29)

\section{Harry Hammond Hess: Spreading the seafloor}

Harry Hammond Hess, a professor of geology at Princeton University, was very influential in setting the stage for the emerging plate-tectonics theory in the early 1960s. He believed in many o the observations Wegener used in defending his theory of continental drift, but he had very different views about large-scale movements of the Earth.

Even while serving in the U.S. Navy during World War II, Hess was keenly interested in the geology of the ocean basins. In between taking part in the fighting in the Marianas, Leyte, Linguayan, and Iwo Jima, Hess - with the cooper ation of his crew-was able to conduct echosounding surveys in the Pacific while cruising from one battle to the next. Building on the work of English geologist Arthur Holmes in the 1930s, Hess' research ultimately resulted in a groundbreaking hypothesis that later would be called seafloor spreading. In 1959, he informally presented this hypothesis in a manuscript that was widely circulated. Hess, like Wegener, ran into resistance because little ocean-floor data existed for testing his ideas. In 1962, these ideas were published in a paper titled "History of Ocean Basins," which was one of the most important contributions in the development of plate tectonics. In this classic paper, Hess outlined the basics of how seafloor spreading works: molten rock (magma) oozes up from the Earth's interior along the mid-oceanic ridges, creating new seafloor that spreads away from the active ridge crest and, eventually, sinks into the deep oceanic trenches.

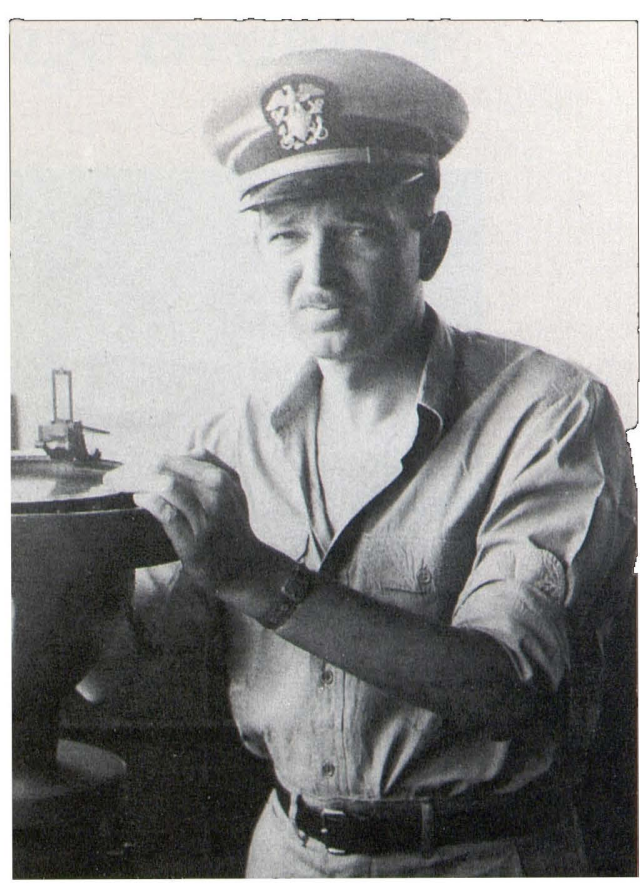

Harry Hess (1906-1969) in his Navy uniform as Captain of the assault transport Cape Johnson during World War II. After the war, he remained active in the Naval Reserve, reaching the rank of Rear Admiral. (Photograph courtesy of Department of Geological and Geophysical Sciences, Princeton University.) 
Hess' concept of a mobile seafloor explained several very puzzling geologic questions. If the oceans have existed for at least 4 billion years, as most geologists believed, why is there so little sediment deposited on the ocean floor? Hess reasoned that the sediment has been accumulating for about $\mathbf{3 0 0}$ million years at most. This interval is approximately the time needed for the ocean floor to move from the ridge crest to the trenches, where oceanic crust descends into the trench and is destroyed. Meanwhile, magma is continually rising along the mid-oceanic ridges, where the "recycling" process is completed by the creation of new oceanic crust. This recycling of the seafloor also explained why the oldest fossils found on the seafloor are no more than about 180 million years old. In contrast, marine fossils in rock strata on land-some of which are found high in the Himalayas, over 8,500 $\mathrm{m}$ above sea level-can be considerably older. Most important, however, Hess' ideas also resolved a question that plagued Wegener's theory of continental drift: how do the continents move? Wegener had a vague notion that the continents must simply "plow" through the ocean floor, which his critics rightly argued was physically impossible. With seafloor spreading, the continents did not have to push through the ocean floor but were carried along as the ocean floor spread from the ridges.

In 1962, Hess was well aware that solid evidence was still lacking to test his hypothesis and to convince a more receptive but still skeptical scientific community. But the Vine-Matthews explanation of magnetic striping of the seafloor a year later and additional oceanic exploration during subsequent years ultimately provided the arguments to confirm Hess' model of seafloor spreading. The theory was strengthened further when dating studies showed that the seafloor becomes older with distance away from the ridge crests. Finally, improved seismic data confirmed that oceanic crust was indeed sinking into the trenches, fully proving Hess' hypothesis, which was based largely on intuitive geologic reasoning. His basic idea of seafloor spreading along mid-oceanic ridges has well withstood the test of time.

Hess, who served for years as the head of Princeton's Geology Department, died in 1969. Unlike Wegener, he was able to see his seafloorspreading hypothesis largely accepted and confirmed as knowledge of the ocean floor increased dramatically during his lifetime. Like Wegener, he was keenly interested in other sciences in addition to geology. In recognition of his enormous stature worldwide, in 1962 Hess-best known for his geologic research-was appointed by President John F. Kennedy to the prestigious position of Chairman of the Space Science Board of the National Academy of Sciences. Thus, in addition to being a major force in the development of plate tectonics, Hess also played a prominent role in designing the nation's space program. 


\section{Exploring the deep ocean floor: Hot springs and strange creatures}

The ocean floor is home to many unique communities of plants and animals. Most of these marine ecosystems are near the water surface, such as the Great Barrier Reef, a 2,000-km-long coral formation off the northwestern coast of Australia. Coral reefs, like nearly all complex living communities, depend on solar energy for growth (photosynthesis). The sun's energy, however, penetrates at most only about $300 \mathrm{~m}$ below the surface of the water. The relatively shallow penetration of solar energy and the sinking of cold, subpolar water combine to make most of the deep ocean floor a frigid environment with few life forms.

In 1977, scientists discovered hot springs at a depth of $2.5 \mathrm{~km}$, on the Galapagos Rift (spreading ridge) off the coast of Ecuador. This exciting discovery was not really a surprise. Since the early 1970s, scientists had predicted that hot springs (geothermal vents) should be found at the active spreading centers along the mid-oceanic ridges, where magma, at temperatures over $1,000^{\circ} \mathrm{C}$, presumably was being erupted to form new oceanic crust. More exciting, because it was totally unexpected, was the discovery of abundant and unusual sea life-giant tube worms, huge clams, and mussels-that thrived around the hot springs.

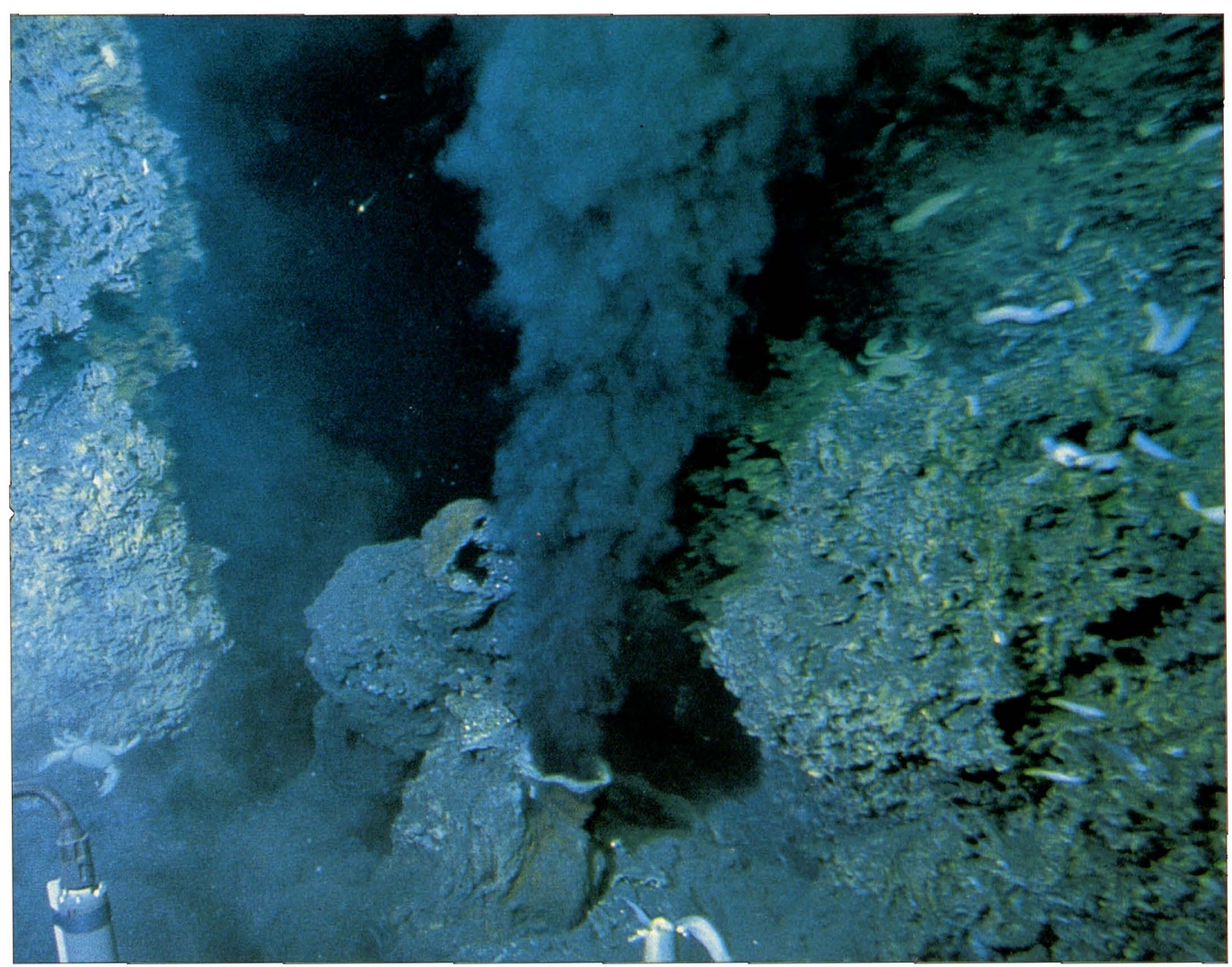

View of the first high-temperature vent $\left(380^{\circ} \mathrm{C}\right)$ ever seen by scientists during a dive of the deep-sea submersible Alvin on the East Pacific Rise (latitude $21^{\circ}$ north) in 1979. Such geothermal vents - called smokers because they resemble chimneys-spew dark, mineral-rich, fluids heated by contact with the newly formed, still-hot oceanic crust. This photograph shows a black smoker, but smokers can also be white, grey, or clear depending on the material being ejected. (Photograph by Dudley Foster from RISE expedition, courtesy of William R. Normark, USGS.) 


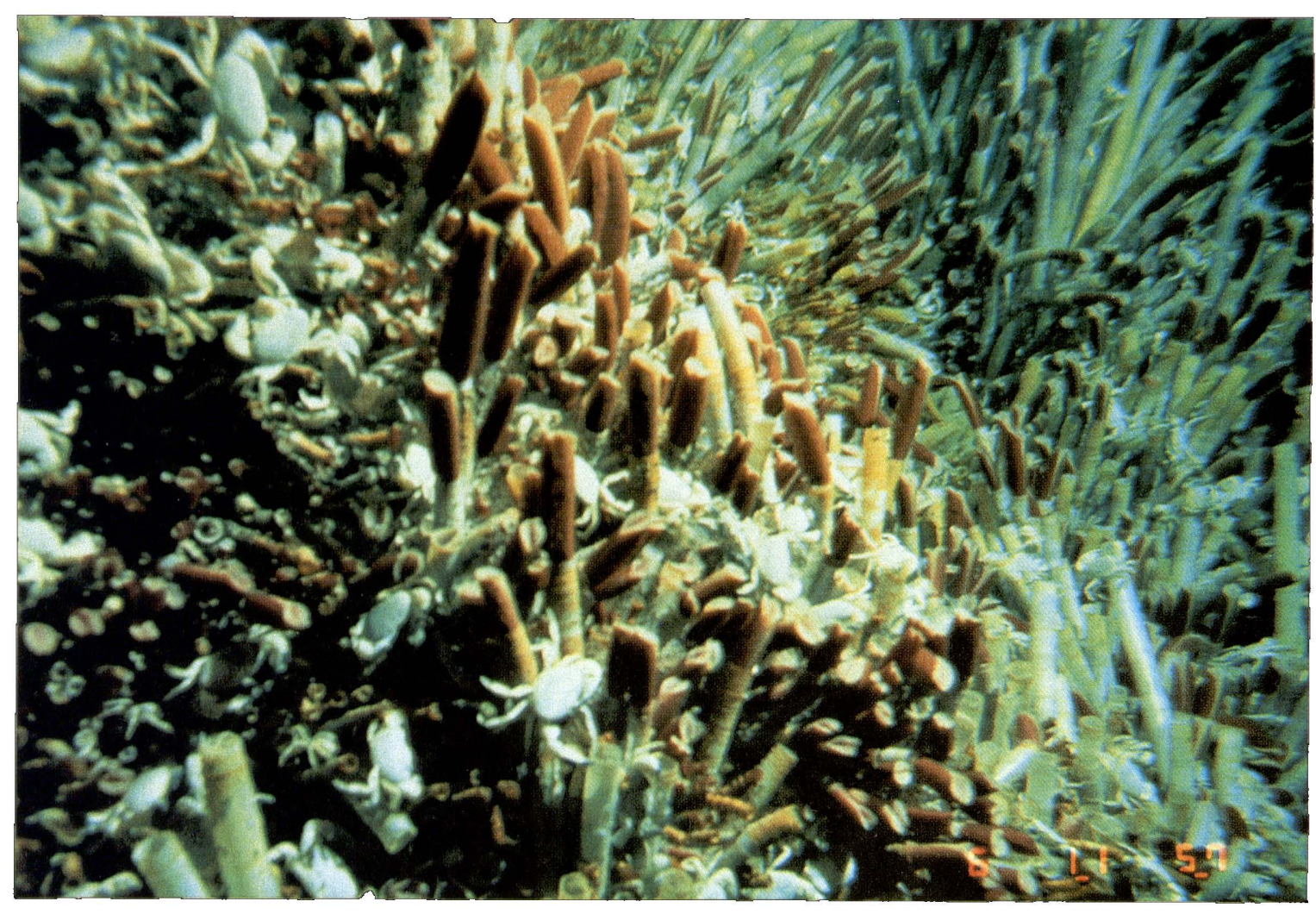

The deep-sea hot-spring environment supports abundant and bizarre sea life, including tube worms, crabs, giant clams. This hot-spring "neighborhood" is at $13^{\circ} \mathrm{N}$ along the East Pacific Rise. (Photograph by Richard A. Lutz, Rutgers University, New Brunswick, New Jersey.)

The size of deep-sea giant clams is evident from the hands of a scientist holding them. (Photograph by William R. Normark, USGS.)

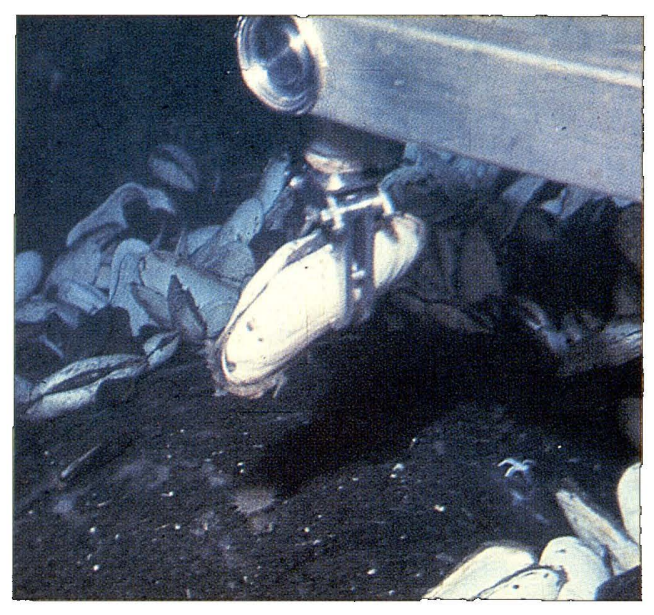

The manipulator arm of the research submersible Alvin collecting a giant clam from the deep ocean floor. (Photograph by John M. Edmond, Massachusetts Institute of Technology.)

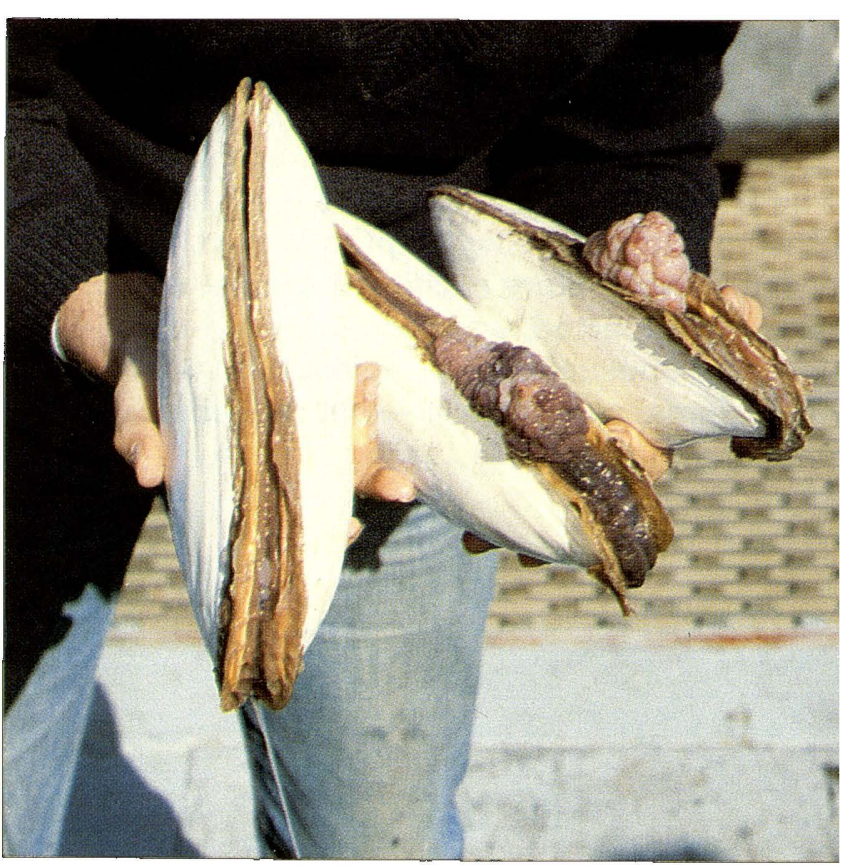




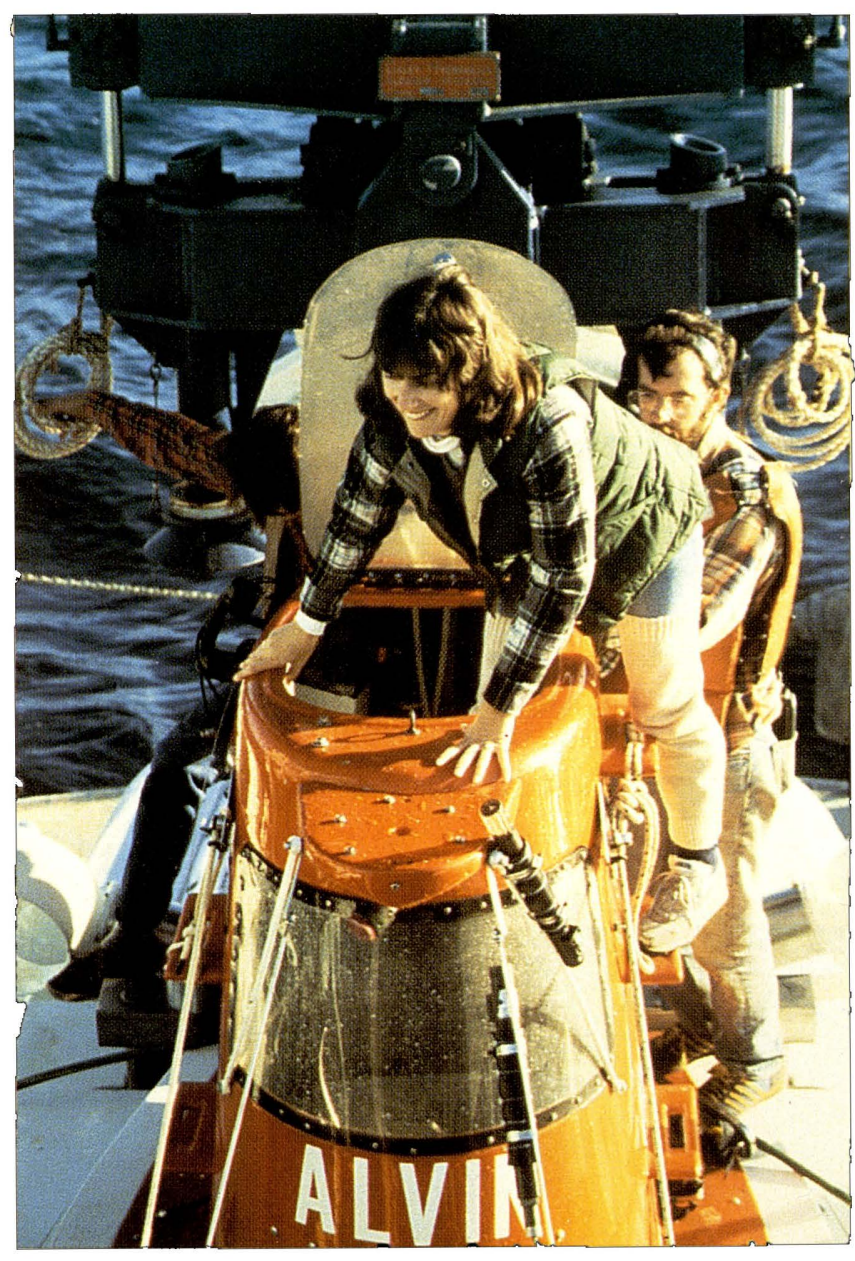

USGS scientist Jan Morton entering the submersible Alvin before its launch to begin a research dive. (Photograph by Randolph A. Koski, USGS.)
The Alvin below water after the launch and en route to the deep seafloor. (Photograph courtesy of the Woods Hole Oceanographic Institution).

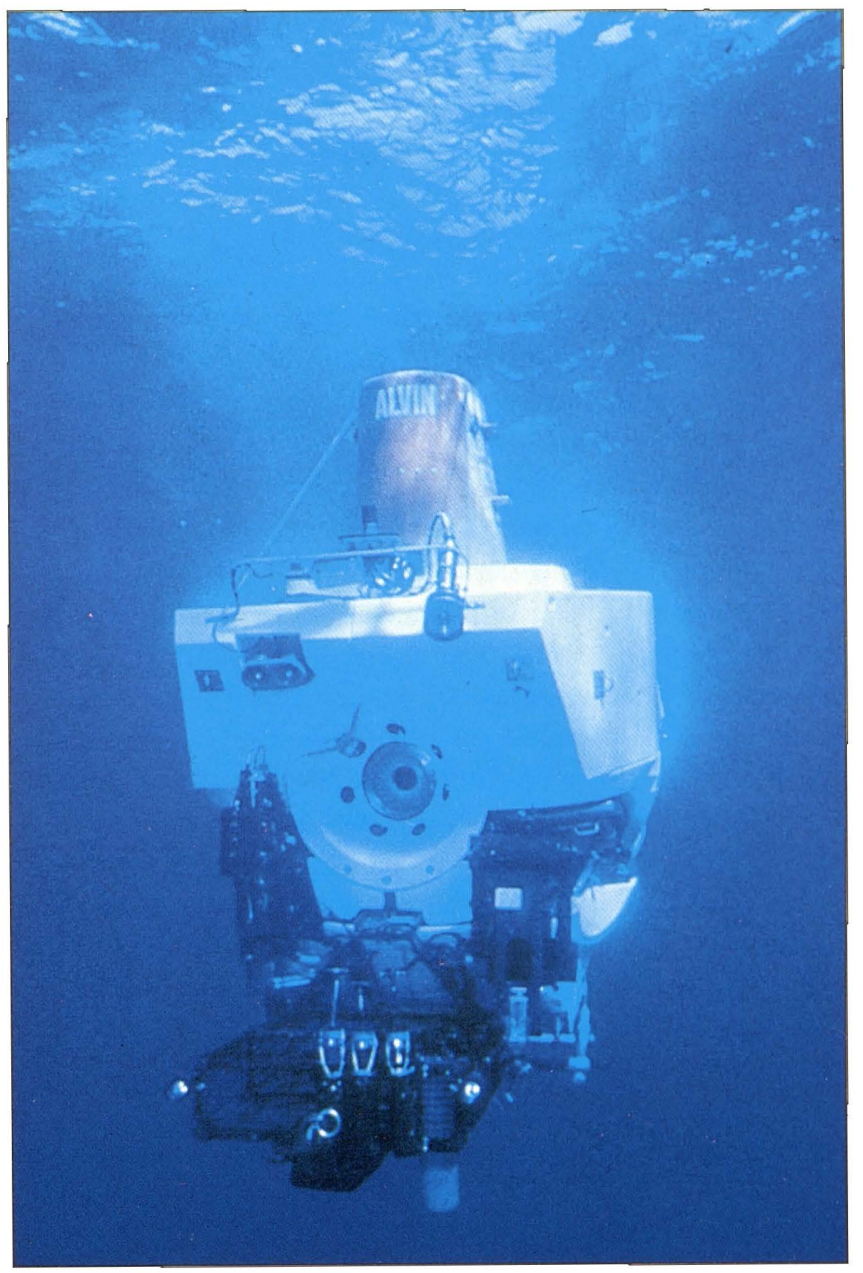

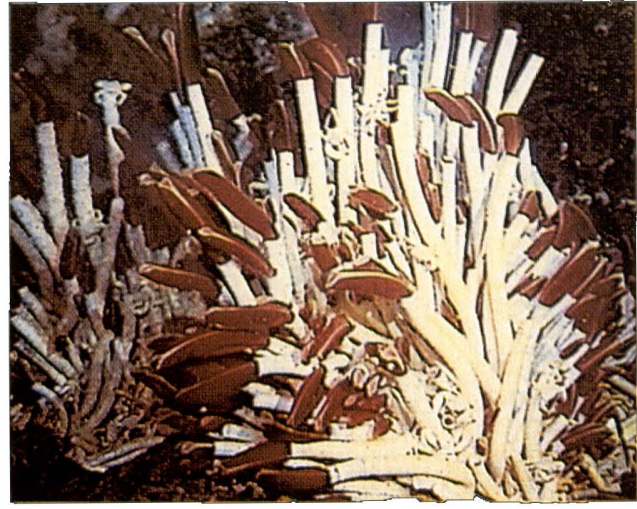

A colony of tube worms, some as long as $1.5 \mathrm{~m}$, clustered around an ocean floor hot spring. (Photograph by Daniel Fornari, Woods Hole Oceanographic Institution.)

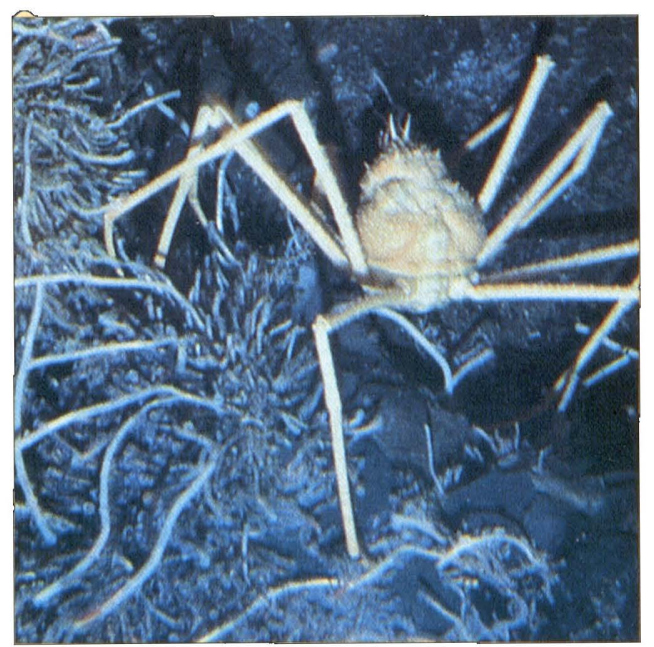

Close-up of spider crab that was observed to be eating tube worms. (Photograph by William R. Normark, USGS.) 
Since 1977, other hot springs and associated sea life have been found at a number of sites along the mid-oceanic ridges, many on the East Pacific Rise. The waters around these deepocean hot springs, which can be as hot as $380^{\circ} \mathrm{C}$, are home to a unique ecosystem. Detailed studies have shown that hydrogen sulfide-oxidizing bacteria, which live symbiotically with the larger organisms, form the base of this ecosystem's food chain. The hydrogen sulfide $\left(\mathrm{H}_{2} \mathrm{~S}\right.$-the gas that smells like rotten eggs) needed by these bacteria to live is contained in the volcanic gases that spew out of the hot springs. Most of the sulfur comes from the Earth's interior; a small portion (less than 15 percent) is produced by chemical reaction of the sulfate $\left(\mathrm{SO}_{4}\right)$ present in the sea water. Thus, the energy source that sustains this deep-ocean ecosystem is not sunlight but rather the energy from chemical reaction (chemosynthesis).

But the story about the source of life-sustaining energy in the deep sea is still unfolding. In the late 1980s, scientists documented the existence of a dim glow at some of the hot geothermal vents, which are the targets of current intensive research. The occurrence of "natural" light on the dark seafloor has great significance, because it implies that photosynthesis may be possible at deep-sea geothermal vents. Thus, the base of the deep-sea ecosystem's food chain may comprise both chemosynthetic and, probably in small proportion, photosynthetic bacteria.

Scientists discovered the hot-springs ecosystems with the help of Alvin, the world's first deepsea submersible. Constructed in the early 1960 s for the U.S. Navy, Alvin is a three-person, selfpropelling capsule-like submarine nearly eight meters long. In 1975, scientists of Project FAMOUS (French-American Mid-Ocean Undersea
Study) used Alvin to dive on a segment of the Mid-Atlantic Ridge in an attempt to make the first direct observation of seafloor spreading. No hot springs were observed on this expedition; it was during the next Alvin expedition, the one in 1977 to the Galapagos Rift, that the hot springs and strange creatures were discovered. Since the advent of Alvin, other manned submersibles have been built and used successfully to explore the deep ocean floor. Alvin has an operational maximum depth of about $4,000 \mathrm{~m}$, more than four times greater than that of the deepest diving military submarine. Shinkai 6500, a Japanese research submarine built in 1989, can work at depths down to $6,400 \mathrm{~m}$. The United States and Japan are developing research submersible systems that will be able to explore the ocean floor's deepest spot: the 10,920-m Challenger Deep at the southern end of the Marianas Trench off the Mariana Islands.

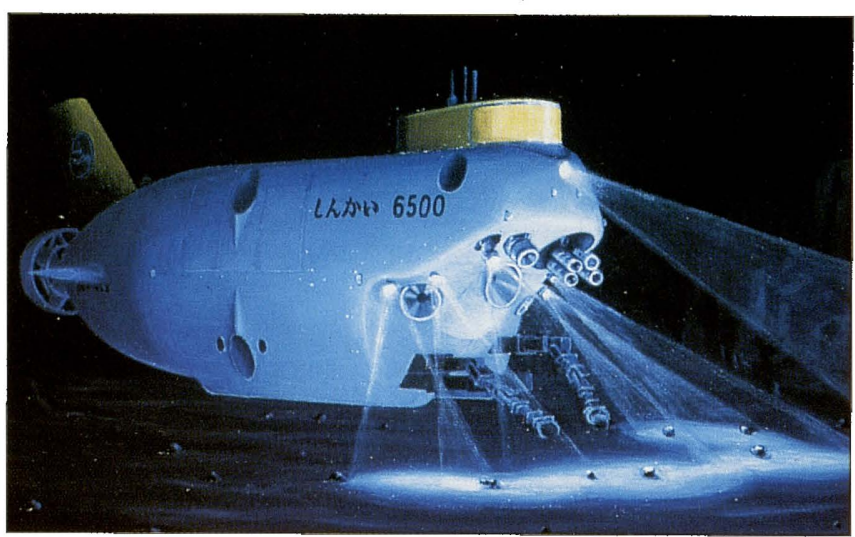

Sketch of the Shinkai 6500, a Japanese vessel that is currently the world's deepest-diving manned research submarine. (Courtesy of Japan Marine Science $\mathcal{E}^{\circ}$ Technology Center.) 


\section{Concentration of earthquakes}

During the 20th century, improvements in seismic instrumentation and greater use of earthquake-recording instruments (seismographs) worldwide enabled scientists to learn that earthquakes tend to be concentrated in certain areas, most notably along the oceanic trenches and spreading ridges. By the late 1920s, seismologists were beginning to identify several prominent earthquake zones parallel to the trenches that typically were inclined $40-60^{\circ}$ from the horizontal and extended several hundred kilometers into the Earth. These zones later became known as Wadati-Benioff zones, or simply Benioff zones, in honor of the seismologists who first recognized them, Kiyoo Wadati of Japan and Hugo Benioff of the United States. The study of global seismicity greatly advanced in the 1960 s with the establishment of the Worldwide Standardized Seismograph Network (WWSSN) to monitor the compliance of the 1963 treaty banning aboveground testing of nuclear weapons. The muchimproved data from the WWSSN instruments allowed seismologists to map precisely the zones of earthquake concentration worldwide.

But what was the significance of the connection between earthquakes and oceanic trenches and ridges? The recognition of such a connection helped confirm the seafloor-spreading hypothesis by pin-pointing the zones where Hess had predicted oceanic crust is being generated (along the ridges) and the zones where oceanic lithosphere sinks back into the mantle (beneath the trenches).

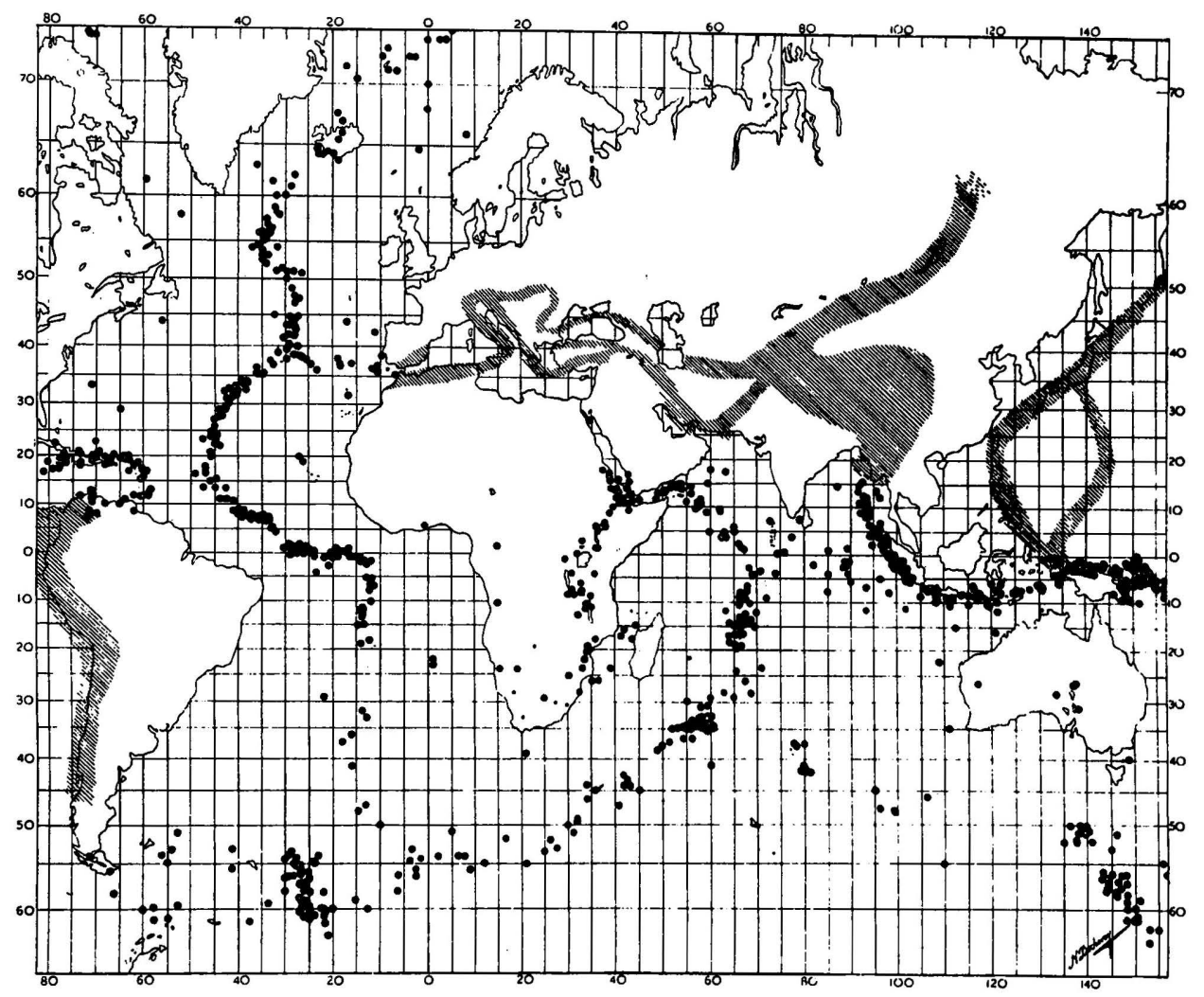

As early as the 1920s, scientists noted that earthquakes are concentrated in very specific narrow zones (see text). In 1954, French seismologist J.P. Rothé published this map showing the concentration of earthquakes along the zones indicated by dots and cross-hatched areas. (Original illustration reproduced with permission of the Royal Society of London.) 


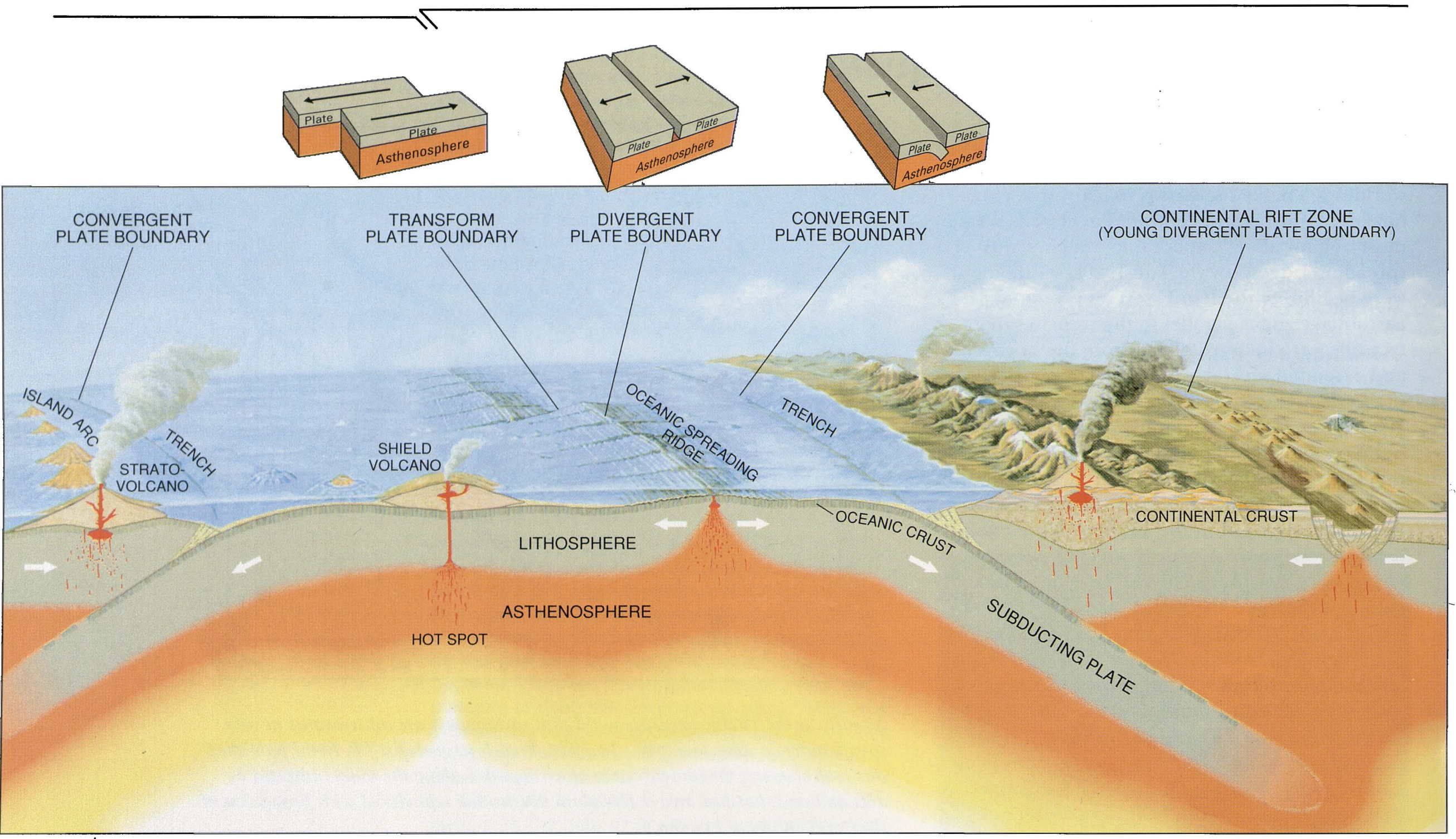

Artist's cross section illustrating the main types of plate boundaries (see text); East African Rift Zone is a good example of a continental rift zone. (Cross section by JoséF. Vigil from This Dynamic Planet-a wall map produced jointly by the U.S. Geological Survey, the Smithsonian Institution, and the U.S. Naval Research Laboratory.) 


\section{Understanding plate motions}

Scientists now have a fairly good understanding of how the plates move and how such movements relate to earthquake activity. Most movement occurs along narrow zones between plates where the results of plate-tectonic forces are most evident.

There are four types of plate boundaries:

- Divergent boundaries-where new crust is generated as the plates pull away from each other.

- Convergent boundaries - where crust is destroyed as one plate dives under another.

- Transform boundaries - where crust is neither produced nor destroyed as the plates slide horizontally past each other.

- Plate boundary zones-broad belts in which boundaries are not well defined and the effects of plate interaction are unclear.

\section{Divergent boundaries}

Divergent boundaries occur along spreading centers where plates are moving apart and new crust is created by magma pushing up from the mantle. Picture two giant conveyor belts, facing each other but slowly moving in opposite directions as they transport newly formed oceanic crust away from the ridge crest.

Perhaps the best known of the divergent boundaries is the Mid-Atlantic Ridge. This submerged mountain range, which extends from the
Arctic Ocean to beyond the southern tip of Africa, is but one segment of the global midocean ridge system that encircles the Earth. The rate of spreading along the Mid-Atlantic Ridge averages about 2.5 centimeters per year $(\mathrm{cm} / \mathrm{yr})$, or $25 \mathrm{~km}$ in a million years. This rate may seem slow by human standards, but because this process has been going on for millions of years, it has resulted in plate movement of thousands of kilometers. Seafloor spreading over the past 100 to 200 million years has caused the Atlantic Ocean to grow from a tiny inlet of water between the continents of Europe, Africa, and the Americas into the vast ocean that exists today.

The volcanic country of Iceland, which straddles the Mid-Atlantic Ridge, offers scientists a natural laboratory for studying on land the processes also occurring along the submerged parts of a spreading ridge. Iceland is splitting along the spreading center between the North American and Eurasian Plates, as North America moves westward relative to Eurasia.

The consequences of plate movement are easy to see around Krafla Volcano, in the northeastern part of Iceland. Here, existing ground cracks have widened and new ones appear every few months. From 1975 to 1984, numerous episodes of rifting (surface cracking) took place along the Krafla fissure zone. Some of these rifting events were accompanied by volcanic activity; the ground would gradually rise 1-2 $\mathrm{m}$ before 
The Mid-Atlantic Ridge, which splits nearly the entire Atlantic Ocean north to south, is probably the best-known and most-studied example of a divergent-plate boundary. (Illustration adapted from the map This Dynamic Planet.)

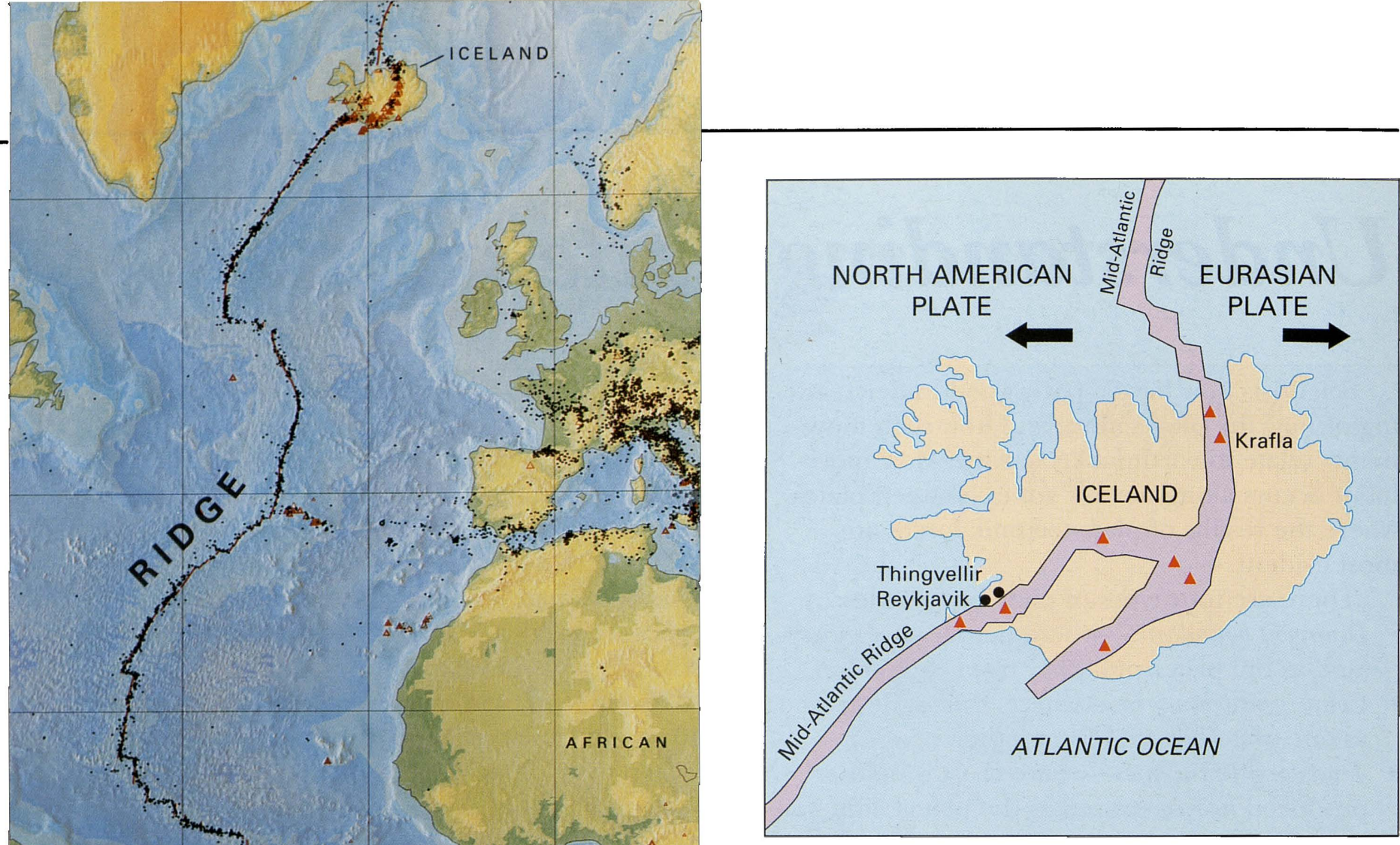

Map showing the Mid-Atlantic Ridge splitting Iceland and separating the North American and Eurasian Plates. The map also shows Reykjavik, the capital of Iceland, the Thinguellir area, and the locations of some of Iceland's active volcanoes (A), including Krafla. 


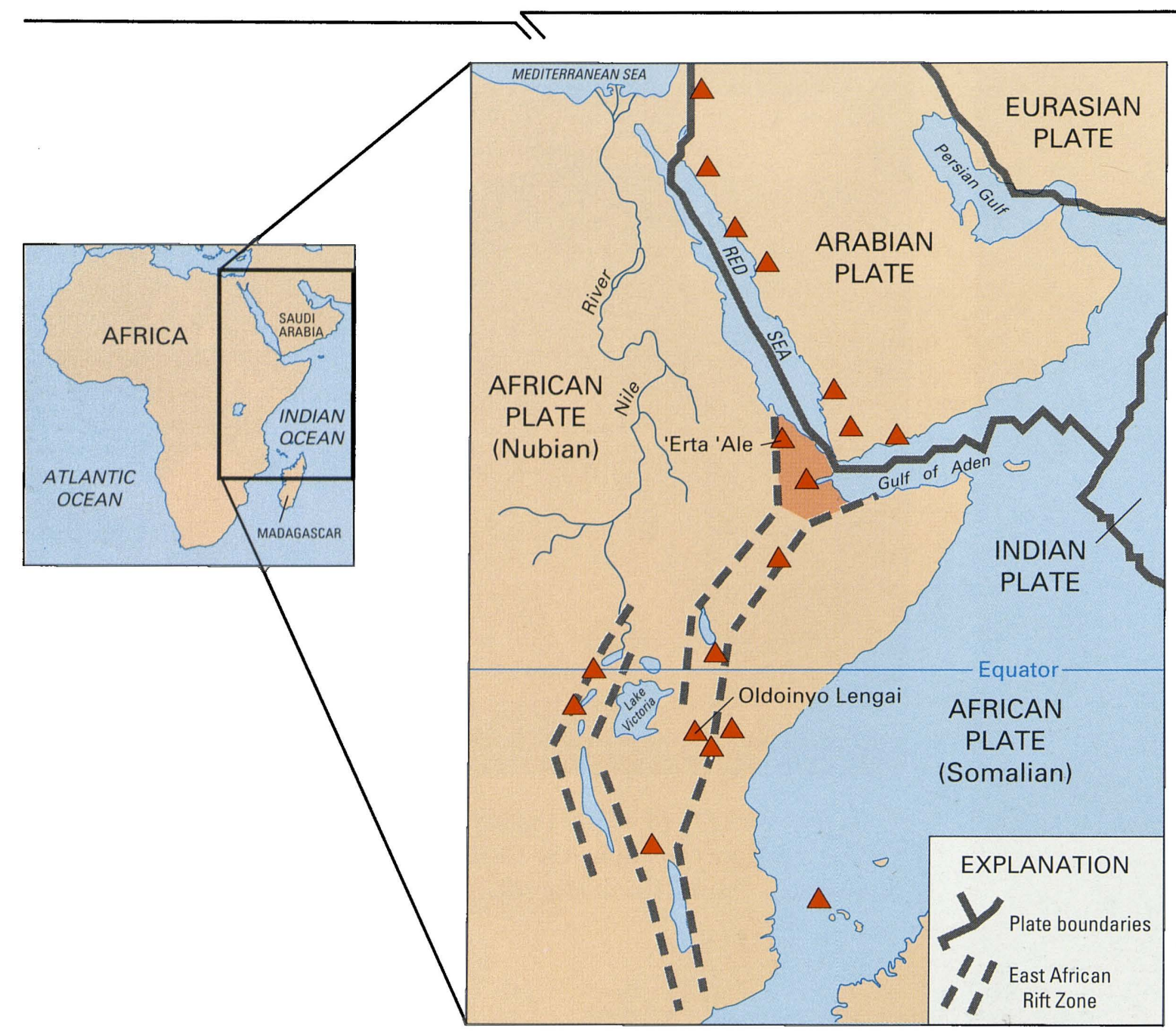

Map of East Africa showing some of the historically active volcanoes $(\mathbf{\Lambda})$ and the Afar Triangle (shaded, center) so-called triple junction (or triple point), where three plates are pulling away from one another: the Arabian Plate, and the two parts of the African Plate (the Nubian and the Somalian) splitting along the East African Rift Zone. abruptly dropping, signalling an impending eruption. Between 1975 and 1984, the displacements caused by rifting totalled about $7 \mathrm{~m}$.

In East Africa, spreading processes have already torn Saudi Arabia away from the rest of the African continent, forming the Red Sea. The actively splitting African Plate and the Arabian Plate meet in what geologists call a triple junction, where the Red Sea meets the Gulf of Aden. A new spreading center may be developing under Africa along the East African Rift Zone. When the continental crust stretches beyond its limits, tension cracks begin to appear on the Earth's surface. Magma rises and squeezes through the widening cracks, sometimes to erupt and form volcanoes. The rising magma, whether or not it erupts, puts more pressure on the crust to produce additional fractures and, ultimately, the rift zone.

East Africa may be the site of the Earth's next major ocean. Plate interactions in the region provide scientists an opportunity to study first hand how the Atlantic may have begun to form about 200 million years ago. Geologists believe that, if spreading continues, the three plates that meet at the edge of the present-day African continent will separate completely, allowing the Indian Ocean to flood the area and making the easternmost corner of Africa (the Horn of Africa) a large island. 
Helicopter view (in February 1994) of the active lava lake within the summit crater of 'Erta 'Ale (Ethiopia), one of the active volcanoes in the East African Rift Zone. Two helmeted, red-suited volcanologists -observing the activity from the crater rim-provide scale. Red color within the crater shows where molten lava is breaking through the lava lake's solidified, black crust. (Photograph by Jacques Durieux, Groupe Volcans Actifs.)
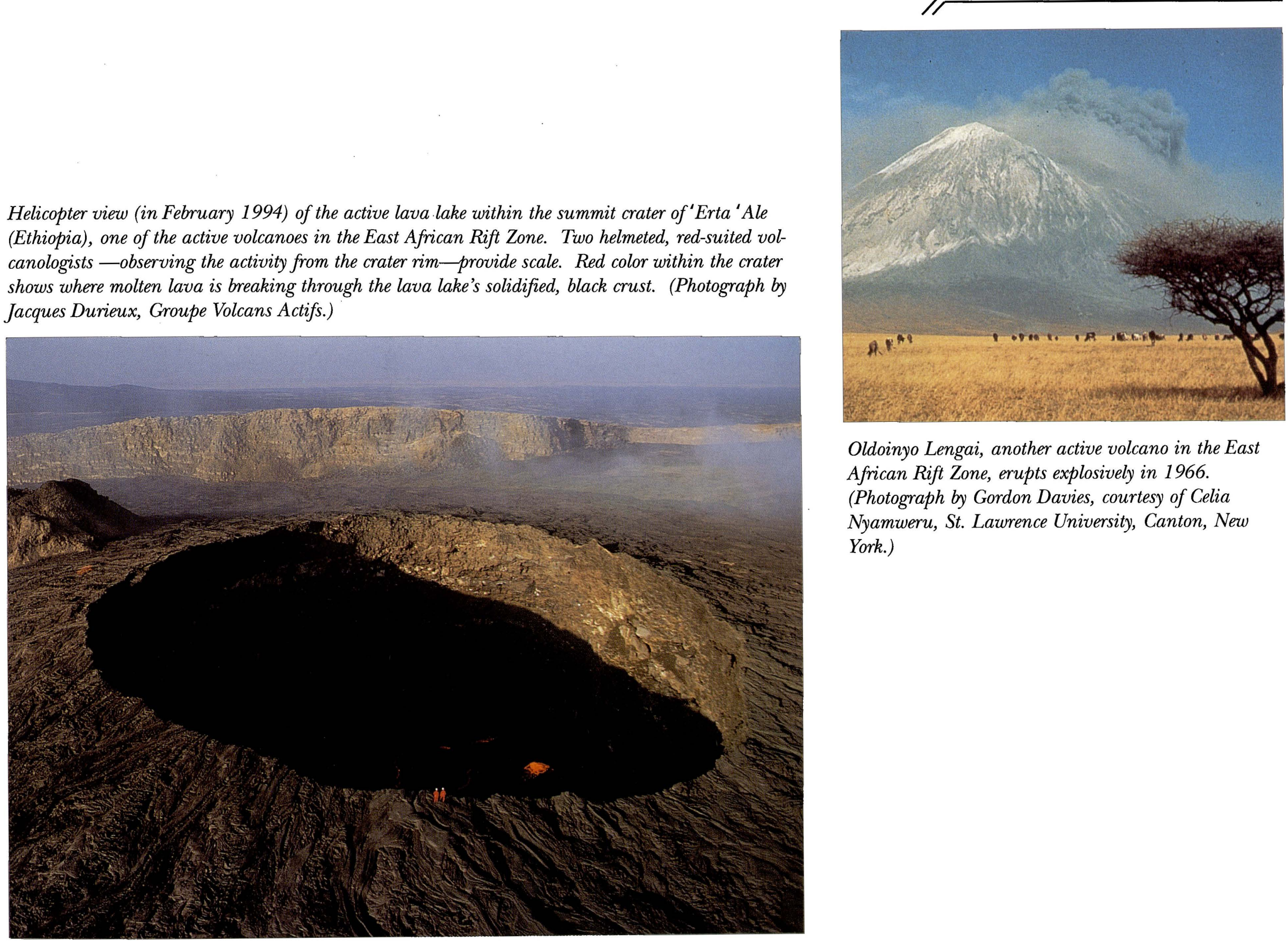

Oldoinyo Lengai, another active volcano in the East African Rift Zone, erupts explosively in 1966. (Photograph by Gordon Davies, courtesy of Celia Nyamweru, St. Lawrence University, Canton, New York.) 


\section{Convergent boundaries}

The size of the Earth has not changed significantly during the past 600 million years, and very likely not since shortly after its formation 4.6 billion years ago. The Earth's unchanging size implies that the crust must be destroyed at about the same rate as it is being created, as Harry Hess surmised. Such destruction (recycling) of crust takes place along convergent boundaries where plates are moving toward each other, and sometimes one plate sinks (is subducted) under another. The location where sinking of a plate occurs is called a subduction zone.

The type of convergence-called by some a very slow "collision"- that takes place between plates depends on the kind of lithosphere involved. Convergence can occur between an oceanic and a largely continental plate, or between two largely oceanic plates, or between two largely continental plates.

\section{Oceanic-continental convergence}

If by magic we could pull a plug and drain the Pacific Ocean, we would see a most amazing sight-a number of long narrow, curving trenches thousands of kilometers long and 8 to $10 \mathrm{~km}$ deep cutting into the ocean floor. Trenches are the deepest parts of the ocean floor and are created by subduction.

Off the coast of South America along the Peru-Chile trench, the oceanic Nazca Plate is pushing into and being subducted under the continental part of the South American Plate.

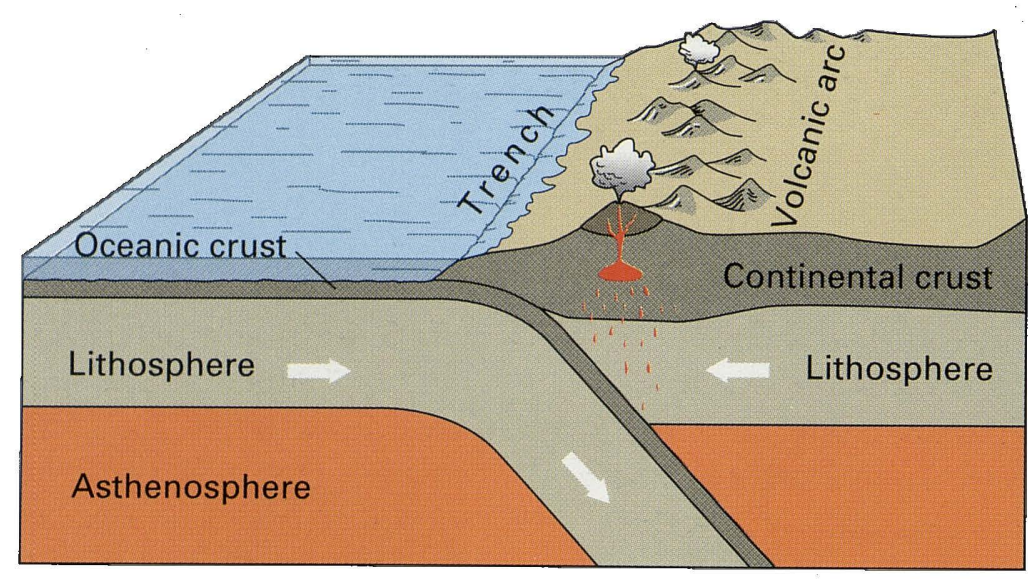

Oceanic-continental convergence 


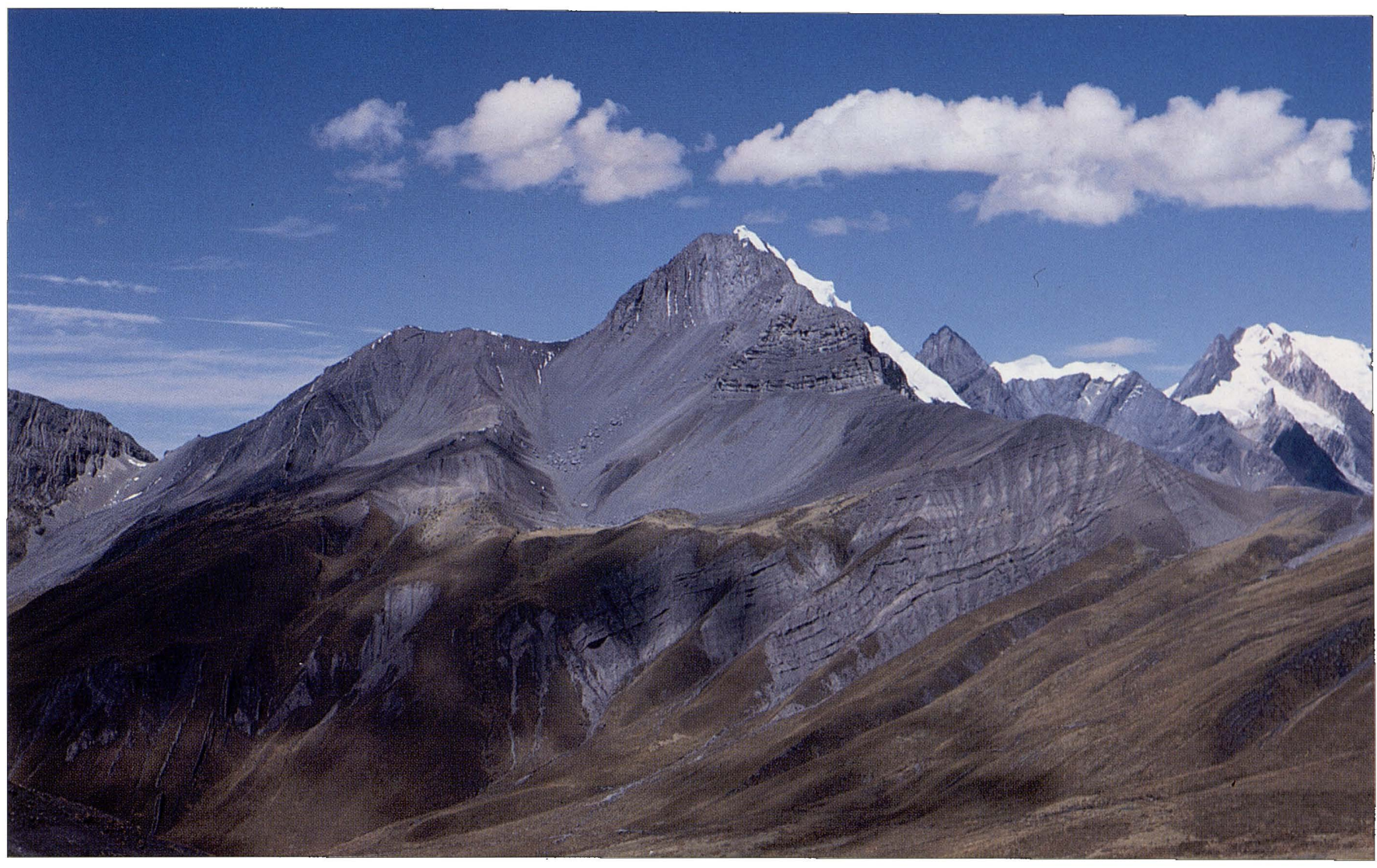

The convergence of the Nazca and South American Plates has deformed and pushed up limestone strata to form towering peaks of the Andes, as seen here in the Pachapaqui mining area in Peru. (Photograph by George Ericksen, USGS.)
In turn, the overriding South American Plate is being lifted up, creating the towering Andes mountains, the backbone of the continent. Strong, destructive earthquakes and the rapid uplift of mountain ranges are common in this region. Even though the Nazca Plate as a whole is sinking smoothly and continuously into the trench, the deepest part of the subducting plate breaks into smaller pieces that become locked in place for long periods of time before suddenly moving to generate large earthquakes. Such earthquakes are often accompanied by uplift of the land by as much as a few meters.

On 9 June 1994, a magnitude-8.3 earthquake struck about $320 \mathrm{~km}$ northeast of La Paz, Bolivia, at a depth of $636 \mathrm{~km}$. This earthquake, within the subduction zone between the Nazca Plate and the South American Plate, was one of deepest and largest subduction earthquakes recorded in South America. Fortunately, even though this 


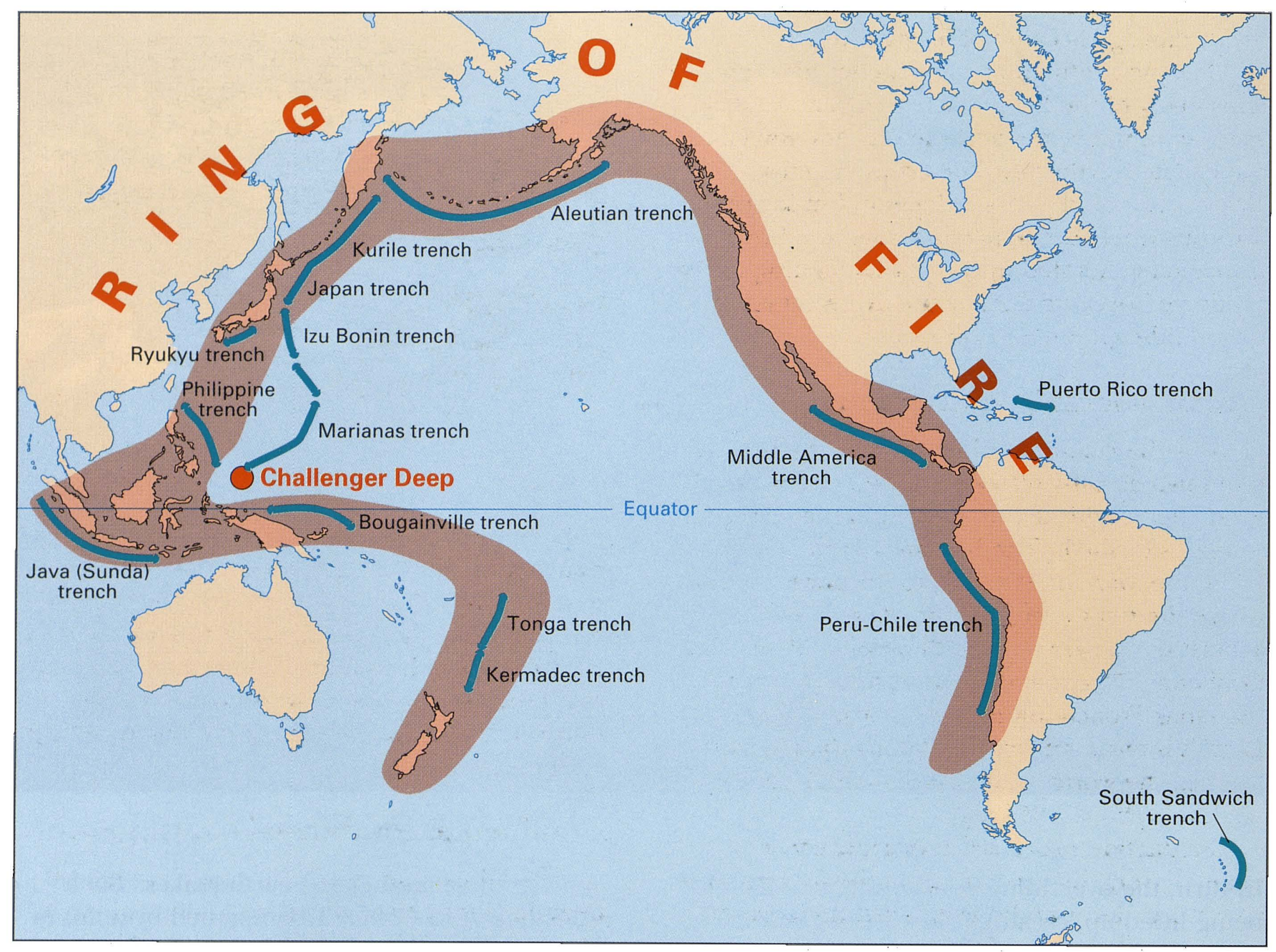

Volcanic arcs and oceanic trenches partly encircling the Pacific Basin form the so-called Ring of Fire, a zone of frequent earthquakes and volcanic eruptions. The trenches are shown in green. The volcanic island arcs, although not labelled, are parallel to, and always landward of, the trenches. For example, the island arc associated with the Aleutian Trench is represented by the long chain of volcanoes that make up the Aleutian Islands. 
powerful earthquake was felt as far away as Minnesota and Toronto, Canada, it caused no major damage because of its great depth.

Oceanic-continental convergence also sustains many of the Earth's active volcanoes, such as those in the Andes and the Cascade Range in the Pacific Northwest. The eruptive activity is clearly associated with subduction, but scientists vigorously debate the possible sources of magma: Is magma generated by the partial melting of the subducted oceanic slab, or the overlying continental lithosphere, or both?

\section{Oceanic-oceanic convergence}

As with oceanic-continental convergence, when two oceanic plates converge, one is usually subducted under the other, and in the process a trench is formed. The Marianas Trench (paralleling the Mariana Islands), for example, marks where the fast-moving Pacific Plate converges against the slower moving Philippine Plate. The Challenger Deep, at the southern end of the Marianas Trench, plunges deeper into the Earth's interior (nearly 11,000 m) than Mount Everest, the world's tallest mountain, rises above sea level (about $8,854 \mathrm{~m}$ ).

Subduction processes in oceanic-oceanic plate convergence also result in the formation of volcanoes. Over millions of years, the erupted lava and volcanic debris pile up on the ocean floor until a submarine volcano rises above sea level to form an island volcano. Such volcanoes are typically strung out in chains called island arcs. As the name implies, volcanic island arcs, which closely parallel the trenches, are generally curved. The trenches are the key to understanding how island arcs such as the Marianas and the

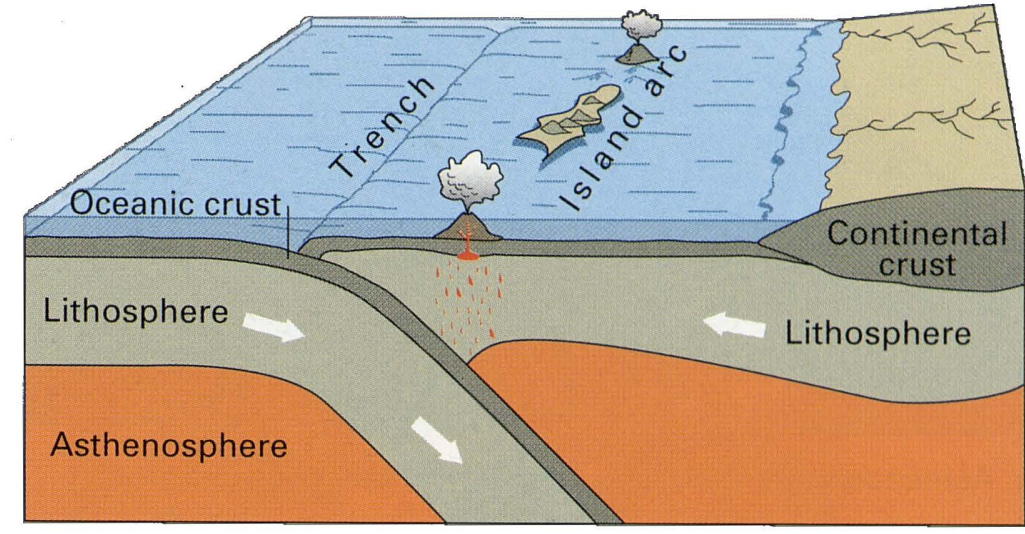

Oceanic-oceanic convergence

Aleutian Islands have formed and why they experience numerous strong earthquakes. Magmas that form island arcs are produced by the partial melting of the descending plate and/or the overlying oceanic lithosphere. The descending plate also provides a source of stress as the two plates interact, leading to frequent moderate to strong earthquakes.

\section{Continental-continental convergence}

The Himalayan mountain range dramatically demonstrates one of the most visible and spectacular consequences of plate tectonics. When two continents meet head-on, neither is subducted because the continental rocks are relatively light and, like two colliding icebergs, resist downward motion. Instead, the crust tends to buckle and be pushed upward or sideways. The collision of India into Asia 50 million years ago caused the Eurasian Plate to crumple up and override the 


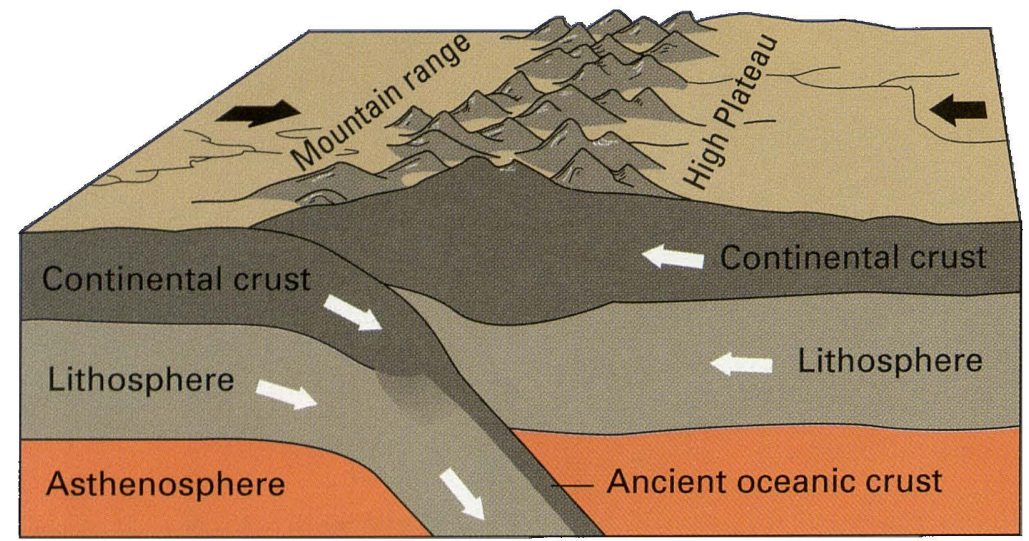

Continental-continental convergence
Indian Plate. After the collision, the slow continuous convergence of the two plates over millions of years pushed up the Himalayas and the Tibetan Plateau to their present heights. Most of this growth occurred during the past 10 million years. The Himalayas, towering as high as $8,854 \mathrm{~m}$ above sea level, form the highest continental mountains in the world. Moreover, the neighboring Tibetan Plateau, at an average elevation of about $4,600 \mathrm{~m}$, is higher than all the peaks in the Alps except for Mont Blanc and Monte Rosa, and is well above the summits of most mountains in the United States.
Far right: The collision between the Indian and Eurasian plates has pushed up the Himalayas and the Tibetan Plateau. Right: Cartoon cross sections showing the meeting of these two plates before and after their collision. The reference points (small squares) show the amount of uplift of an imaginary point in the Earth's crust during this mountain-building process.
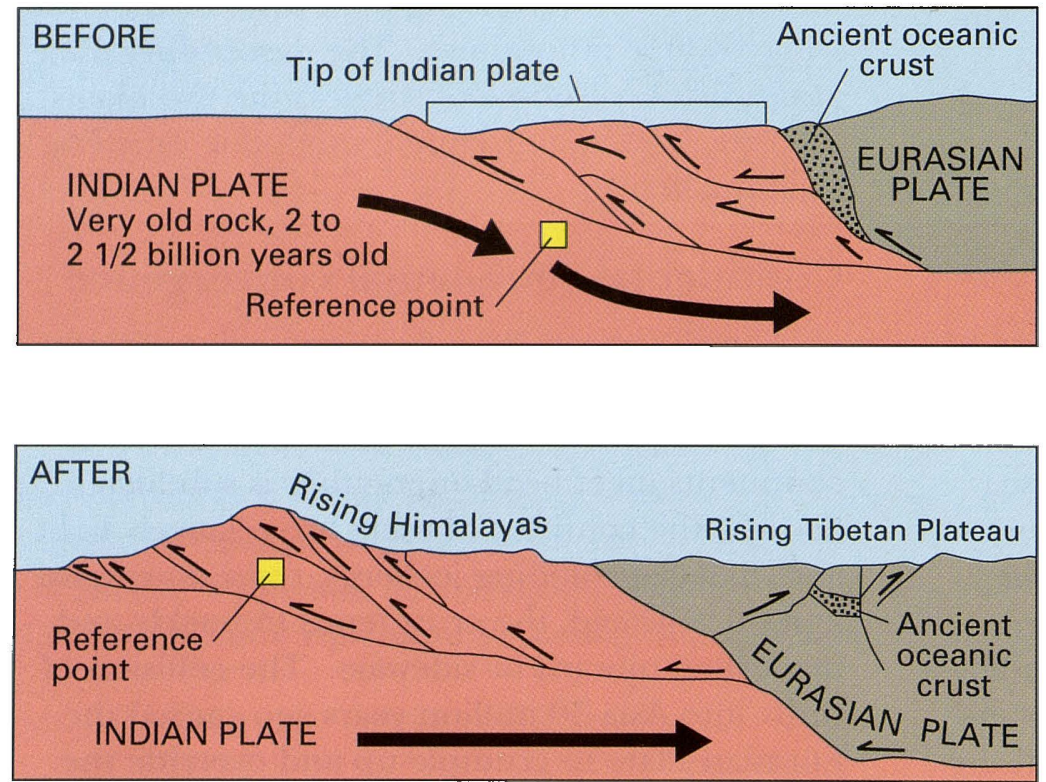

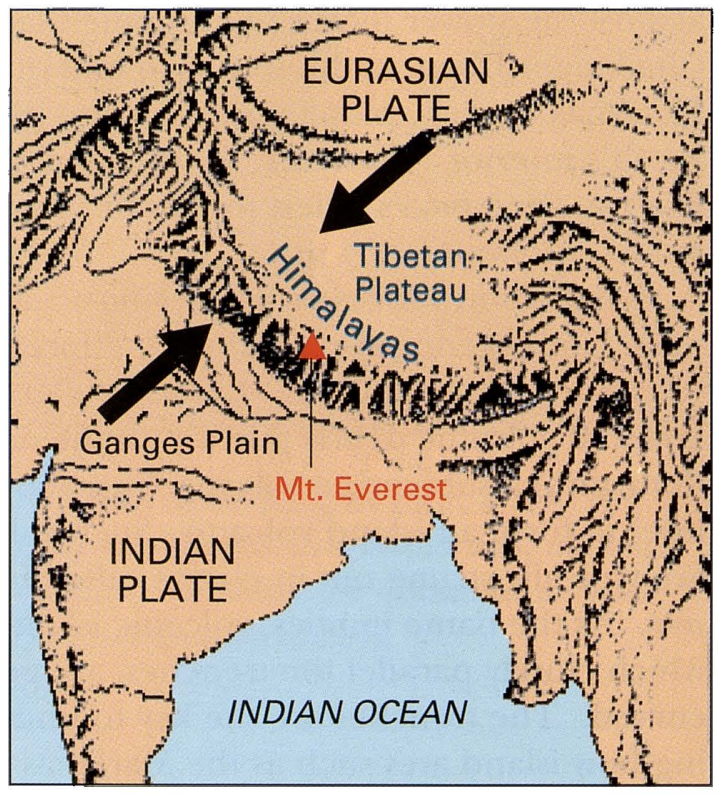




\section{The Himalayas: Two continents collide}

Among the most dramatic and visible creations of plate-tectonic forces are the lofty Himalayas, which stretch 2,900 km along the border between India and Tibet. This immense mountain range began to form between 40 and 50 million years ago, when two large landmasses, India and Eurasia, driven by plate movement, collided. Because both these continental landmasses have about the same rock density, one plate could not be subducted under the other. The pressure of the impinging plates could only be relieved by thrusting skyward, contorting the collision zone, and forming the jagged Himalayan peaks.

About 225 million years ago, India was a large island still situated off the Australian coast, and a vast ocean (called Tethys Sea) separated India from the Asian continent. When Pangaea broke apart about $\mathbf{2 0 0}$ million years ago, India began to forge northward. By studying the history-and ultimately the closing - of the Tethys, scientists have reconstructed India's northward journey. About 80 million years ago, India was located roughly $6,400 \mathrm{~km}$ south of the Asian continent, moving northward at a rate of about $9 \mathrm{~m}$ a century. When India rammed into Asia about 40 to 50 million years ago, its northward advance slowed by about half. The collision and associated decrease in the rate of plate movement are interpreted to mark the beginning of the rapid uplift of the Himalayas.

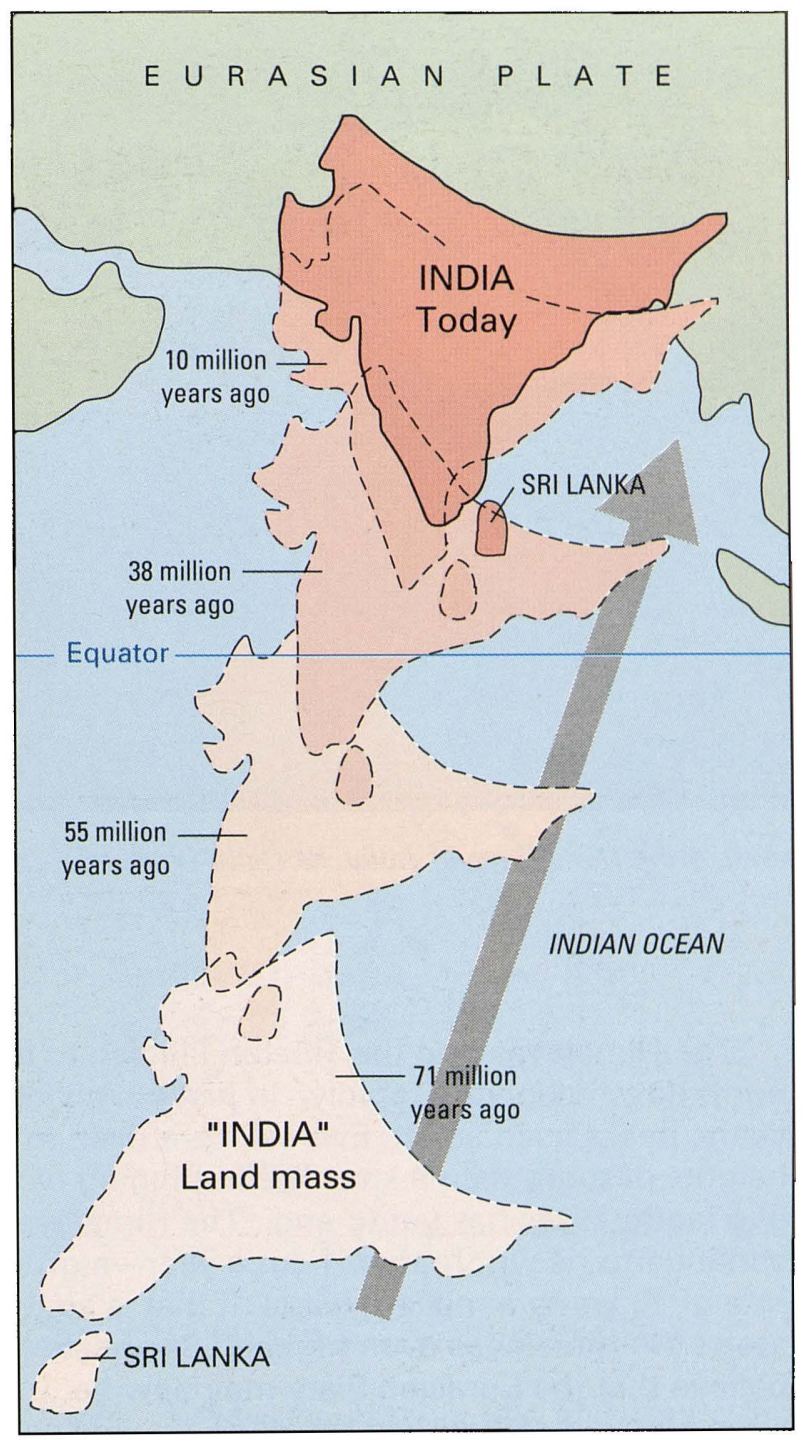

The 6,000-km-plus journey of the India landmass (Indian Plate) before its collision with Asia (Eurasian Plate) about 40 to 50 million years ago (see text).

India was once situated well south of the Equator, near the continent of Australia. 


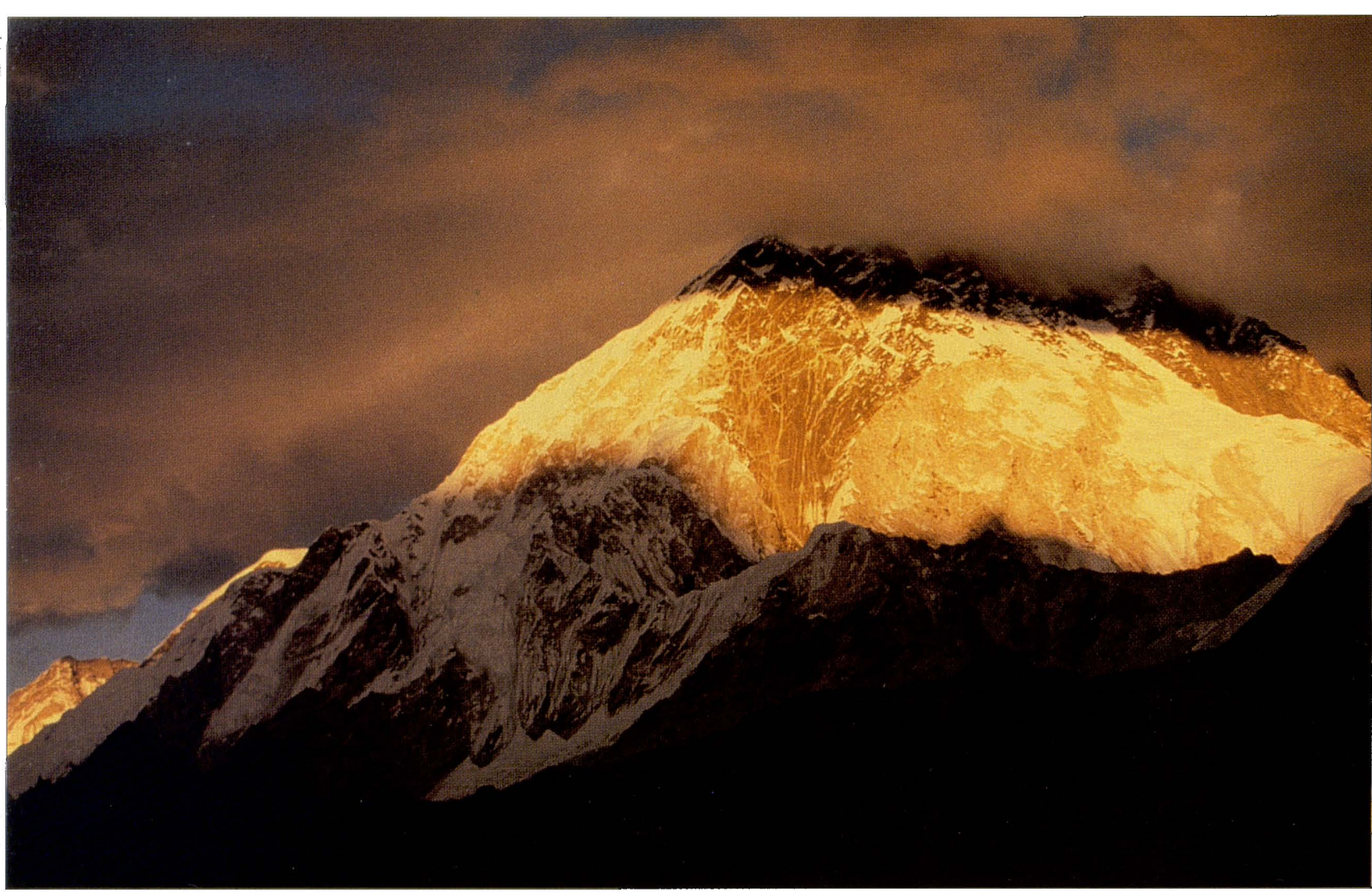

Sunset view of towering, snow-capped Mt. Everest, from the village of Lobuche (Solu-khumbu), Nepal. (Photograph by Gimmy Park Li.)
Fifty kilometers north of Lhasa (the capital of Tibet), scientists found layers of pink sandstone containing grains of magnetic minerals ( $\mathrm{mag}$ netite) that have recorded the pattern of the Earth's flip-flopping magnetic field. These sandstones also contain plant and animal fossils that were deposited when the Tethys Sea periodically flooded the region. The study of these fossils has revealed not only their geologic age but also the type of environment and climate in which they formed. For example, such studies indicate that the fossils lived under a relatively mild, wet environment about 105 million years ago, when Tibet was closer to the equator. Today, Tibet's climate is much more arid, reflecting the region's uplift and northward shift of nearly $2,000 \mathrm{~km}$. Fossils found in the sandstone layers offer dramatic evidence of the climate change in the Tibetan region due to plate movement over the past 100 million years.

At present, the movement of India continues to put enormous pressure on the Asian continent, and Tibet in turn presses on the landmass to the north that is hemming it in. The net effect of plate-tectonics forces acting on this geologically complicated region is to squeeze parts of Asia eastward toward the Pacific Ocean. One serious consequence of these processes is a deadly "domino" effect: tremendous stresses build up within the Earth's crust, which are relieved periodically by earthquakes along the numerous faults that scar the landscape. Some of the world's most destructive earthquakes in history are related to continuing tectonic processes that began some 50 million years ago when the Indian and Eurasian continents first met.
The Himalayas and the Tibetan Plateau to the north have risen very rapidly. In just 50 million years, peaks such as Mt. Everest have risen to heights of more than $9 \mathrm{~km}$. The impinging of the two landmasses has yet to end. The Himalayas continue to rise more than $1 \mathrm{~cm}$ a year-a growth rate of $10 \mathrm{~km}$ in a million years! If that is so, why aren't the Himalayas even higher? Scientists believe that the Eurasian Plate may now be stretching out rather than thrusting up, and such stretching would result in some subsidence due to gravity. 


\section{Transform boundaries}

The zone between two plates sliding horizontally past one another is called a transform-fault boundary, or simply a transform boundary. The concept of transform faults originated with Canadian geophysicist J. Tuzo Wilson, who proposed that these large faults or fracture zones connect two spreading centers (divergent plate boundaries) or, less commonly, trenches (convergent plate boundaries). Most transform faults are found on the ocean floor. They commonly offset the active spreading ridges, producing zigzag plate margins, and are generally defined by shallow earthquakes. However, a few occur on land, for example the San Andreas fault zone in California. This transform fault connects the East Pacific Rise, a divergent boundary to the south, with the South Gorda-Juan de Fuca-

Explorer Ridge, another divergent boundary to the north.

The San Andreas fault zone, which is about $1,300 \mathrm{~km}$ long and in places tens of kilometers wide, slices through two thirds of the length of California. Along it, the Pacific Plate has been grinding horizontally past the North American Plate for 10 million years, at an average rate of about $5 \mathrm{~cm} / \mathrm{yr}$. Land on the west side of the fault zone (on the Pacific Plate) is moving in a northwesterly direction relative to the land on the east side of the fault zone (on the North American Plate).

Oceanic fracture zones are ocean-floor valleys that horizontally offset spreading ridges; some of these zones are hundreds to thousands of kilometers long and as much as $8 \mathrm{~km}$ deep.

Examples of these large scars include the

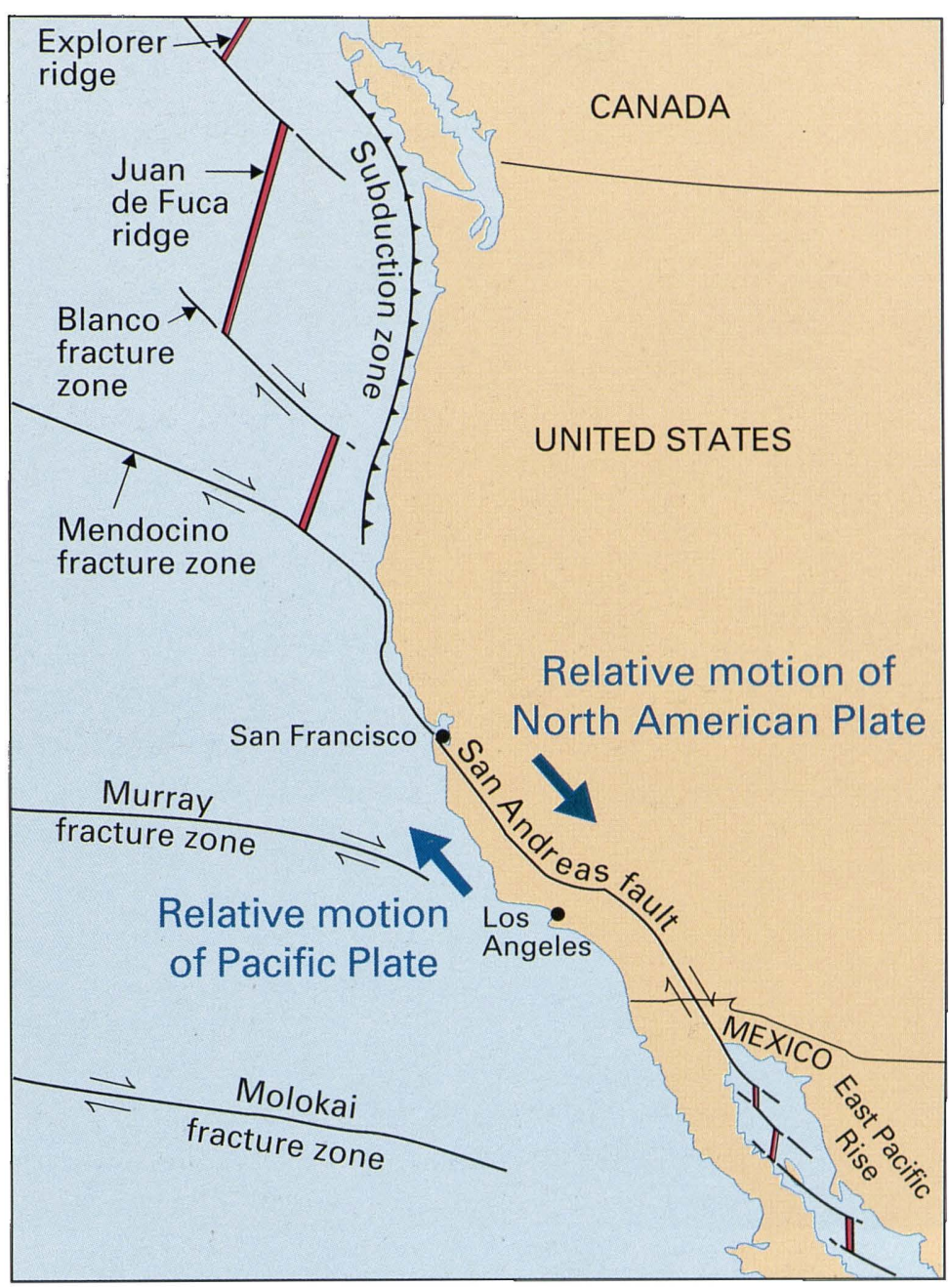

The Blanco, Mendocino, Murray, and Molokai fracture zones are some of the many fracture zones (transform faults) that scar the ocean floor and offset ridges (see text). The San Andreas is one of the few transform faults exposed on land. 


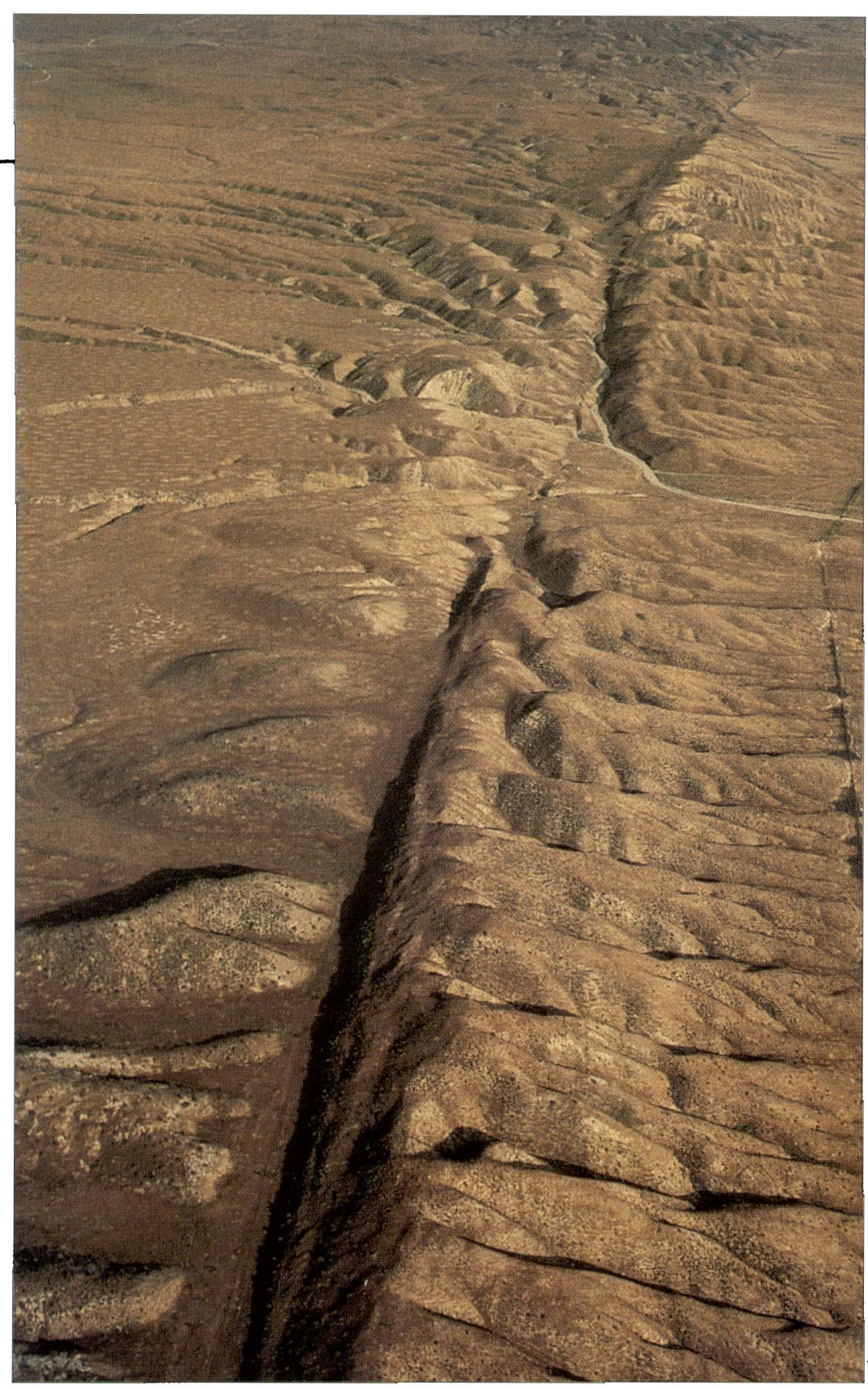

Clarion, Molokai, and Pioneer fracture zones in the Northeast Pacific off the coast of California and Mexico. These zones are presently inactive, but the offsets of the patterns of magnetic striping provide evidence of their previous transformfault activity.

\section{Plate-boundary zones}

Not all plate boundaries are as simple as the main types discussed above. In some regions, the boundaries are not well defined because the plate-movement deformation occurring there extends over a broad belt (called a plate-boundary zone). One of these zones marks the Mediterranean-Alpine region between the Eurasian and African Plates, within which several smaller fragments of plates (microplates) have been recognized. Because plate-boundary zones involve at least two large plates and one or more microplates caught up between them, they tend to have complicated geological structures and earthquake patterns.

Aerial view of the San Andreas fault slicing through the Carrizo Plain in the Temblor Range east of the city of San Luis Obispo. (Photograph by Robert E. Wallace, USGS.) 


\section{Rates of motion}

We can measure how fast tectonic plates are moving today, but how do scientists know what the rates of plate movement have been over geologic time? The oceans hold one of the key pieces to the puzzle. Because the ocean-floor magnetic striping records the flip-flops in the Earth's magnetic field, scientists, knowing the approximate duration of the reversal, can calculate the average rate of plate movement during a given time span. These average rates of plate separations can range widely. The Arctic Ridge has the slowest rate (less than $2.5 \mathrm{~cm} / \mathrm{yr}$ ), and the East Pacific Rise near Easter Island, in the South Pacific about 3,400 km west of Chile, has the fastest rate (more than $15 \mathrm{~cm} / \mathrm{yr}$ ).

Evidence of past rates of plate movement also can be obtained from geologic mapping studies. If a rock formation of known age-with distinctive composition, structure, or fossils-mapped on one side of a plate boundary can be matched with the same formation on the other side of the boundary, then measuring the distance that the formation has been offset can give an estimate of the average rate of plate motion. This simple but effective technique has been used to determine the rates of plate motion at divergent boundaries, for example the Mid-Atlantic Ridge, and transform boundaries, such as the San Andreas Fault.

Current plate movement can be tracked directly by means of ground-based or space-based geodetic measurements; geodesy is the science of the size and shape of the Earth. Ground-based measurements are taken with conventional but very precise ground-surveying techniques, using laser-electronic instruments. However, because plate motions are global in scale, they are best measured by satellite-based methods. The late 1970 s witnessed the rapid growth of space geodesy, a term applied to space-based techniques for

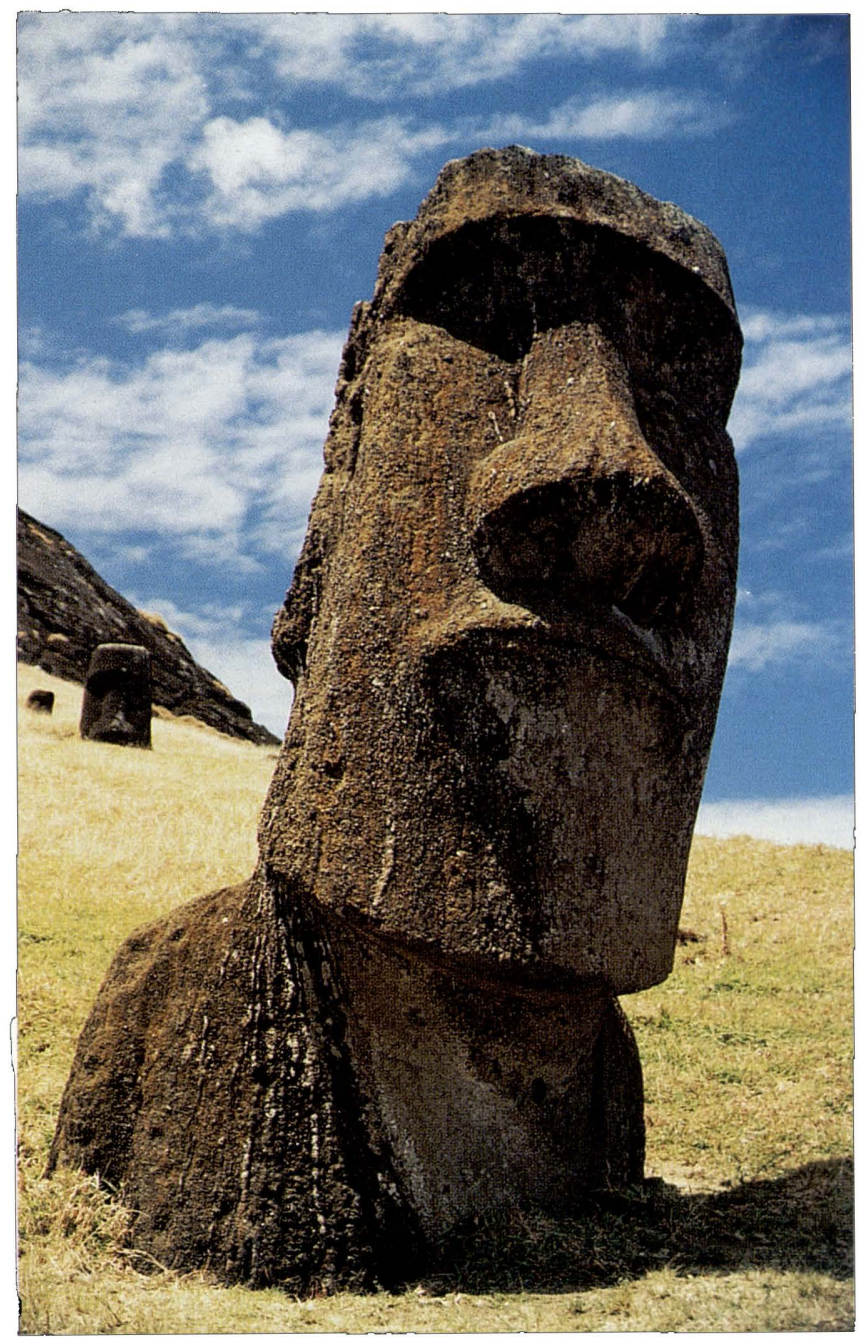

One of the mysterious, imposing stone monoliths-some standing $5 \mathrm{~m}$ tall and weighing 14 tons-on Easter Island (Chile), carved by ancient Polynesians out of volcanic rock. Easter Island, which lies on the Nazca Plate close to the East Pacific Rise, is moving eastward toward South America by seafloor spreading at the fastest rate known in the world (see text). (Photograph by Carlos Capurro, U.S. Embassy, Santiago, Chile.) 
Right: Artist's conception of a Global Positioning System (GPS) satellite in orbit. (Illustration courtesy of NASA.) Below: A GPS ground receiver-here set up on the flank of Augustine Volcano (Cook Inlet, Alaska)-recording the signals sent by four or more of the orbiting GPS satellites. (Photograph by Jerry Svarc, USGS.)

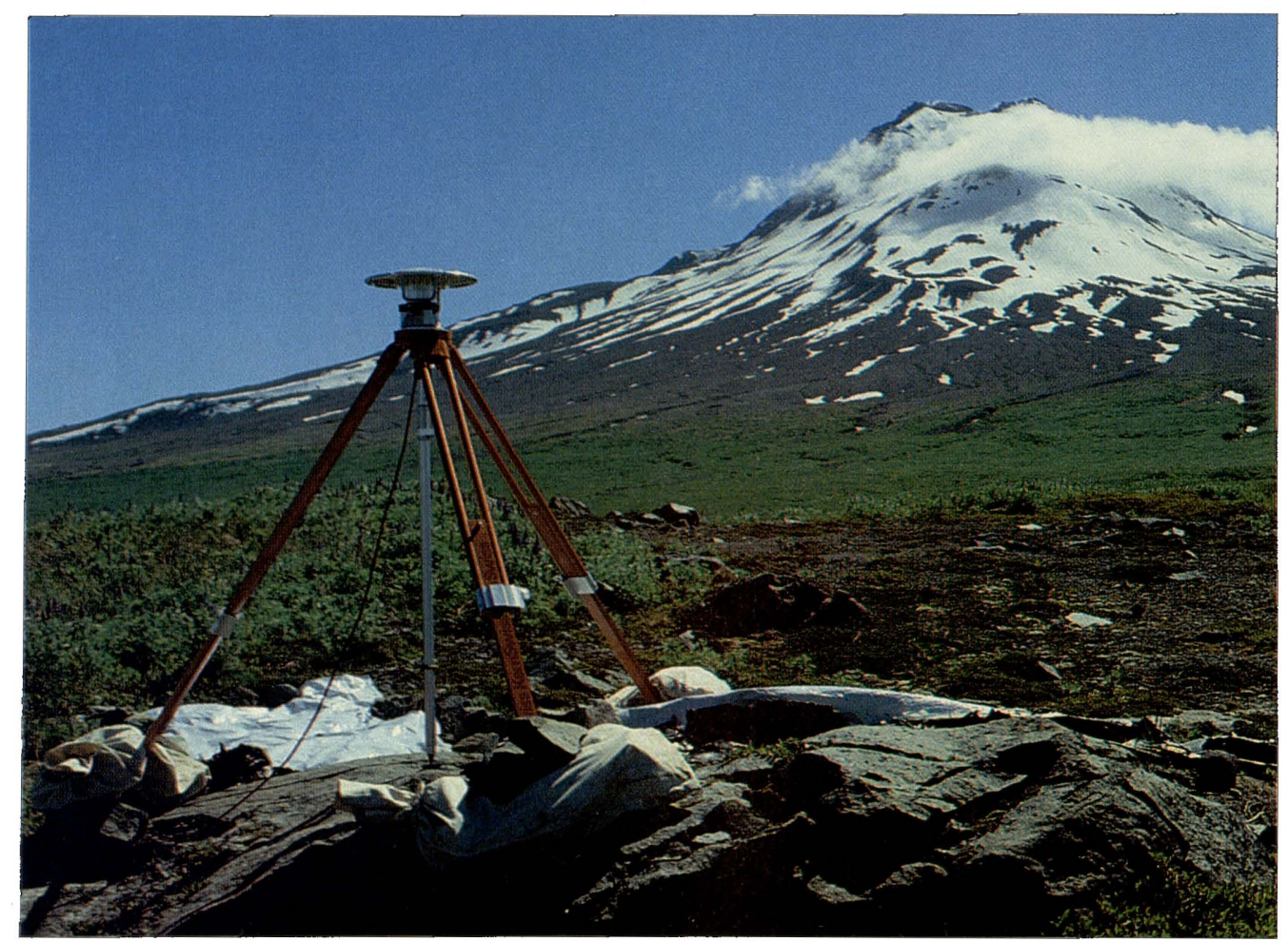

taking precise, repeated measurements of carefully chosen points on the Earth's surface separated by hundreds to thousands of kilometers. The three most commonly used space-geodetic techniques-very long baseline interferometry (VLBI), satellite laser ranging (SLR), and the Global Positioning System (GPS) - are based on technologies developed for military and aerospace research, notably radio astronomy and satellite tracking.

Among the three techniques, to date the GPS has been the most useful for studying the Earth's crustal movements. Twenty-one satellites are currently in orbit $20,000 \mathrm{~km}$ above the Earth as part of the NavStar system of the U.S. Department of Defense. These satellites continuously transmit radio signals back to Earth. To determine its precise position on Earth (longitude, latitude, elevation), each GPS ground site must simultaneously receive signals from at least four satellites, recording the exact time and location of each satellite when its signal was received. By repeatedly measuring distances between specific points, geologists can determine if there has been active movement along faults or between plates. The separations between GPS sites are already being measured regularly around the Pacific basin. By monitoring the interaction between the Pacific Plate and the surrounding, largely continental plates, scientists hope to learn more about the events building up to earthquakes and volcanic eruptions in the circum-Pacific Ring of Fire. Space-geodetic data have already confirmed that the rates and direction of plate movement, averaged over several years, compare well with rates and direction of plate movement averaged over millions of years. 


\section{"Hotspots": Mantle thermal plumes}

The vast majority of earthquakes and volcanic eruptions occur near plate boundaries, but there are some exceptions. For example, the Hawaiian Islands, which are entirely of volcanic origin, have formed in the middle of the Pacific Ocean more than $3,200 \mathrm{~km}$ from the nearest plate boundary. How do the Hawaiian Islands and other volcanoes that form in the interior of plates fit into the plate-tectonics picture?

In 1963, J. Tuzo Wilson, the Canadian geophysicist who discovered transform faults, came up with an ingenious idea that became known as the "hotspot" theory. Wilson noted that in certain locations around the world, such as Hawaii, volcanism has been active for very long periods of time. This could only happen, he reasoned, if relatively small, long-lasting, and exceptionally hot regions-called hotspots-existed below the plates that would provide localized sources of high heat energy (thermal plumes) to sustain volcanism. Specifically, Wilson hypothesized that the distinctive linear shape of the Hawaiian Island-Emperor Seamounts chain resulted from the Pacific Plate moving over a deep, stationary hotspot in the mantle, located beneath the present-day position of the Island of Hawaii. Heat from this hotspot produced a persistent source of magma by partly melting the overriding Pacific Plate. The magma, which is lighter than the surrounding solid rock, then rises through the mantle and crust to erupt onto the seafloor,

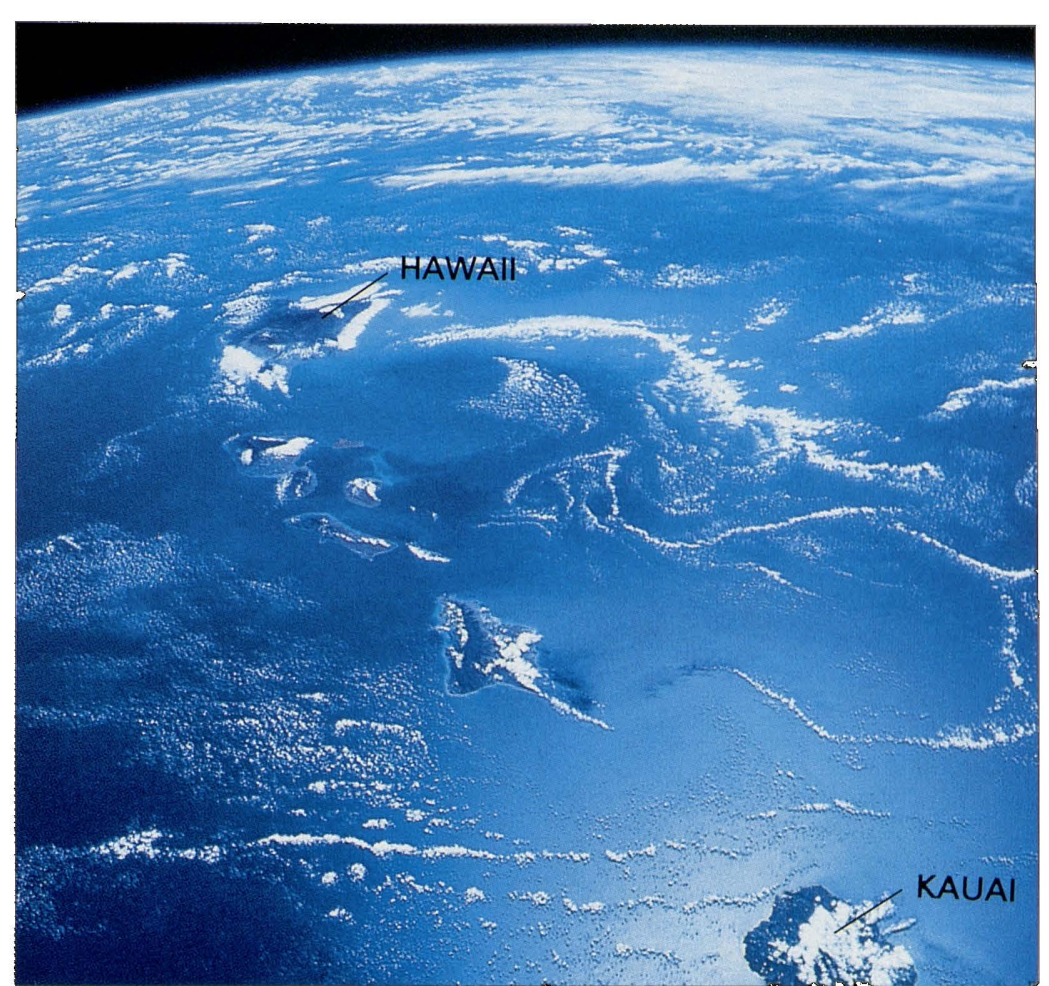

Space Shuttle photograph of the Hawaiian Islands, the southernmost part of the long volcanic trail of the "Hawaiian hotspot" (see text). Kauai is in the lower right corner (edge) and the Big Island of Hawaii in the upper left corner. Note the curvature of the Earth (top edge). (Photograph courtesy of NASA.) 


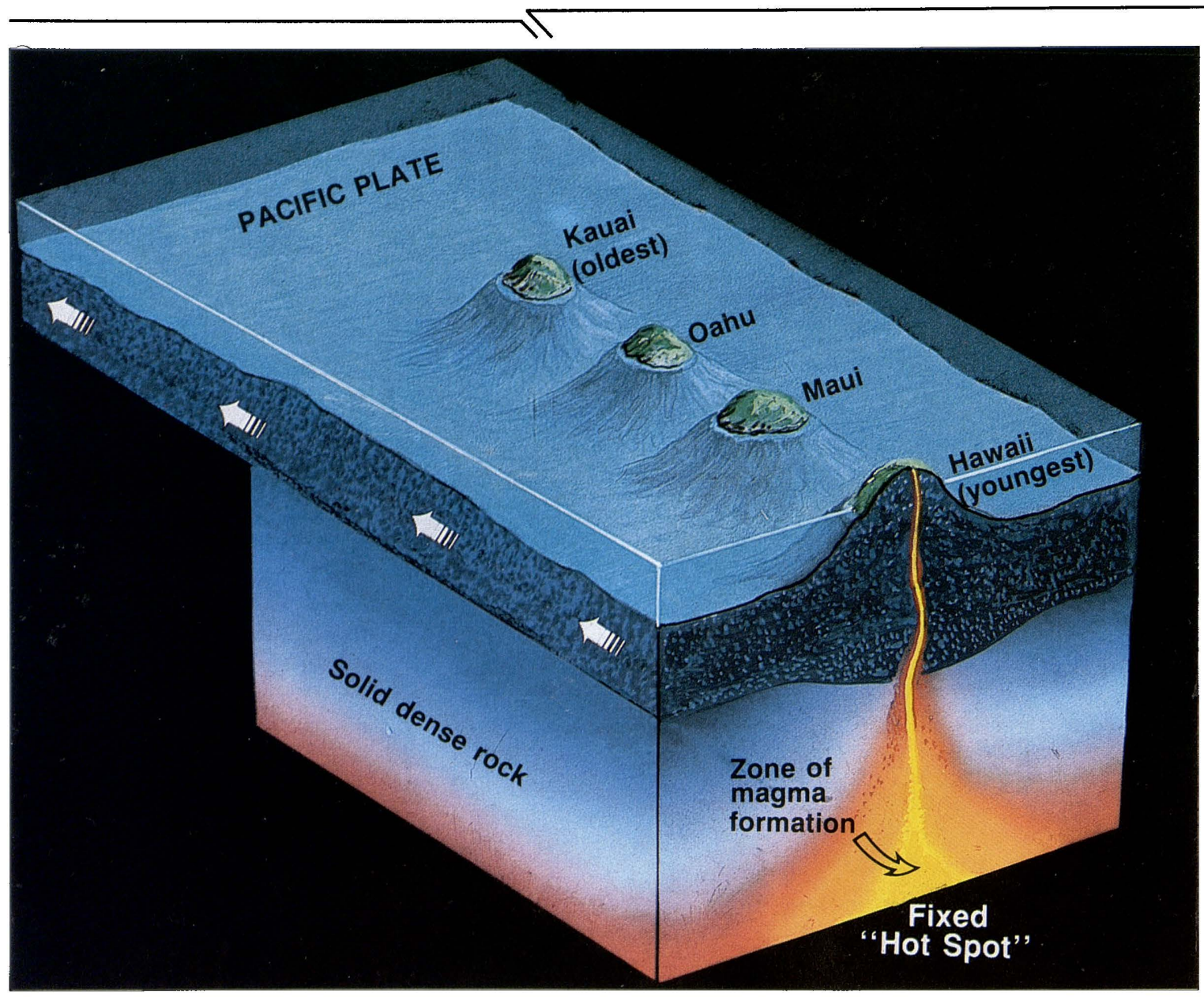

forming an active seamount. Over time, countless eruptions cause the seamount to grow until it finally emerges above sea level to form an island volcano. Wilson suggested that continuing plate movement eventually carries the island beyond the hotspot, cutting it off from the magma source, and volcanism ceases. As one island volcano becomes extinct, another develops over the hotspot, and the cycle is repeated. This process of volcano growth and death, over many millions of years, has left a long trail of volcanic islands and seamounts across the Pacific Ocean floor.

According to Wilson's hotspot theory, the volcanoes of the Hawaiian chain should get progressively older and become more eroded the farther they travel beyond the hotspot. The oldest volcanic rocks on Kauai, the northwesternmost inhabited Hawaiian island, are about 5.5 million years old and are deeply eroded. By comparison, on the "Big Island" of Hawaii-southeasternmost in the chain and presumably still positioned over the hotspot-the oldest exposed rocks are less than 0.7 million years old and new volcanic rock is continually being formed.

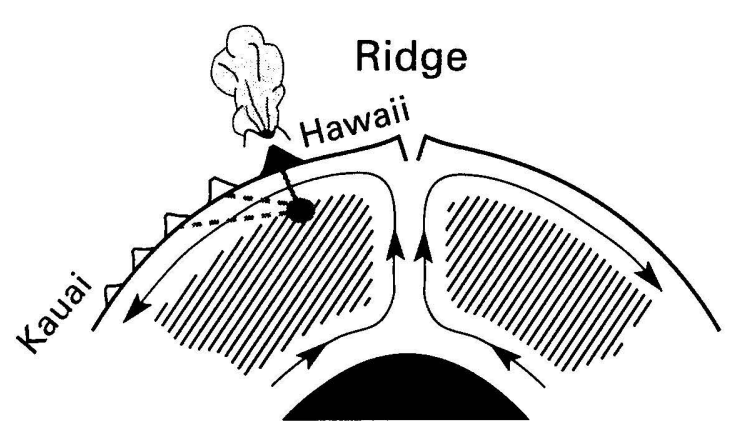

(a) Section

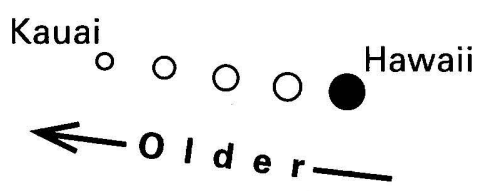

(b) Plan
Above: Artist's conception of the movement of the Pacific Plate over the fixed Hawaiian "Hot Spot," illustrating the formation of the Hawaiian Ridge-Emperor Seamount Chain. (Modified from a drawing provided by Maurice Krafft, Centre de Volcanologie, France). Left: J. Tuzo Wilson's original diagram (slightly modified), published in 1963, to show his proposed origin of the Hawaiian Islands. (Reproduced with permission of the Canadian Journal of Physics.) 


\section{J. Tuzo Wilson: Discovering transforms and hotspots}

Canadian geophysicist J. Tuzo Wilson was also pivotal in advancing the plate-tectonics theory. Intrigued by Wegener's notion of a mobile Earth and influenced by Harry Hess' exciting ideas, Wilson was eager to convert others to the revolution brewing in the earth sciences in the early 1960s. Wilson had known Hess in the late 1930s, when he was studying for his doctorate at Princeton University, where Hess was a dynamic young lecturer.

In 1963, Wilson developed a concept crucial to the plate-tectonics theory. He suggested that the Hawaiian and other volcanic island chains may have formed due to the movement of a plate over a stationary "hotspot" in the mantle. This hypothesis eliminated an apparent contradiction to the plate-tectonics theory-the occurrence of active volcanoes located many thousands of kilometers from the nearest plate boundary. Hundreds of subsequent studies have proven Wilson right. However, in the early 1960 s, his idea was considered so radical that his "hotspot" manuscript was rejected by all the major international scientific journals. This manuscript ultimately was published in 1963 in a relatively obscure publication, the Canadian Journal of Physics, and became a milestone in plate tectonics.

Another of Wilson's important contributions to the development of the plate-tectonics theory was published two years later. He proposed that there must be a third type of plate boundary to connect the oceanic ridges and trenches, which he noted can end abruptly and "transform" into major faults that slip horizontally. A well-known example of such a transform-fault boundary is the San Andreas Fault zone. Unlike ridges and trenches, transform faults offset the crust horizontally, without creating or destroying crust.
Wilson was a professor of geophysics at the University of Toronto from 1946 until 1974, when he retired from teaching and became the Director of the Ontario Science Centre. He was a tireless lecturer and traveller until his death in 1993. Like Hess, Wilson was able to see his concepts of hotspots and transform faults confirmed, as knowledge of the dynamics and seismicity of the ocean floor increased dramatically. Wilson and other scientists, including Robert Dietz, Harry Hess, Drummond Matthews, and Frederick Vine, were the principal architects in the early development of plate tectonics during the mid-1960s-a theory that is as vibrant and exciting today as it was when it first began to evolve less than 30 years ago. Interestingly, Wilson was in his midfifties, at the peak of his scientific career, when he made his insightful contributions to the plate-tectonics theory. If Alfred Wegener had not died at age 50 in his scientific prime, the plate tectonics revolution may have begun sooner.

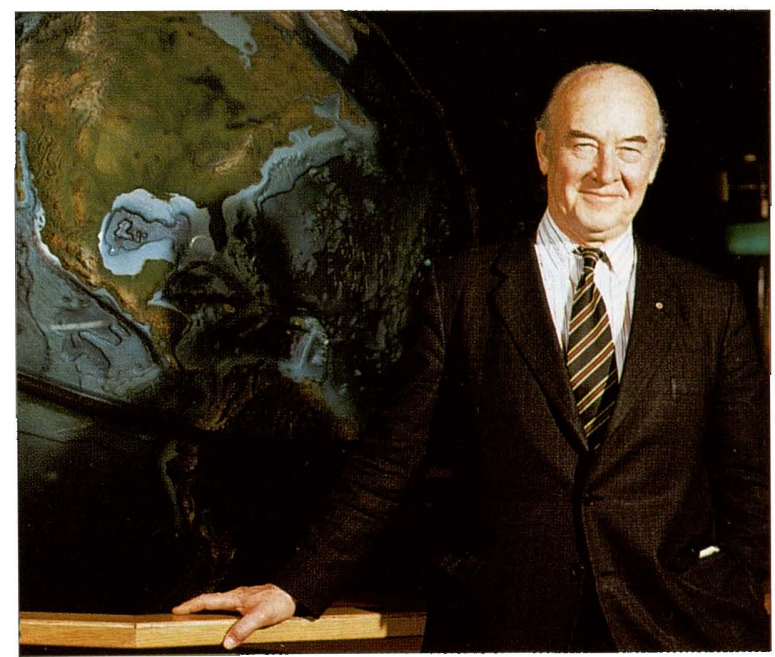

J. Tuzo Wilson (1908-1993) made major contributions to the development of the plate-tectonics theory in the 1960s and 1970s. He remained a dominant force in the Canadian scientific scene until his death. (Photograph courtesy of the Ontario Science Centre.) 
The possibility that the Hawaiian Islands become younger to the southeast was suspected by the ancient Hawaiians, long before any scientific studies were done. During their voyages, sea-faring Hawaiians noticed the differences in erosion, soil formation, and vegetation and recognized that the islands to the northwest (Niihau and Kauai) were older than those to the southeast (Maui and Hawaii). This idea was handed down from generation to generation in the legends of Pele, the fiery Goddess of Volcanoes. Pele originally lived on Kauai. When her older sister Namakaokahai, the Goddess of the Sea, attacked her, Pele fled to the Island of Oahu. When she was forced by Namakaokahai to flee again, Pele moved southeast to Maui and finally to Hawaii, where she now lives in the Halemaumau Crater at the summit of Kilauea Volcano. The mythical flight of Pele from Kauai to Hawaii, which alludes to the eternal struggle between the growth of volcanic islands from eruptions and their later erosion by ocean waves, is consistent with geologic evidence obtained centuries later that clearly shows the islands becoming younger from northwest to southeast.

\section{EXPLANATION}

\section{Divergent plate boundaries- Where new crust is generated as the plates pull away from each other.

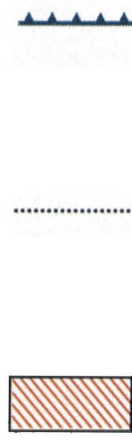 \\ Convergent plate boundaries- Where crust is consumed in the Earth's interior as one plate dives under another. \\ Transform plate boundaries- Where crust is neither produced nor destroyed as plates slide horizontally past each other. \\ Plate boundary zones-Broad belts in which deformation is diffuse and boundaries are not well defined.}

Selected prominent hotspots

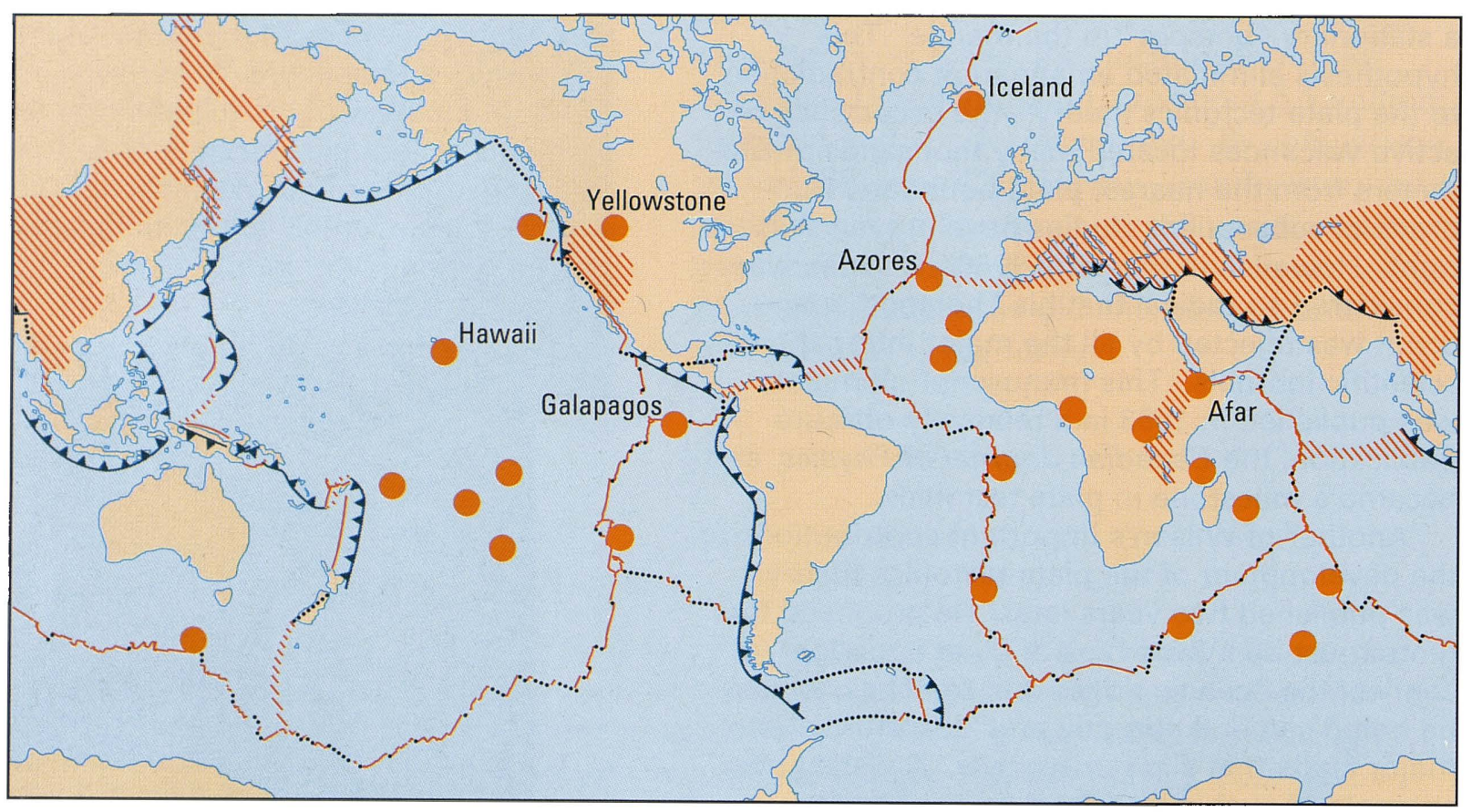

World map showing the locations of selected prominent hotspots; those labelled are mentioned in the text. (Modified from the map This Dynamic Planet.) 
Although Hawaii is perhaps the best known hotspot, others are thought to exist beneath the oceans and continents. More than a hundred hotspots beneath the Earth's crust have been active during the past 10 million years. Most of these are located under plate interiors (for example, the African Plate), but some occur near diverging plate boundaries. Some are concentrated near the mid-oceanic ridge system, such as beneath Iceland, the Azores, and the Galapagos Islands.

A few hotspots are thought to exist below the North American Plate. Perhaps the best known is the hotspot presumed to exist under the continental crust in the region of Yellowstone National Park in northwestern Wyoming. Here are several calderas (large craters formed by the ground collapse accompanying explosive volcanism) that were produced by three gigantic eruptions during the past two million years, the most recent of which occurred about 600,000 years ago. Ash deposits from these powerful eruptions have been mapped as far away as Iowa, Missouri, Texas, and even northern Mexico. The thermal energy of the presumed Yellowstone hotspot fuels more than 10,000 hot pools and springs, geysers (like Old Faithful), and bubbling mudpots (pools of boiling mud). A large body of magma, capped by a hydrothermal system (a zone of pressurized steam and hot water), still exists beneath the caldera. Recent surveys demonstrate that parts of the Yellowstone region rise and fall by as much as $1 \mathrm{~cm}$ each year, indicating the area is still geologically restless. However, these measurable ground movements, which most likely reflect hydrothermal pressure changes, do not necessarily signal renewed volcanic activity in the area.
While the existence of the Hawaiian hotspot is now widely accepted, little scientific agreement exists on the precise number and locations of the other presumed hotspots, despite recent studies. Even the presumed hotspot beneath Yellowstone, one of the best candidates for a continental hotspot, is still considered to be highly speculative, especially by the scientists most knowledgeable about the geology of the Western United States.

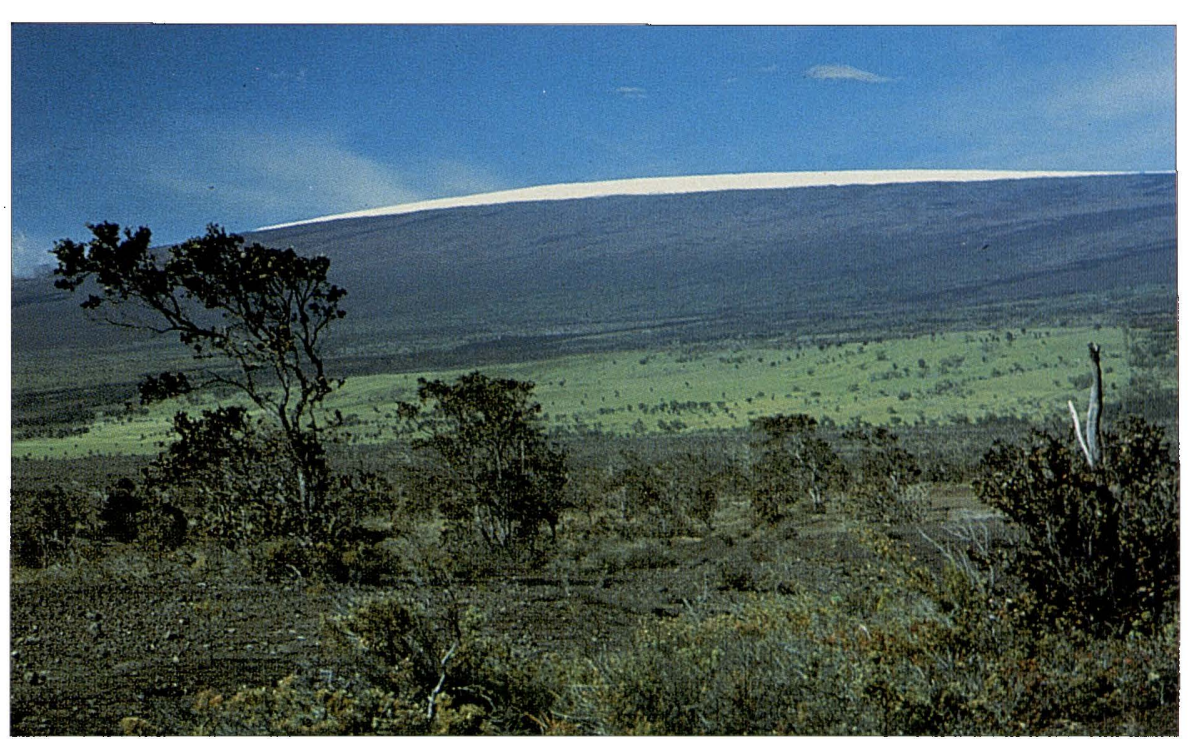

Snow-capped 4,169-m-high Mauna Loa Volcano, Island of Hawaii, seen from the USGS Hawaiian Volcano Observatory. Built by Hawaiian hotspot volcanism, Mauna Loa - the largest mountain in the world-is a classic example of a shield volcano. (Photograph by Robert I. Tilling, USGS.) 


\section{The long trail of the Hawaiian hotspot}

Map of part of the Pacific basin showing the volcanic trail of the Hawaiian hotspot-6,000-km-long Hawaiian Ridge-Emperor Seamounts chain. (Base map reprinted by permission from World Ocean Floor by Bruce C. Heezen and Marie Tharp, Copyright 1977.)

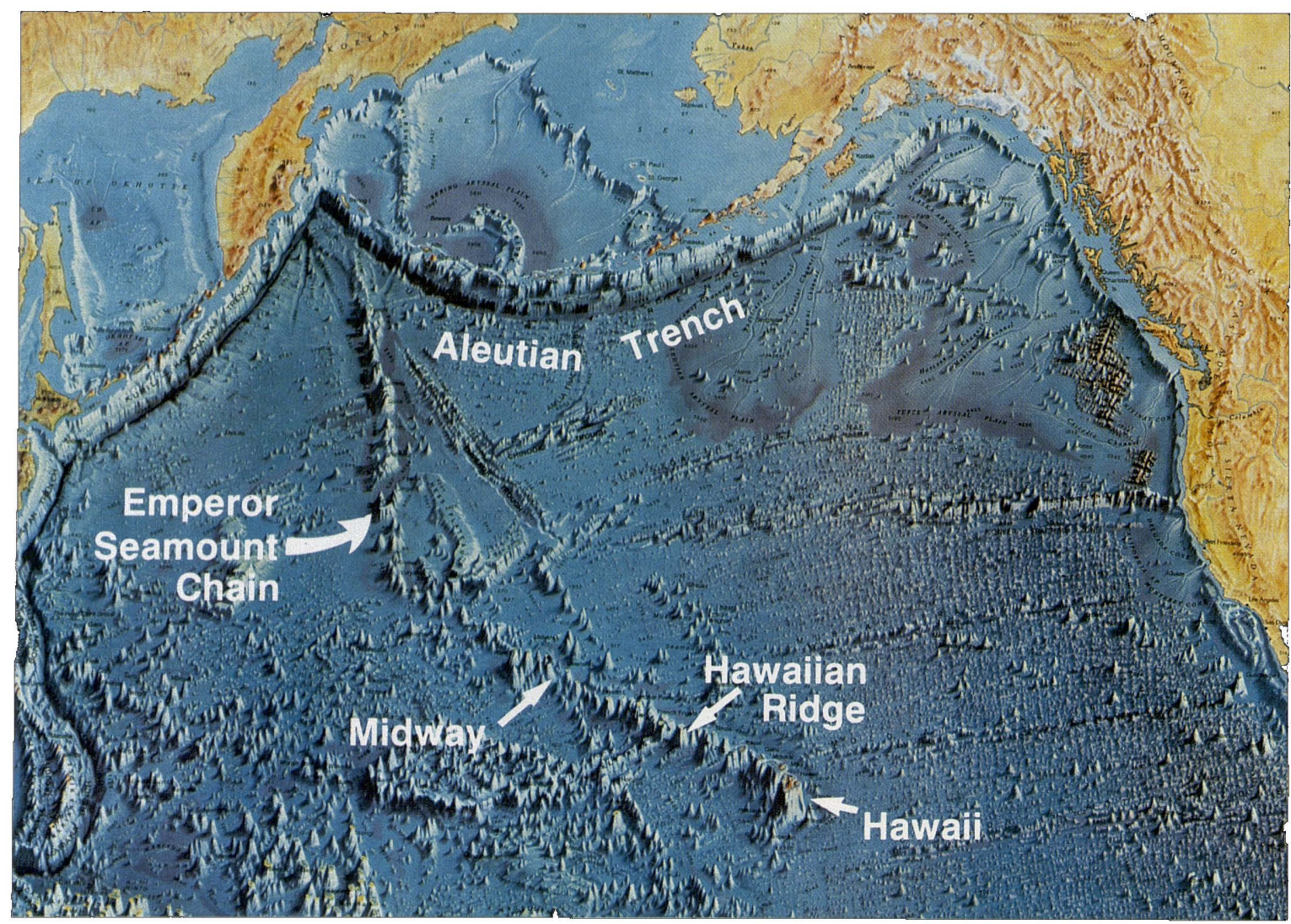

Over the past 70 million years, the combined processes of magma formation, volcano eruption and growth, and continued movement of the Pacific Plate over the stationary Hawaiian "hotspot" have left a long trail of volcanoes across the Pacific Ocean floor. The Hawaiian RidgeEmperor Seamounts chain extends some 6,000 $\mathrm{km}$ from the "Big Island" of Hawaii to the Aleutian Trench off Alaska. The Hawaiian Islands themselves are a very small part of the chain and are the youngest islands in the immense, mostly submarine mountain chain composed of more than 80 volcanoes. The length of the Hawaiian Ridge segment alone, from the Big Island northwest to Midway Island, is about equal to the distance from Washington, D.C. to Denver, Colorado $(2,600 \mathrm{~km})$. The amount of lava erupted to form the Hawaiian-Emperor chain is calculated to be at least 750,000 cubic kilometers-more than enough to blanket the entire State of California with a layer of lava roughly $1.5 \mathrm{~km}$ thick.

A sharp bend in the chain indicates that the motion of the Pacific Plate abruptly changed about 43 million years ago, as it took a more westerly turn from its earlier northerly direction. Why the Pacific Plate changed direction is not known, but the change may be related in some way to the collision of India into the Asian continent, which began about the same time.

As the Pacific Plate continues to move westnorthwest, the Island of Hawaii will be carried beyond the hotspot by plate motion, setting the stage for the formation of a new volcanic island in its place. In fact, this process may be under way. Loihi Seamount, an active submarine volcano, is forming about $35 \mathrm{~km}$ off the southern coast of Hawaii. Loihi already has risen about 3 $\mathrm{km}$ above the ocean floor to within $1 \mathrm{~km}$ of the ocean surface. According to the hotspot theory, assuming Loihi continues to grow, it will become the next island in the Hawaiian chain. In the geologic future, Loihi may eventually become fused with the Island of Hawaii, which itself is composed of five volcanoes knitted together-Kohala, Mauna Kea, Hualalai, Mauna Loa, and Kilauea. 


\section{Some unanswered questions}

The tectonic plates do not randomly drift or wander about the Earth's surface; they are driven by definite yet unseen forces. Although scientists can neither precisely describe nor fully understand the forces, most believe that the relatively shallow forces driving the lithospheric plates are coupled with forces originating much deeper in the Earth.

\section{What drives the plates?}

From seismic and other geophysical evidence and laboratory experiments, scientists generally agree with Harry Hess' theory that the plate-driving force is the slow movement of hot, softened mantle that lies below the rigid plates. This idea was first considered in the 1930s by Arthur Holmes, the English geologist who later influenced Harry Hess' thinking about seafloor spreading. Holmes speculated that the circular motion of the mantle carried the continents along in much the same way as a conveyor belt. However, at the time that Wegener proposed his theory of continental drift, most scientists still believed the Earth was a solid, motionless body. We now know better. As J. Tuzo Wilson eloquently stated in 1968, "The earth, instead of appearing as an inert statue, is a living, mobile thing." Both the Earth's surface and its interior are in motion. Below the lithospheric plates, at some depth the mantle is partially molten and can flow, albeit slowly, in response to steady forces applied for long periods of time. Just as a solid metal like steel, when exposed to heat and pressure, can be softened and take different shapes, so too can solid rock in the mantle when subjected to heat and pressure in the Earth's interior over millions of years.

The mobile rock beneath the rigid plates is believed to be moving in a circular manner somewhat like a pot of thick soup when heated to boiling. The heated soup rises to the surface, spreads and begins to cool, and then sinks back to the bottom of the pot where it is reheated and rises again. This cycle is repeated over and over to generate what scientists call a convection cell or convective flow. While convective flow can be observed easily in a pot of boiling soup, the idea of such a process stirring up the Earth's interior is much more difficult to grasp. While we know that convective motion in the Earth is much, much slower than that of boiling soup, many unanswered questions remain: How many convection cells exist? Where and how do they originate? What is their structure?

Convection cannot take place without a source of heat. Heat within the Earth comes from two main sources: radioactive decay and residual heat. Radioactive decay, a spontaneous process that is the basis of "isotopic clocks" used to date rocks, involves the loss of particles from the nucleus of an isotope (the parent) to form an isotope of a new element (the daughter). The 
Right: Conceptual drawing of assumed convection cells in the mantle (see text).

Below a depth of about $700 \mathrm{~km}$, the descending slab begins to soften and flow, losing its form. Below: Sketch showing convection cells commonly seen in boiling water or soup. This analogy, however, does not take into account the huge differences in the size and the flow rates of these cells.

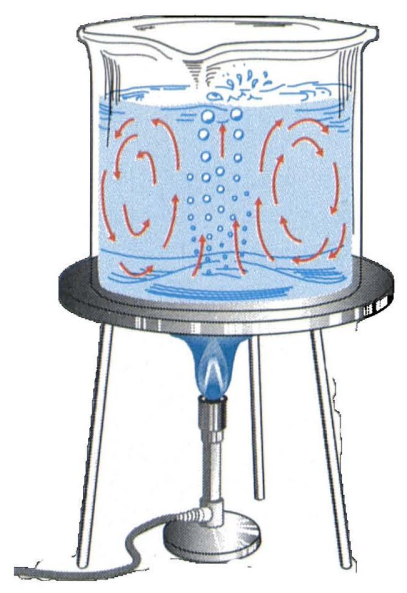

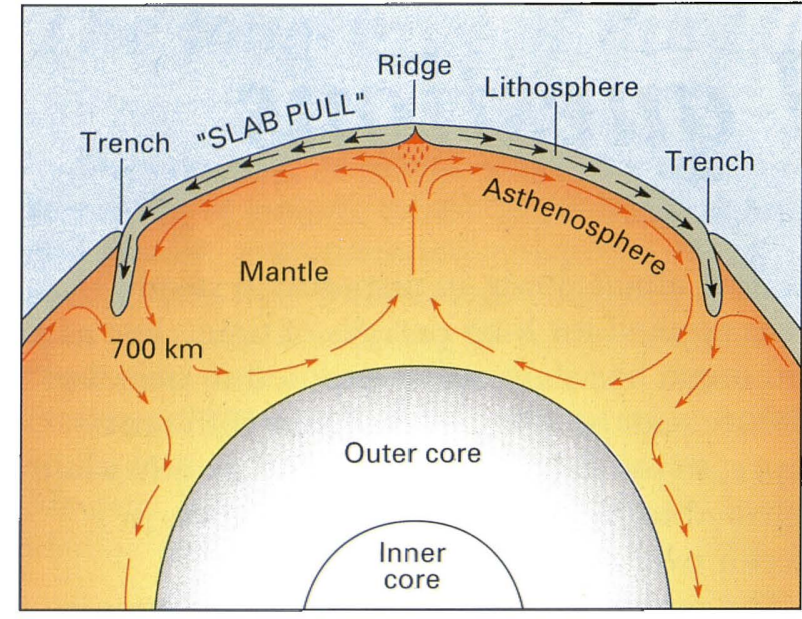

radioactive decay of naturally occurring chemical elements-most notably uranium, thorium, and potassium-releases energy in the form of heat, which slowly migrates toward the Earth's surface. Residual heat is gravitational energy left over from the formation of the Earth- 4.6 billion years ago-by the "falling together" and compression of cosmic debris. How and why the escape of interior heat becomes concentrated in certain regions to form convection cells remains a mystery.

Until the 1990s, prevailing explanations about what drives plate tectonics have emphasized mantle convection, and most earth scientists believed that seafloor spreading was the primary mechanism. Cold, denser material convects downward and hotter, lighter material rises because of gravity; this movement of material is an essential part of convection. In addition to the convective forces, some geologists argue that the intrusion of magma into the spreading ridge provides an additional force (called "ridge push") to propel and maintain plate movement. Thus, subduction processes are considered to be secondary, a logical but largely passive consequence of seafloor spreading. In recent years however, the tide has turned. Most scientists now favor the notion that forces associated with subduction are more important than seafloor spreading. Professor Seiya Uyeda (Tokai University, Japan), a world-renowned expert in plate tectonics, concluded in his keynote address at a major scientific conference on subduction processes in June 1994 that "subduction...plays a more fundamental role than seafloor spreading in shaping the earth's surface features" and "running the plate tectonic machinery." The gravity-controlled sinking of a cold, denser oceanic slab into the subduction zone (called "slab pull") — dragging the rest of the plate along with it-is now considered to be the driving force of plate tectonics.

We know that forces at work deep within the Earth's interior drive plate motion, but we may never fully understand the details. At present, none of the proposed mechanisms can explain all the facets of plate movement; because these forces are buried so deeply, no mechanism can be tested directly and proven beyond reasonable doubt. The fact that the tectonic plates have moved in the past and are still moving today is beyond dispute, but the details of why and how they move will continue to challenge scientists far into the future. 


\section{What went on before the break-up of Pangaea?}

Plate-tectonic movements since the break-up of the supercontinent Pangaea are now fairly well understood. Most scientists believe that similar processes must also have occurred earlier.

However, the pre-Pangaea history of plate tectonics is very difficult to decipher, because nearly al of the evidence has been obscured by later geologic and plate-tectonic processes, including the subduction of older oceanic crust, which carried with it the record of magnetic reversals and hotspot traces.

The clues to past plate tectonics can only be found on the present-day continents-in rocks, fossils, and structures older than about 200 million years. This is because the average age of the present-day oceanic crust is about 55 million years; the oldest parts are about $\mathbf{1 8 0}$ million years old, indicating that oceanic crust is entirely recycled every 150 million years or so. By contrast, the average age of the present-day continental crust is about 2.3 billion years, with the oldest known rocks (other than meteorites) dating back 3.96 billion years; these oldest rocks in turn contain minerals (zircons) derived from older rocks, possibly as old as 4.3 billion years.

Continents are built of blocks of crust varying in age, size, rock composition, structure, and fossil assemblage (fauna and flora). In general, most continents have stable, older interiors (called cratons), while the zones bordering the cratons typically consist of younger, structurally more complicated rocks. Some bordering zones are composed of remnants of ancient oceanic lithosphere, volcanic arcs, or mountain rangesreasonably interpreted to be products of prePangaea plate tectonics-that have attached themselves to the cratons. In other zones, however, the geological arrangement of these attached remnants seemed totally chaotic, defying reasonable explanation by geologists until recently. For example, one remnant characterized by a specific kind of rock or fossil of distinctive age may lie next to, or be surrounded by, other remnants characterized by entirely different groups of rocks or fossils, even though they may be similar in geologic age. With the platetectonics model, it is now possible to provide more rational explanations for these zones of oddly juxtaposed crustal remnants.

Scientists now recognize that continental margins are often a mosaic of lithosphere fragments that have been added as a result of plates impinging on one another during movement. The process by which the lithospheric fragments, actually pieces of other plates, became attached to the continents is called accretion. Such fragments can be either continental or oceanic in origin; if they are sufficiently large and share similar geologic characteristics, these fragments are called terranes. Terranes that seem out of place geologically, called exotic or suspect terranes, are composed of pieces of plates that have broken off and then drifted great distances before attaching (accreting) to some other terrane or continental landmass. Western North America is an example of a complex geologic region that is best interpreted as a patchwork of several far-travelled terranes that accreted together after the break-up of Pangaea. 


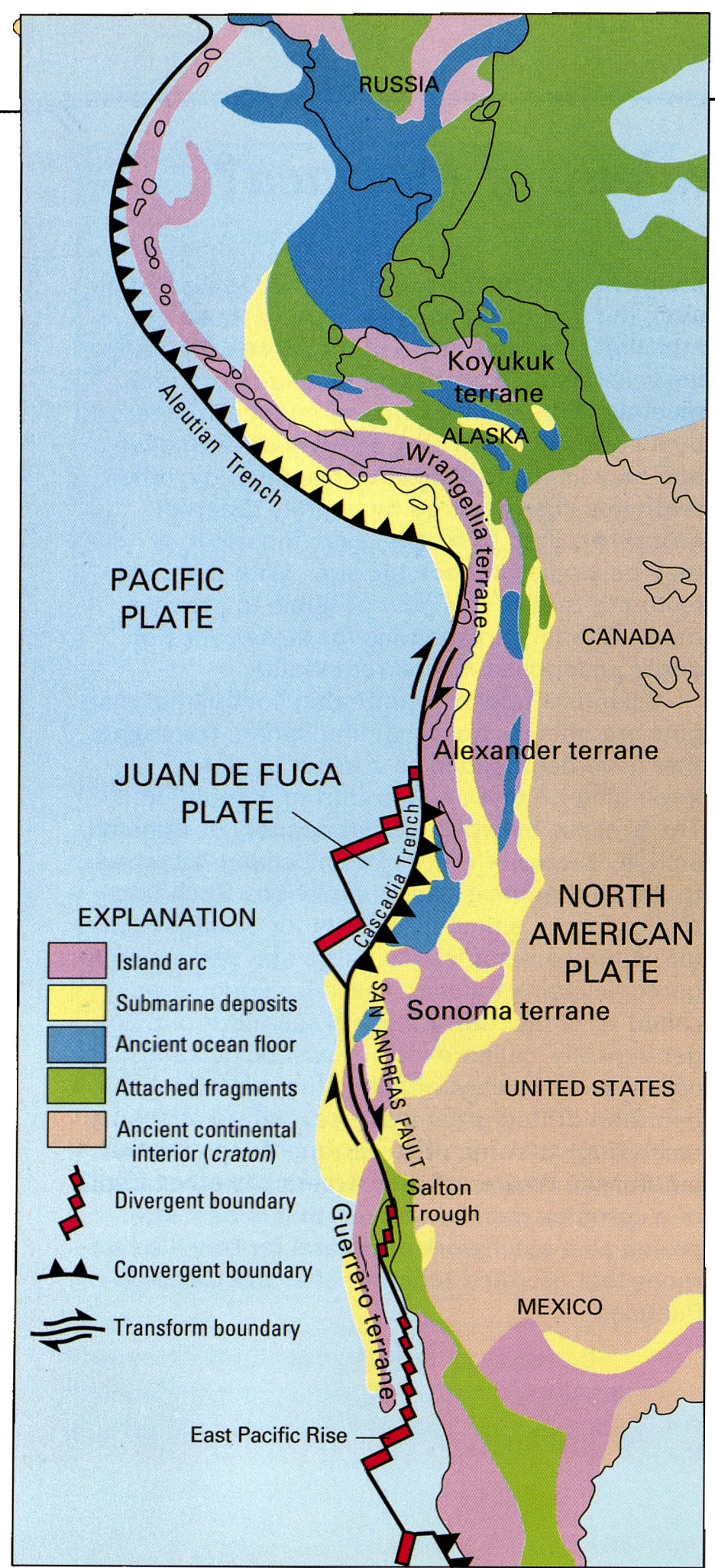

In recent years, the study of terranes (called "terrane tectonics" or "terrane analysis") has become a specialized field within plate-tectonics research. Such studies suggest that plate tectonics has been operating in some fashion since very early in the Earth's history, perhaps as early as 3.8 billion years ago. An intriguing, but sketchy, picture seems to be emerging: There have been several cycles of supercontinent formation, each followed by break-up and subsequent drifting of the fragmented parts. Pangaea itself may have been formed by the aggregation of separate continents that drifted back together after the breakup of an older supercontinent that existed about 550 million years ago.

Dr. David G. Howell (USGS, Menlo Park,

California), a specialist in terrane analysis, likens such movement of continents-as the plates join and separate again and again throughout the Earth's history-to the motion of "lithospheric bumper cars." There are several important differences, however: this imaginative comparison ignores the fact that electric bumper cars at amusement parks can each move independently, rather than being parts of an integrated system. And their average speeds are at least 500 million times faster than those of tectonic plates!

Western North America showing some important platetectonics features and the mosaic of far-travelled exotic terranes plastered against the long-lived, stable interior of the continent (see text). (Modified from illustration provided by Oceanus Magazine; original figure by Jack Cook, Woods Hole Oceanographic Institution.) 


\section{Extraterrestrial plate tectonics?}

The Earth may be unique in our solar system because it appears to be the only planet that is still volcanically and tectonically active; our planet therefore remains very much alive, while the others apparently have long ceased activity. Volcanic activity requires a source of internal heat, and it is the escape of this heat that fuels plate tectonics. While volcanism played a major role in the early history of Mars, the Moon, and probably Mercury, their small sizes relative to Earth resulted in the loss of internal heat at a much faster rate. They have been inactive globes for the last billion years or so.

Venus may still be active, though the evidence is questionable. In 1979, the Pioneer-Venus spacecraft measured a high amount of sulfur in the upper atmosphere of the planet; the sulfur amount then decreased over the next few years. This observation suggested that the high sulfur concentration measured in 1979 may have resulted from a catastrophic event, perhaps a volcanic eruption. Beginning in 1990, radar images made by the Magellan spacecraft revealed dramatic volcanic features and long, deep valleys similar in size and shape to oceanic trenches on Earth.

The Voyager spacecraft discovered several volcanic plumes rising many hundreds of kilometers above the surface of Io, one of the moons of Jupiter and about the size of our Moon. Scientists speculate that large pools of liquid sulfur may exist on Io, possibly heated by tidal forces resulting from gravitational attraction between Io and Jupiter. The thermal energy generated by such tidal forces may be enough to produce

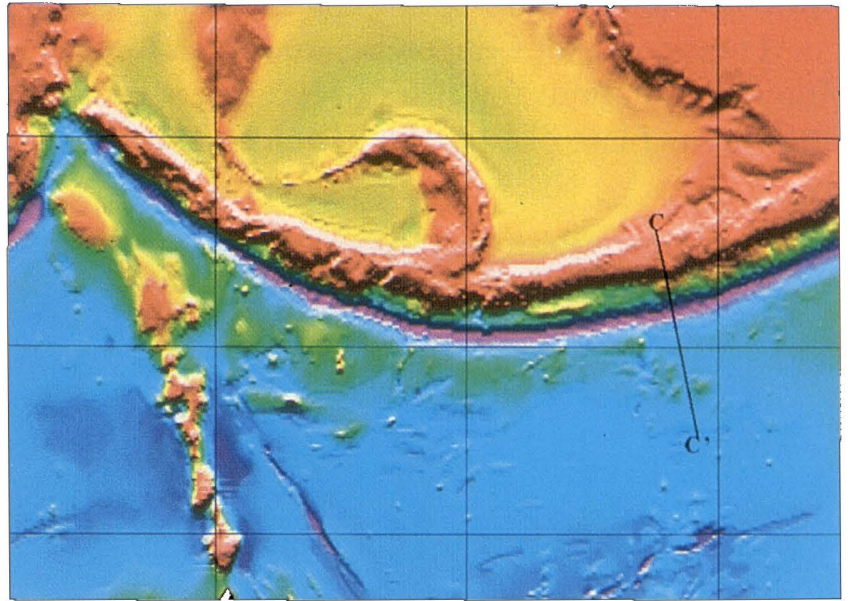

Top: A computer-generated image of the Aleutian Trench (in violet); "warm" colors (yellow to red) indicate topographic highs, and "cool" colors (green to blue) represent lower elevations. Bottom: The topography of Artemis Corona, $a$ trench-like feature on Venus, shown at the same vertical and horizontal scale as the Aleutian Trench. (Imagery courtesy of David T. Sandwell, Scripps Institution of Oceanography.)

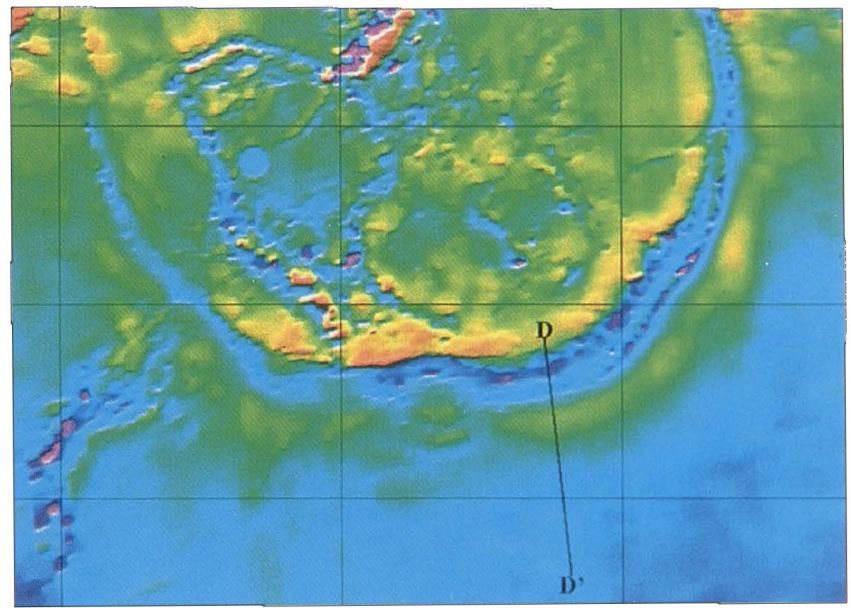


convection in Io's interior, although no one has clearly recognized any surface feature that may have formed from such convection.

The surface of Ganymede, another moon of Jupiter and about the size of Mercury, is broken into many plate-like blocks, with long narrow

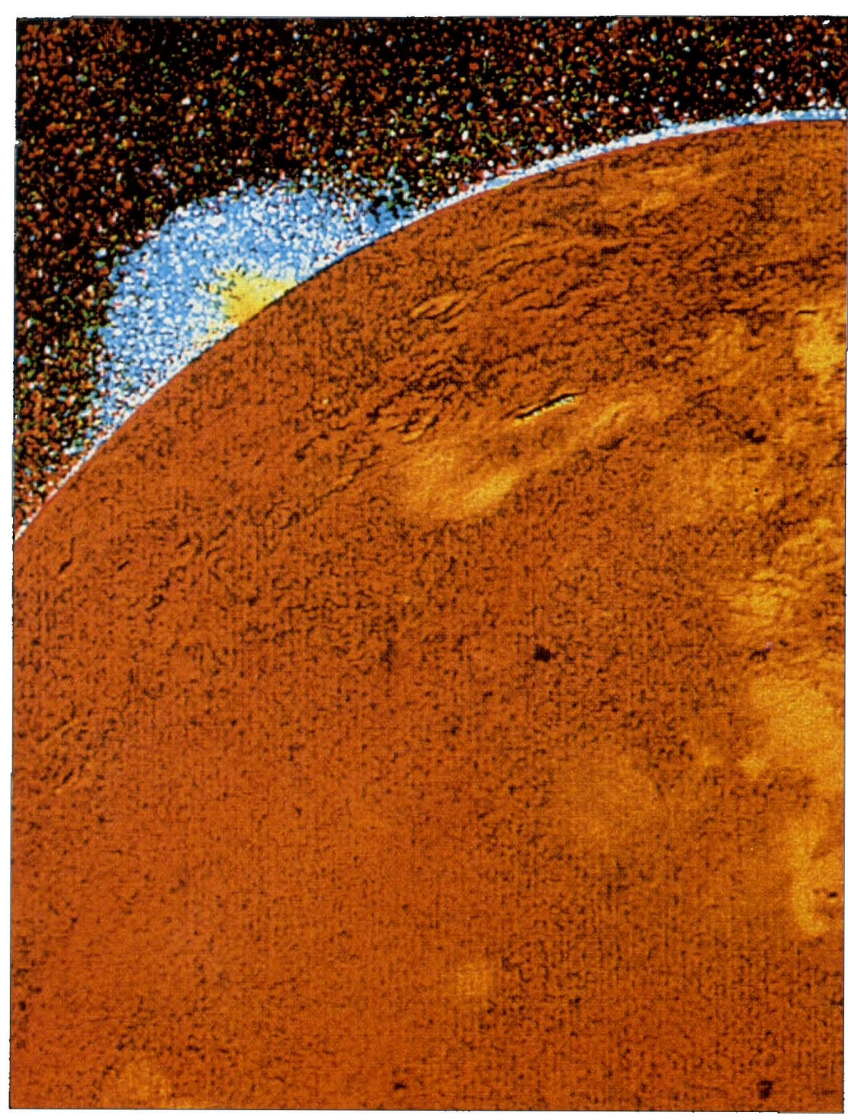

A volcanic plume of sulfur dioxide $\left(\mathrm{SO}_{2}\right)$ gas rising about $150 \mathrm{~km}$ above the surface of Io. This computerenhanced image was captured "live" by the Voyager 2 spacecraft on 4 March 1979. (Imagery courtesy of NASA.) depressions between some of them. Whether these surface features represent ancient "fossil" plate tectonics, or are actively forming, remains to be answered. Crucial to determining whether plate tectonics is occurring on Ganymede is the search for evidence of a deep ocean beneath its icy surface. Such a body of water, if it exists, might contribute to internal convection.

The rate of heat loss is critical to a planet's tectonic activity. Size is one determining factor: larger bodies lose heat more slowly and will therefore remain active longer. Another factor is composition, which influences the ability of a body to convect. For example, a liquid interior, such as may exist within Ganymede, is more likely to convect and drive plate tectonics than the "stony" interiors of the Moon, Mercury, Venus, and Mars. The amount of radioactive elements present in the planet's composition also affects the likelihood of internal convection, because the decay of these elements produces heat. Apparently, the interiors of the Moon, Mercury, and Mars are either too rigid or have lost too much of their internal heat to convect and drive plate tectonics.

Eventually the Earth, too, will lose so much heat that its interior will stop convecting. Earthquake and volcanic activity will then cease. No new mountains will form, and the geologic cycle of mountain building, erosion, sedimentation, and soil formation will be disrupted and also will cease. Exactly how a cooled-down Earth will change surface conditions-and whether our planet will still be habitable-nobody knows. Fortunately, these changes will not happen for many billions of years! 


\section{Plate tectonics and people}

Over geologic time, plate movements in concert with other geologic processes, such as glacial and stream erosion, have created some of nature's most magnificent scenery. The Himalayas, the Swiss Alps, and the Andes are some spectacular examples. Yet violent earthquakes related to plate tectonics have caused terrible catastrophes-such as the magnitude-7.7 earthquake that struck the Chinese province of Haicheng in 1976 and killed as many as 800,000 people.

\section{Natural hazards}

Most earthquakes and volcanic eruptions do not strike randomly but occur in specific areas, such as along plate boundaries. One such area is the circum-Pacific Ring of Fire, where the Pacific Plate meets many surrounding plates. The Ring of Fire is the most seismically and volcanically active zone in the world.

\section{Earthquakes}

Because many major population centers are located near active fault zones, such as the San Andreas, millions of people have suffered personal and economic losses as a result of destructive earthquakes, and even more have experienced earthquake motions. Not surprisingly, some people believe that, when the "Big One" hits, California will suddenly "break off" and "fall into the Pacific," or that the Earth will "open up" along the fault and "swallow" people, cars, and houses. Such beliefs have no scientific basis whatsoever. Although ground slippage commonly takes place in a large earthquake, the Earth will not open up. Nor will California fall into the sea, because the fault zone only extends about $15 \mathrm{~km}$ deep, which is only about a quarter of the thickness of the continental crust. Furthermore, California is composed of continental crust, whose relatively low density keeps it riding high, like an iceberg above the ocean.

Like all transform plate boundaries, the San Andreas is a strike-slip fault, movement along which is dominantly horizontal. Specifically, the San Andreas fault zone separates the Pacific and North American Plates, which are slowly grinding past each other in a roughly north-south direction. The Pacific Plate (western side of the fault) is moving horizontally in a northerly direction relative to the North American Plate (eastern side of the fault). Evidence of the sideways shift of these two landmasses can be found all along the fault zone, as seen from the differences in topography, geologic structures, and, sometimes, vegetation of the terrain from one side of the fault to the other. For example, the San Andreas runs directly along Crystal Springs Reservoir on the San Francisco Peninsula.
Aerial view, looking north toward San Francisco, of Crystal Springs Reservoir, which follows the San Andreas fault zone. (Photograph by Robert E. Wallace, USGS.)

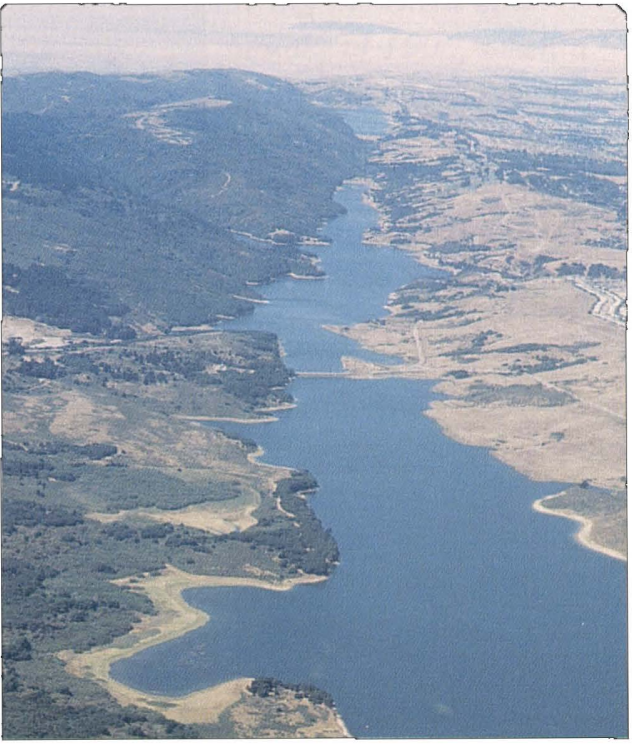




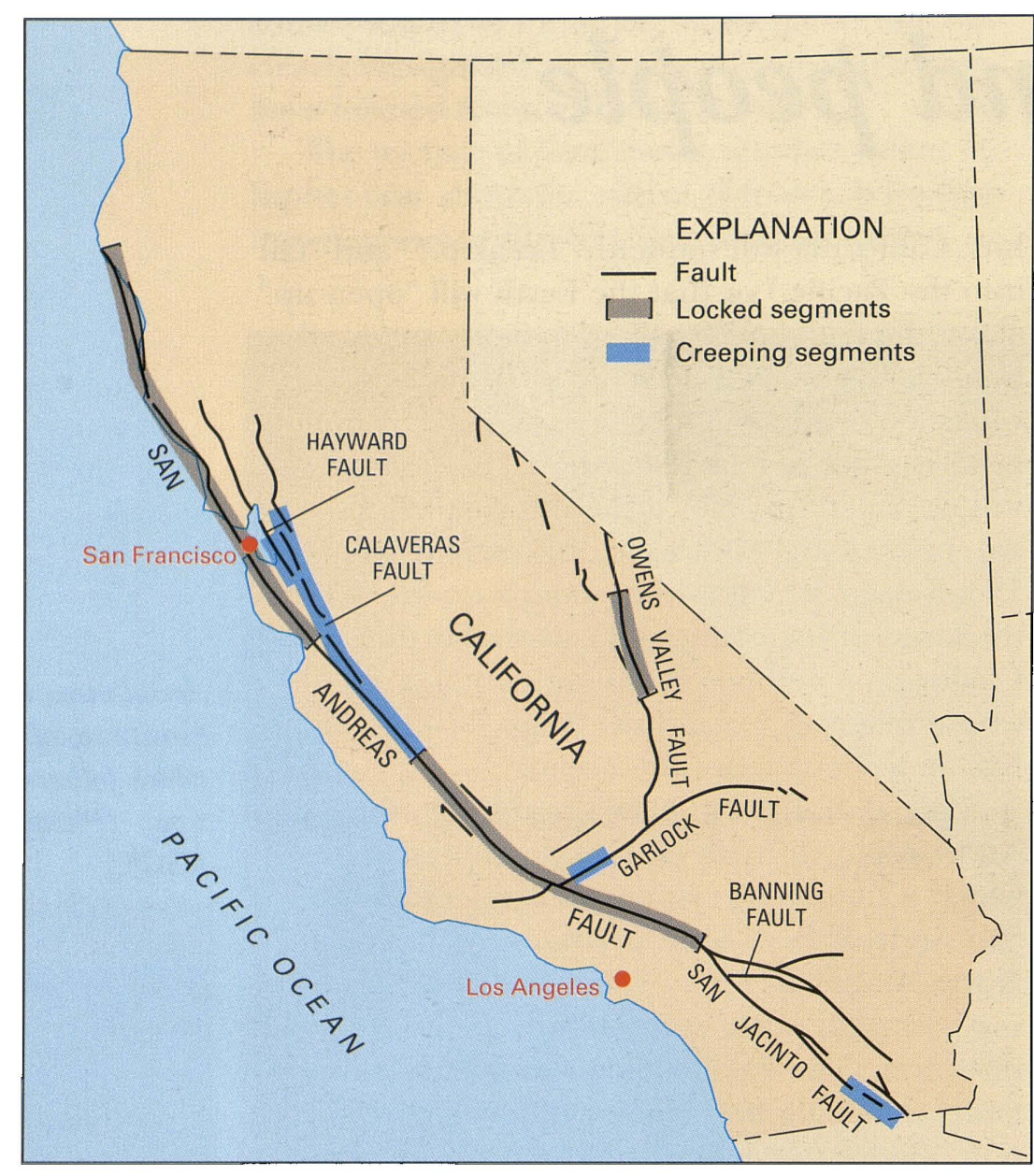

Map of the San Andreas and a few of the other faults in California, segments of which display different behavior: locked or creeping (see text). (Simplified from USGS Professional Paper 1515.)
Topographically, this reservoir fills a long, straight, narrow valley that was formed by erosion of the easily erodible rocks mashed within the fault zone.

Movement along the San Andreas can occur either in sudden jolts or in a slow, steady motion called creep. Fault segments that are actively creeping experience many small to moderate earthquakes that cause little or no damage.

These creeping segments are separated by segments of infrequent earthquake activity (called seismic gaps), areas that are stuck or locked in place within the fault zone. Locked segments of the fault store a tremendous amount of energy that can build up for decades, or even centuries, before being unleashed in devastating earthquakes. For example, the Great San Francisco Earthquake (8.3-magnitude) in 1906 ruptured along a previously locked $430 \mathrm{~km}$-long segment of the San Andreas, extending from Cape Mendocino south to San Juan Bautista.

The stresses that accumulate along a locked segment of the fault and the sudden release can be visualized by bending a stick until it breaks. The stick will bend fairly easily, up to a certain point, until the stress becomes too great and it snaps. The vibrations felt when the stick breaks represent the sudden release of the stored-up energy. Similarly, the seismic vibrations produced when the ground suddenly ruptures radiate out through the Earth's interior from the rupture point, called the earthquake focus. The geographic point directly above the focus is called the earthquake epicenter. In a major earthquake, the energy released can cause damage hundreds to thousands of kilometers away from the epicenter. 


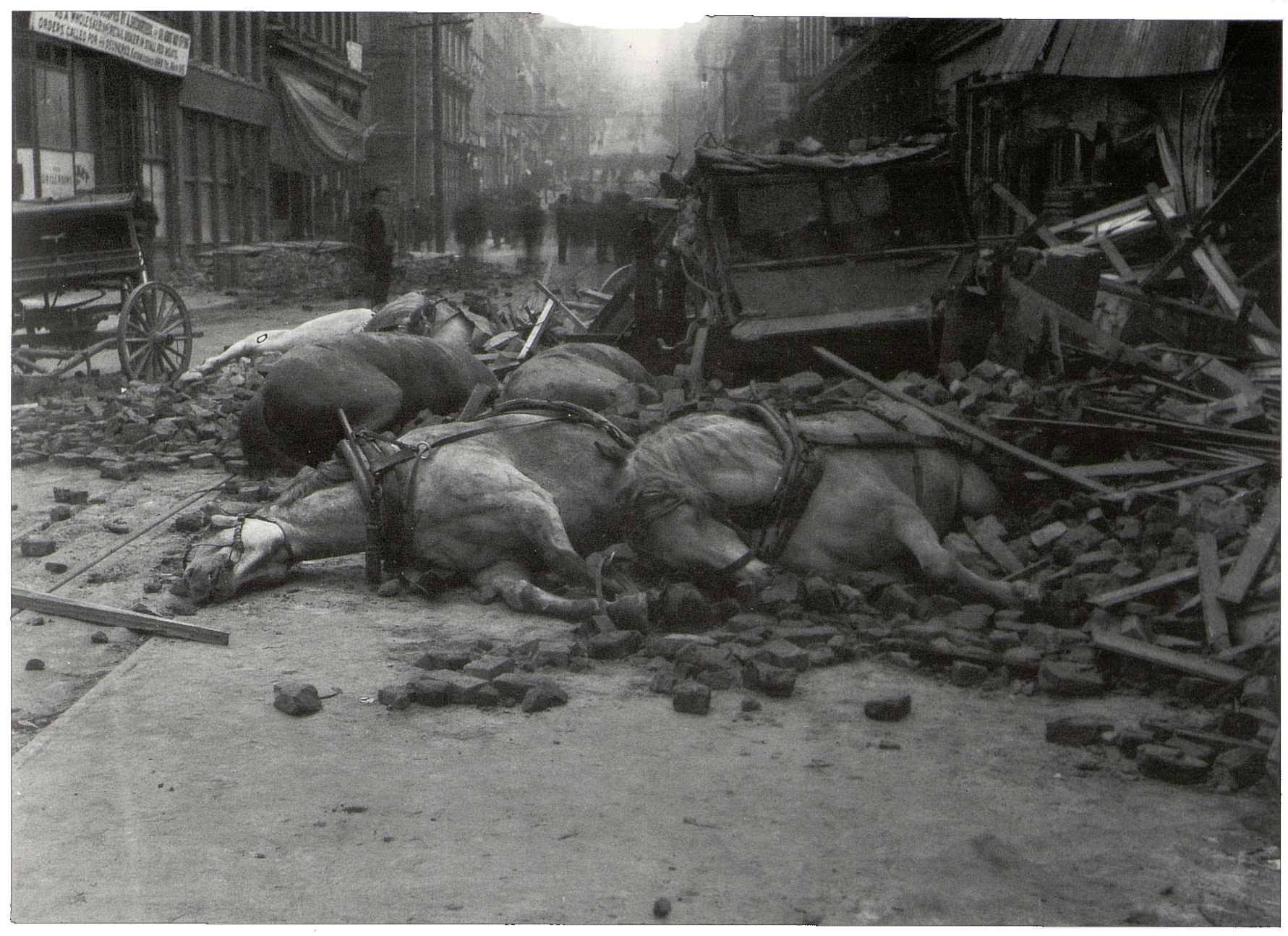

A dramatic photograph of horses killed by falling debris during the Great San

Francisco Earthquake of 1906, when a locked segment of the San Andreas fault suddenly lurched, causing a devastating magnitude-8.3 earthquake. (Photograph by Edith Irvine, courtesy of Brigham Young University Library, Provo, Utah.)

The magnitude-7.1 Loma Prieta earthquake of October 1989 occurred along a segment of the San Andreas Fault which had been locked since the great 1906 San Francisco earthquake. Even though the earthquake's focus (approximately $80 \mathrm{~km}$ south of San Francisco) was centered in a sparsely populated part of the Santa Cruz Mountains, the earthquake still caused 62 deaths and nearly $\$ 6$ billion in damage. Following the Loma Prieta earthquake, the fault remains locked from Pt. Arena, where it enters California from the ocean, south through San Francisco and the peninsula west of San Francisco Bay, thus posing the threat of a potential destructive earthquake occurring in a much more densely populated area. 
The lesser known Hayward Fault running east of San Francisco Bay, however, may pose a potential threat as great as, or perhaps even greater than, the San Andreas. From the televised scenes of the damage caused by the 7.2-magnitude earthquake that struck Kobe, Japan, on 16 January 1995, Bay Area residents saw the possible devastation that could occur if a comparable size earthquake were to strike along the Hayward Fault. This is because the Hayward and the Nojima fault that produced the Kobe earthquake are quite similar in several ways. Not only are they of the same type (strike-slip), they are also about the same length $(60-80 \mathrm{~km})$ and both cut through densely populated urban areas, with many buildings, freeways, and other structures built on unstable bay landfill.

On 17 January 1994, one of the costliest natural disasters in United States history struck southern California. A magnitude-6.6 earthquake hit near Northridge, a city located in the populous San Fernando Valley just north of Los Angeles, California. This disaster, which killed more than 60 people, caused an estimated $\$ 30$ billion in damage, nearly five times that resulting from the Loma Prieta earthquake. The Northridge earthquake did not directly involve movement along one of the strands of the San Andreas Fault system. It instead occurred along the Santa Monica Mountains Thrust Fault, one of several smaller, concealed faults (called blind thrust faults) south of the San Andreas Fault zone where it bends to the east, roughly paralleling the Transverse Mountain Range. With a thrust fault, whose plane is inclined to the Earth's surface, one side moves upward over the other.
Movement along a blind thrust fault does not break the ground surface, thus making it difficult or impossible to map these hidden but potentially dangerous faults. Although scientists have found measurable uplift at several places in the Transverse Range, they have not found any conclusive evidence of ground rupture from the 1994 Northridge earthquake. Similar earthquakes struck the region in 1971 and 1987; the San Fernando earthquake (1971) caused substantial damage, including the collapse of a hospital and several freeway overpasses.

Not all fault movement is as violent and destructive. Near the city of Hollister in central California, the Calaveras Fault bends toward the San Andreas. Here, the Calaveras fault creeps at a slow, steady pace, posing little danger. Much of the Calaveras fault creeps at an average rate of 5 to $6 \mathrm{~mm} / \mathrm{yr}$. On average, Hollister has some 20,000 earthquakes a year, most of which are too small to be felt by residents. It is rare for an area undergoing creep to experience an earthquake with a magnitude greater than 6.0 because stress is continually being relieved and, therefore, does not accumulate. Fault-creep movement generally is non-threatening, resulting only in gradual offset of roads, fences, sidewalks, pipelines, and other structures that cross the fault. However, the persistence of fault creep does pose a costly nuisance in terms of maintenance and repair.

Mid-plate earthquakes-those occurring in the interiors of plates-are much less frequent than those along plate boundaries and more difficult to explain. Earthquakes along the Atlantic seaboard of the United States are most likely related in some way to the westward movement 
of the North American Plate away from the MidAtlantic Ridge, a continuing process begun with the break-up of Pangaea. However, the causes of these infrequent earthquakes are still not understood.

East Coast earthquakes, such as the one that struck Charleston, South Carolina, in 1886 are felt over a much larger area than earthquakes occurring on the West Coast, because the eastern half of the country is mainly composed of older rock that has not been fractured and cracked by frequent earthquake activity in the recent geologic past. Rock that is highly fractured and crushed absorbs more seismic energy than rock that is less fractured. The Charleston earthquake, with an estimated magnitude of about 7.0, was felt as far away as Chicago, more than $1,300 \mathrm{~km}$ to the northwest, whereas the 7.1-magnitude Loma Prieta earthquakes was felt no farther than Los Angeles, about $500 \mathrm{~km}$ south. The most widely felt earthquakes ever to strike the United States were centered near the town of New Madrid, Missouri, in 1811 and 1812. Three earthquakes, felt as far away as Washington D.C., were each estimated to be above 8.0 in magnitude. Most of us do not associate earthquakes with New York City, but beneath Manhattan is a network of intersecting faults, a few of which are capable of causing earthquakes. The most recent carthquake to strike New York City occurred in 1985 and measured 4.0 in magnitude, and a pair of earthquakes (magnitude 4.0 and 4.5) shook Reading, Pennsylvania, in January 1994 causing minor damage.

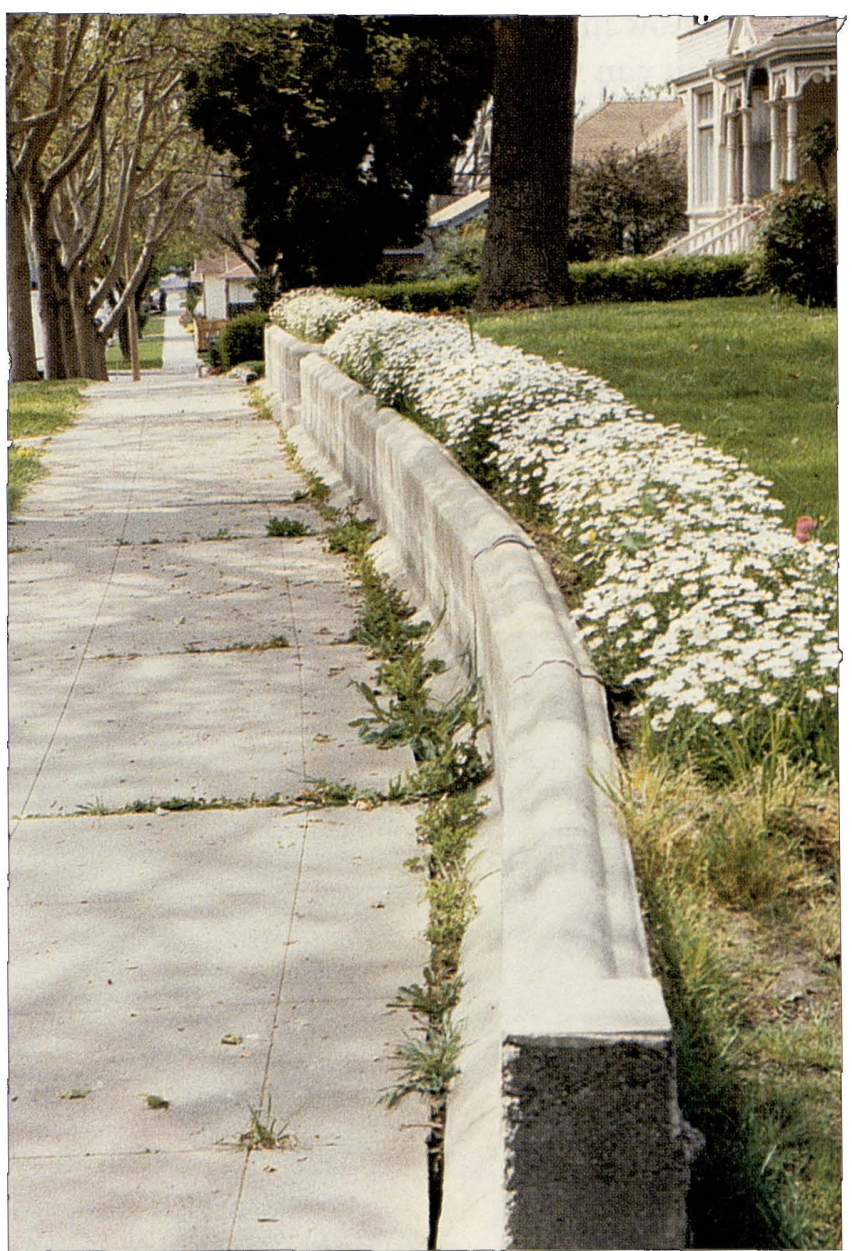

Above: Creeping along the Calaveras fault has bent the retaining wall and offset the sidewalk along 5 th Street in Hollister, California (about $75 \mathrm{~km}$ southsoutheast of San Jose). Right: Close-up of the offset of the curb. (Photographs by W. Jacquelyne Kious.)

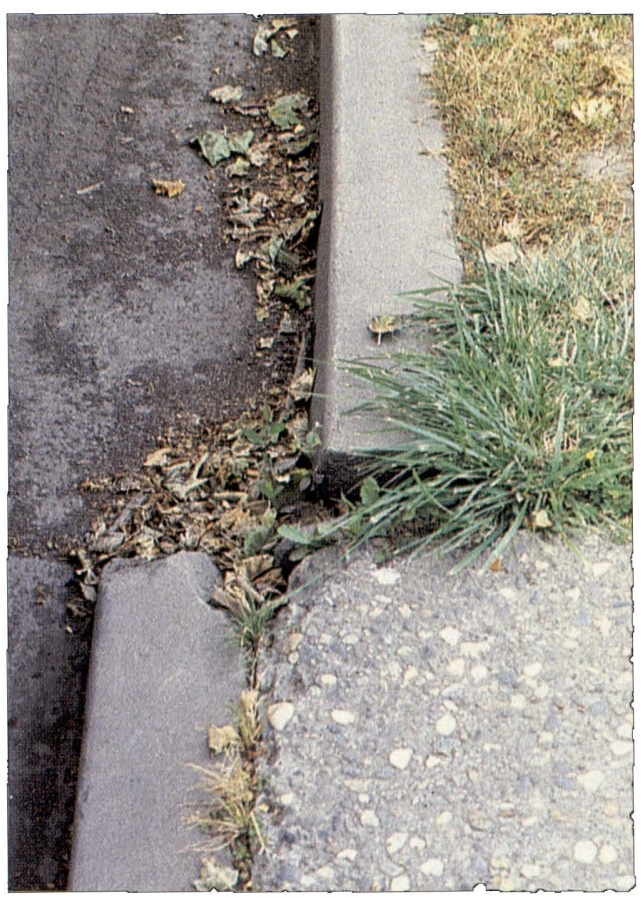


We know in general how most earthquakes occur, but can we predict when they will strike? This question has challenged and frustrated scientists studying likely precursors to moderate and large earthquakes. Since the early 1980s, geologists and seismologists have been intensively studying a segment of the San Andreas near the small town of Parkfield, located about halfway between San Francisco and Los Angeles, to try to detect the physical and chemical changes that might take place-both above and below ground-before an earthquake strikes. The
USGS and State and local agencies have blanketed Parkfield and the surrounding countryside with seismographs, creep meters, stress meters, and other ground-motion measurement devices.

The Parkfield segment has experienced earthquakes measuring magnitude 6.0 about every 22 years on average since 1881. During the most recent two earthquakes $(1934,1966)$, the same section of the fault slipped and the amount of slippage was about the same. In 1983, this evidence, in addition to the earlier recorded history of earthquake activity, led the USGS to predict
Time-exposure photograph of the electronic-laser, ground-motion measurement system in operation at Parkfield, California, to track movement along the San Andreas fault (see text). (Photograph by John Nakata, USGS.)

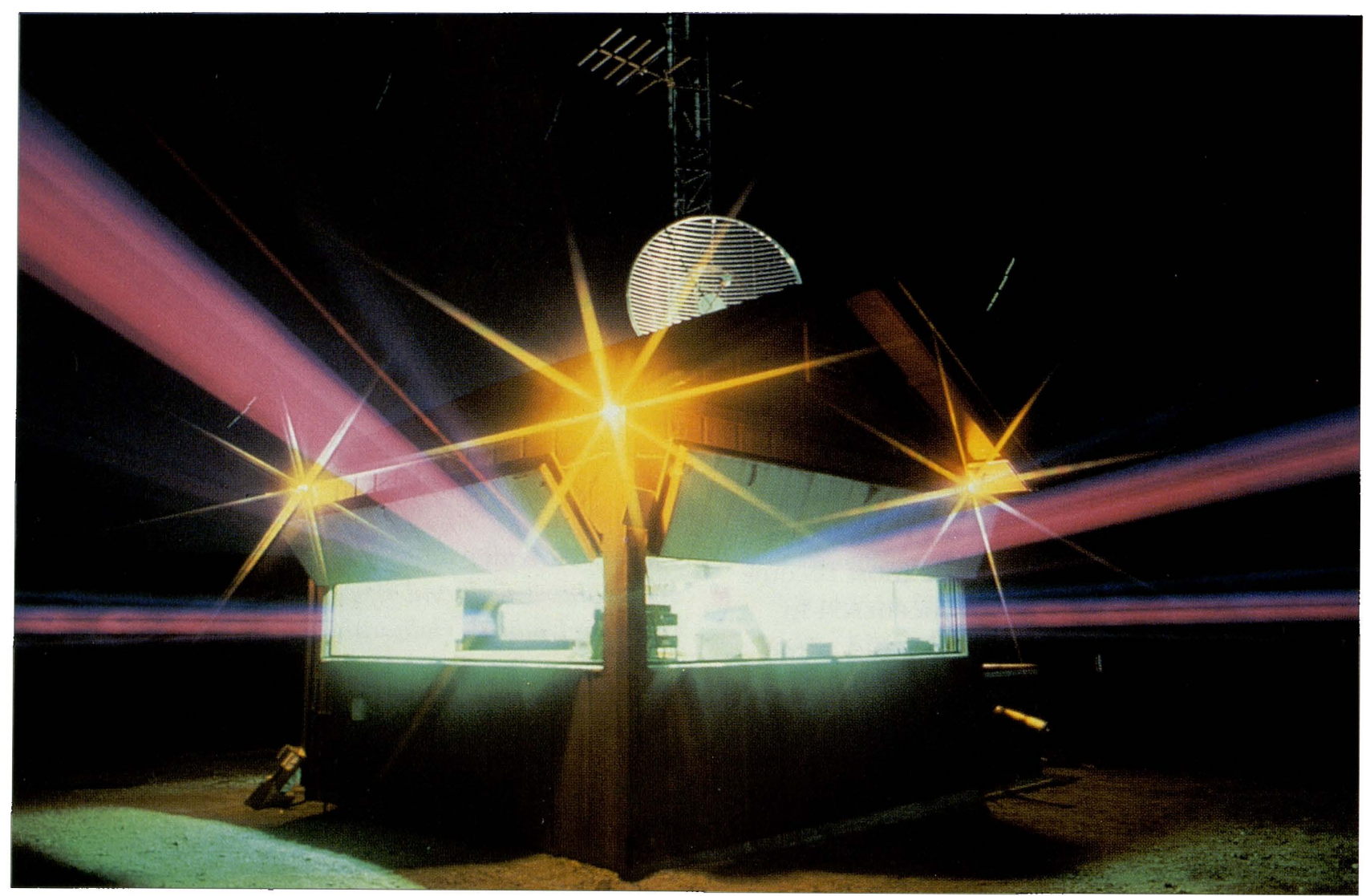


that there was a 95 percent chance of a 6.0 earthquake striking Parkfield before 1993. But the anticipated earthquake of magnitude 6.0 or greater did not materialize. The Parkfield experiment is continuing, and its primary goals remain unchanged: to issue a short-term prediction; to monitor and analyze geophysical and geochemical effects before, during, and after the anticipated earthquake; and to develop effective communications between scientists, emergencymanagement officials, and the public in responding to earthquake hazards.

While scientists are studying and identifying possible precursors leading to the next Parkfield earthquake, they also are looking at these same precursors to see if they may be occurring along other segments of the fault. Studies of past earthquakes, together with data and experience gained from the Parkfield experiment, have been used by geoscientists to estimate the probabilities of major earthquakes occurring along the entire San Andreas Fault system. In 1988, the USGS identified six segments of the San Andreas as most likely to be hit by a magnitude 6.5 or larger earthquake within the next thirty years (1988-2018). The Loma Prieta earthquake in 1989 occurred along one of these six segments. The Parkfield experiment and other studies carried out by the USGS as part of the National Earthquake Hazards Reduction Program have led to an increased official and public awareness of the inevitability of future earthquake activity in California. Consequently, residents and State and local officials have become more diligent in planning and preparing for the next big earthquake.

\section{Volcanic eruptions}

As with earthquakes, volcanic activity is linked to plate-tectonic processes. Most of the world's active above-sea volcanoes are located near convergent plate boundaries where subduction is occurring, particularly around the Pacific basin. However, much more volcanism-producing about three quarters of all lava erupted on Earth-takes place unseen beneath the ocean, mostly along the oceanic spreading centers, such as the Mid-Atlantic Ridge and the East Pacific Rise.

Subduction-zone volcanoes like Mount St. Helens (in Washington State) and Mount Pinatubo (Luzon, Philippines), are called composite cones and typically erupt with explosive force, because the magma is too stiff to allow easy escape of volcanic gases. As a consequence, tremendous internal pressures mount as the trapped gases expand during ascent, before the pent-up pressure is suddenly released in a violent eruption. Such an explosive process can be compared to putting your thumb over an opened bottle of a carbonated drink, shaking it vigorously, and then quickly removing the thumb. The shaking action separates the gases from the liquid to form bubbles, increasing the internal pressure. Quick release of the thumb allows the gases and liquid to gush out with explosive speed and force. 
temperatures recorded worldwide and the brilliant sunsets and sunrises have been attributed to this eruption that sent fine ash and gases high into the stratosphere, forming a large volcanic cloud that drifted around the world. The sulfur dioxide $\left(\mathrm{SO}_{2}\right)$ in this cloud-about 22 million tons-combined with water to form droplets of sulfuric acid, blocking some of the sunlight from reaching the Earth and thereby cooling temperatures in some regions by as much as $0.5^{\circ} \mathrm{C}$. An eruption the size of Mount Pinatubo could affect the weather for a few years. A similar phenomenon occurred in April of 1815 with the cataclysmic eruption of Tambora Volcano in Indonesia, the most powerful eruption in recorded history. Tambora's volcanic cloud lowered global temperatures by as much as $3{ }^{\circ} \mathrm{C}$. Even a year after the eruption, most of the northern hemisphere experienced sharply cooler temperatures during the summer months. In part of Europe and in North America, 1816 was known as "the year without a summer."

Apart from possibly affecting climate, volcanic clouds from explosive eruptions also pose a hazard to aviation safety. During the past two decades, more than 60 airplanes, mostly commercial jetliners, have been damaged by in-flight encounters with volcanic ash. Some of these encounters have resulted in the power loss of all engines, necessitating emergency landings. Luckily, to date no crashes have happened because of jet aircraft flying into volcanic ash.

Since the year A.D. 1600 , nearly 300,000 people have been killed by volcanic eruptions. Most deaths were caused by pyroclastic flows and mudflows, deadly hazards which often accompany explosive eruptions of subduction-zone volca-

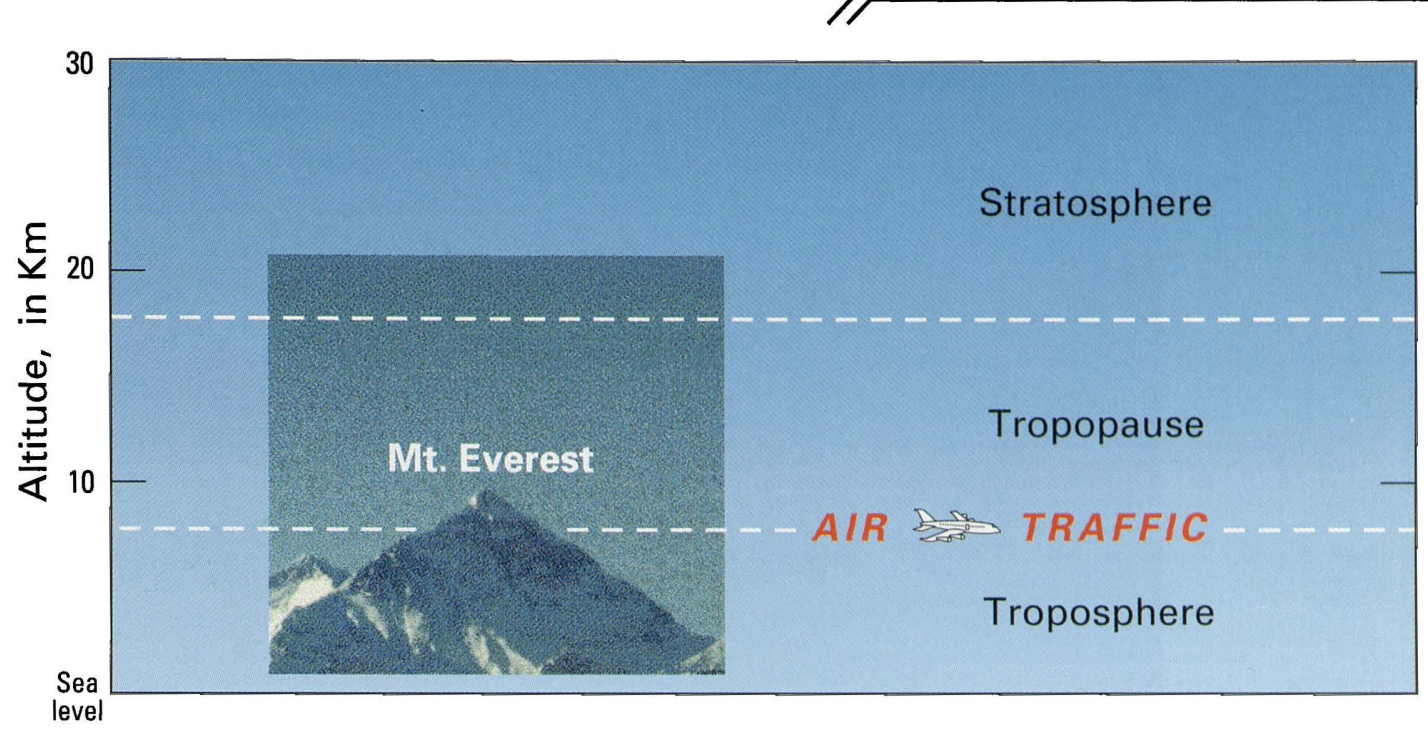

Diagram showing the lower two layers of the atmosphere: the troposphere and the stratosphere. The tropopause-the boundary between these two layers-varies in altitude from 8 to $18 \mathrm{~km}$ (dashed white lines), depending on Earth latitude and season of the year. The summit of Mt. Everest (inset photograph) and the altitudes commonly flown by commercial jetliners are given for reference. (Photograph by David G. Howell, USGS.)

noes. Pyroclastic flows, also called nuées ardentes ("glowing clouds" in French), are fast-moving, avalanche-like, ground-hugging incandescent mixtures of hot volcanic debris, ash, and gases that can travel at speeds in excess of $150 \mathrm{~km}$ per hour. Approximately 30,000 people were killed by pyroclastic flows during the 1902 eruption of Mont Pelée on the Island of Martinique in the Caribbean. In March-April 1982, three explosive eruptions of El Chichón Volcano in the State of Chiapas, southeastern Mexico, caused the worst volcanic disaster in that country's history. Villages within $8 \mathrm{~km}$ of the volcano were destroyed by pyroclastic flows, killing more than 2,000 people. 
Mudflows (also called debris flows or lahars, an Indonesian term for volcanic mudflows) are mixtures of volcanic debris and water. The water usually comes from two sources: rainfall or the melting of snow and ice by hot volcanic debris. Depending on the proportion of water to volcanic material, mudflows can range from soupy floods to thick flows that have the consistency of wet cement. As mudflows sweep down the steep sides of composite volcanoes, they have the strength and speed to flatten or bury everything in their paths. Hot ash and pyroclastic flows from the eruption of the Nevado del Ruiz
Volcano in Colombia, South America, melted snow and ice atop the 5,390-m-high Andean peak; the ensuing mudflows buried the city of Armero, killing 25,000 people.

Eruptions of Hawaiian and most other midplate volcanoes differ greatly from those of composite cones. Mauna Loa and Kilauea, on the island of Hawaii, are known as shield volcanoes, because they resemble the wide, rounded shape of an ancient warrior's shield. Shield volcanoes tend to erupt non-explosively, mainly pouring out huge volumes of fluid lava. Hawaiian-type eruptions are rarely life threatening because the
Aerial view of the city of Armero, Colombia, devastated by mudflows triggered by the eruption of Nevado del Ruiz in November 1985. The mudflows destroyed everything in their paths and killed about 25,000 people. (Photograph by Darrell G. Herd, USGS.)

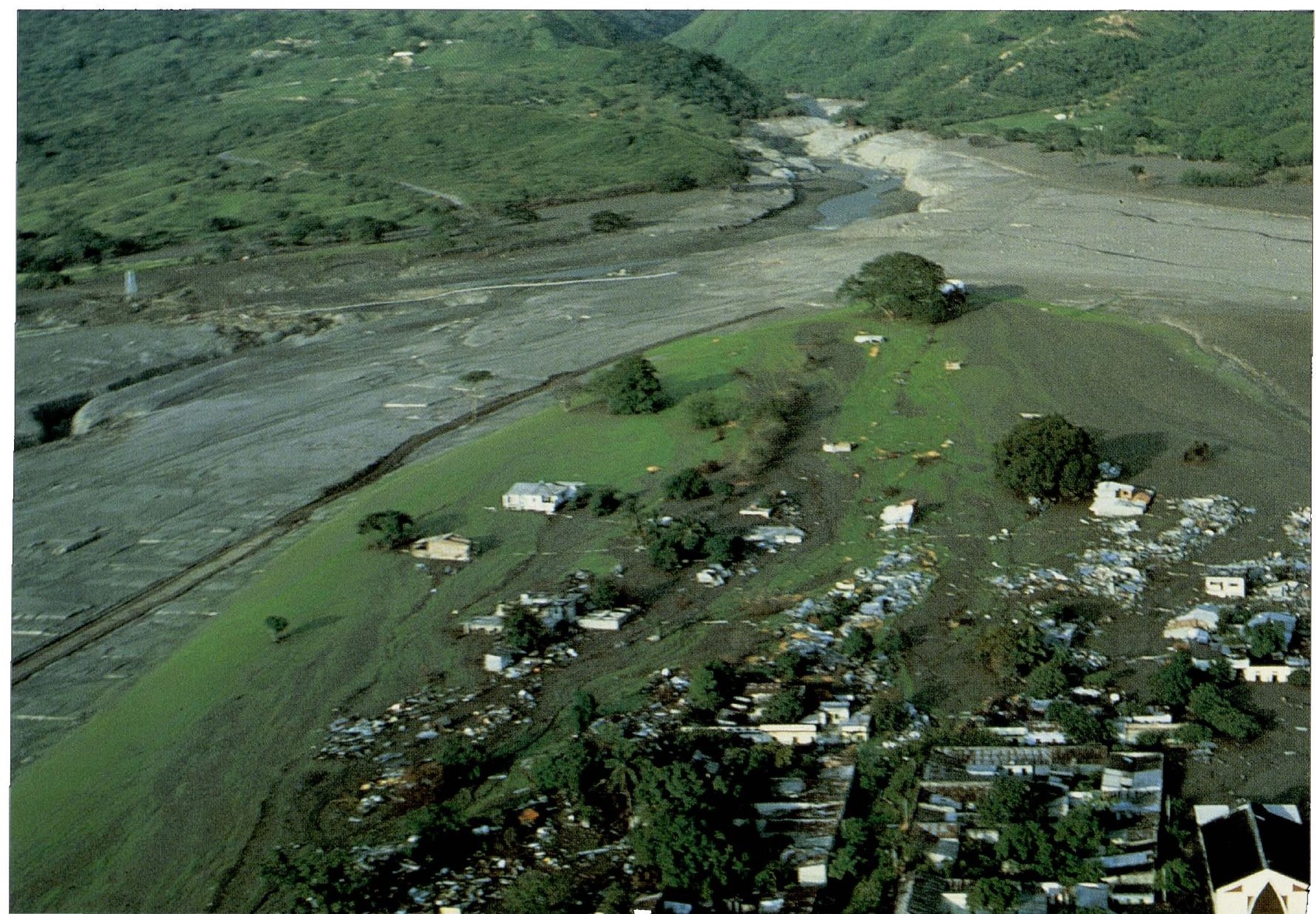


lava advances slowly enough to allow safe evacuation of people, but large lava flows can cause considerable economic loss by destroying property and agricultural lands. For example, lava from the ongoing eruption of Kilauea, which began in January 1983, has destroyed more than 200 structures, buried kilometers of highways, and disrupted the daily lives of local residents. Because Hawaiian volcanoes erupt frequently and pose little danger to humans, they provide an ideal natural laboratory to safely study volcanic phenomena at close range. The USGS Hawaiian Volcano Observatory, on the rim of Kilauea, was among the world's first modern volcano observatories, established early in this century.

In recorded history, explosive eruptions at subduction-zone (convergent-boundary) volcanoes have posed the greatest hazard to civilizations. Yet scientists have estimated that about three quarters of the material erupted on Earth each year originates at spreading mid-ocean ridges. However, no deep submarine eruption has yet been observed "live" by scientists. Because the great water depths preclude easy observation, few detailed studies have been made of the numerous possible eruption sites along the tremendous length $(50,000 \mathrm{~km})$ of the global mid-oceanic ridge system. Recently however, repeated surveys of specific sites along the Juan de Fuca Ridge, off the coast of the Oregon and Washington, have mapped deposits of fresh lava, which must have been erupted sometime between the surveys. In June 1993, seismic signals typically associated with submarine eruptions-called T-phases-were detected along part of the spreading Juan de Fuca Ridge and interpreted as being caused by eruptive activity.

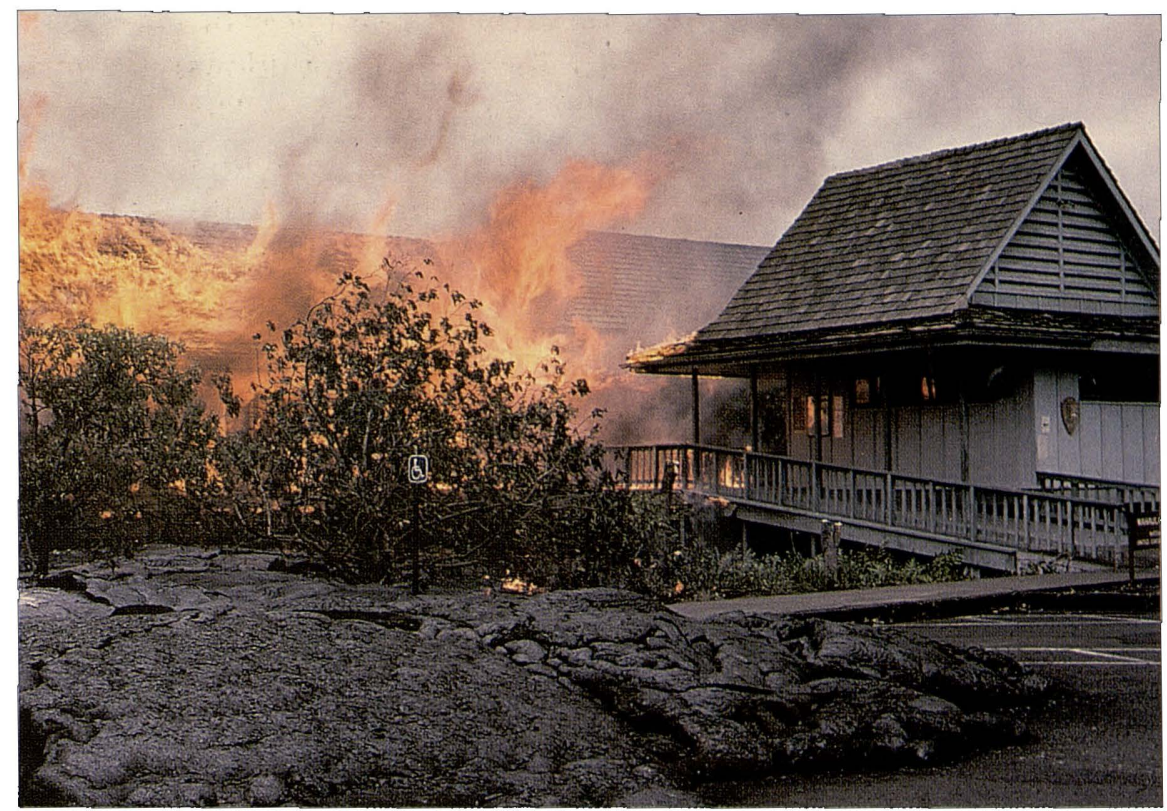

Iceland, where the Mid-Atlantic Ridge is exposed on land, is a different story. It is easy to see many Icelandic volcanoes erupt nonexplosively from fissure vents, in similar fashion to typical Hawaiian eruptions; others, like Hekla Volcano, erupt explosively. (After Hekla's catastrophic eruption in 1104, it was thought in the Christian world to be the "Mouth to Hell.") The voluminous, but mostly non-explosive, eruption at Lakagígar (Laki), Iceland, in 1783, resulted in one of the world's worst volcanic disasters.

About 9,000 people-almost $20 \%$ of the country's population at the time-died of starvation after the eruption, because their livestock had perished from grazing on grass contaminated by fluorine-rich gases emitted during this eight month-long eruption.
Wahaula Visitor Center, Hawaii Volcanoes National Park, was one of more than 200 structures overrun by lava flows (foreground) from the 1983present eruption at Kilauea Volcano. (Photograph by J.D. Griggs, USGS.) 


\section{Tsunamis}

Major earthquakes occurring along subduction zones are especially hazardous, because they can trigger tsunamis (from the Japanese word tsunami meaning "harbor wave") and pose a potential danger to coastal communities and islands that dot the Pacific. Tsunamis are often mistakenly called "tidal waves" when, in fact, they have nothing to do with tidal action.

Rather, tsunamis are seismic sea waves caused by earthquakes, submarine landslides, and, infrequently, by eruptions of island volcanoes. During a major earthquake, the seafloor can move by several meters and an enormous amount of water is suddenly set into motion, sloshing back and forth for several hours. The result is a series

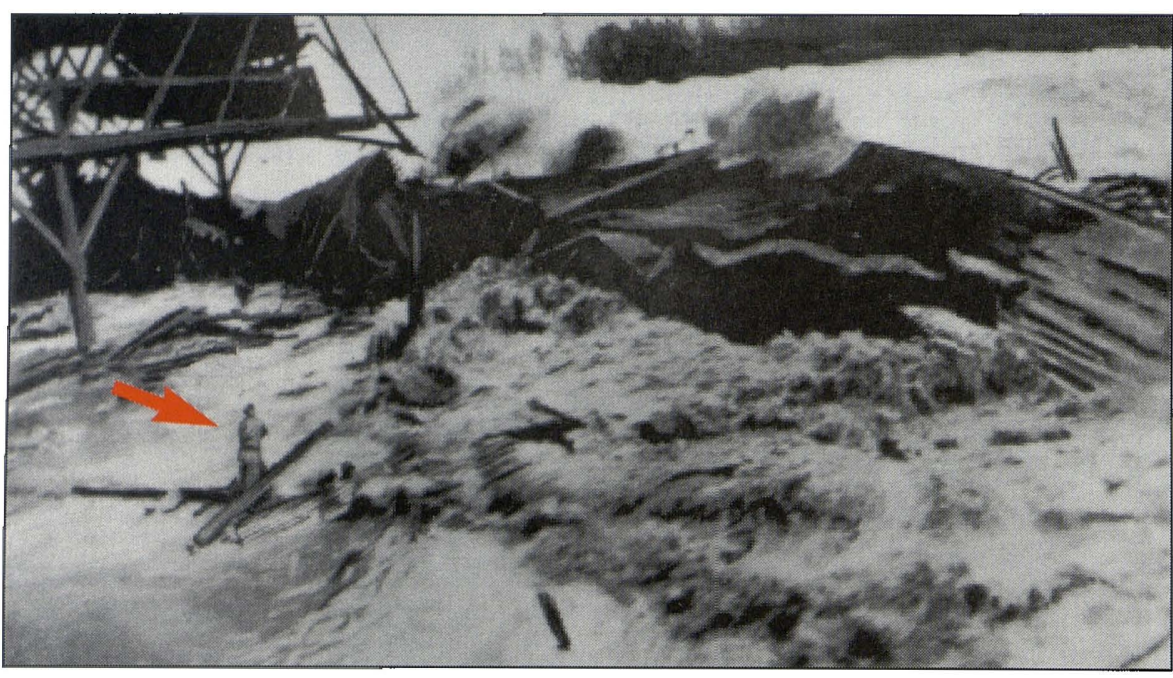

A giant wave engulfs the pier at Hilo, Hawaii, during the 1946 tsunami, which killed 159 people. The arrow points to a man who was swept away seconds later. (Retouched photograph courtesy of NOAA/EDIS.) of waves that race across the ocean at speeds of more than $800 \mathrm{~km}$ per hour, comparable to those of commercial jetliners. The energy and momentum of these trans-oceanic waves can take them thousands of kilometers from their origin before slamming into far-distant islands or coastal areas.

To someone on a ship in the open ocean, the passage of a tsunami wave would barely elevate the water surface. However, when it reaches shallower water near the coastline and "touches bottom," the tsunami wave increases in height, piling up into an enormous wall of water. As a tsunami approaches the shore, the water near shore commonly recedes for several minuteslong enough for someone to be lured out to collect exposed sea shells, fish, etc.--before suddenly rushing back toward land with frightening speed and height.

The 1883 eruption of Krakatau Volcano, located in the Sunda Straits between the islands of Sumatra and Java, Indonesia, provides an excellent example of an eruption-caused tsunami. A series of tsunamis washed away 165 coastal villages on Java and Sumatra, killing 36,000 people. The larger tsunamis were recorded by tide gauges as far away as the southern coast of the Arabian Peninsula-more than 7,000 km from Krakatau!

Because of past killer tsunamis, which have caused hundreds of deaths on the Island of Hawaii and elsewhere, the International Tsunami Information Center was created in 1965. This center issues tsunami warnings based on earthquake and wave-height information gathered from seismic and tide-gauge stations located around the Pacific Ocean basin and on Hawaii. 


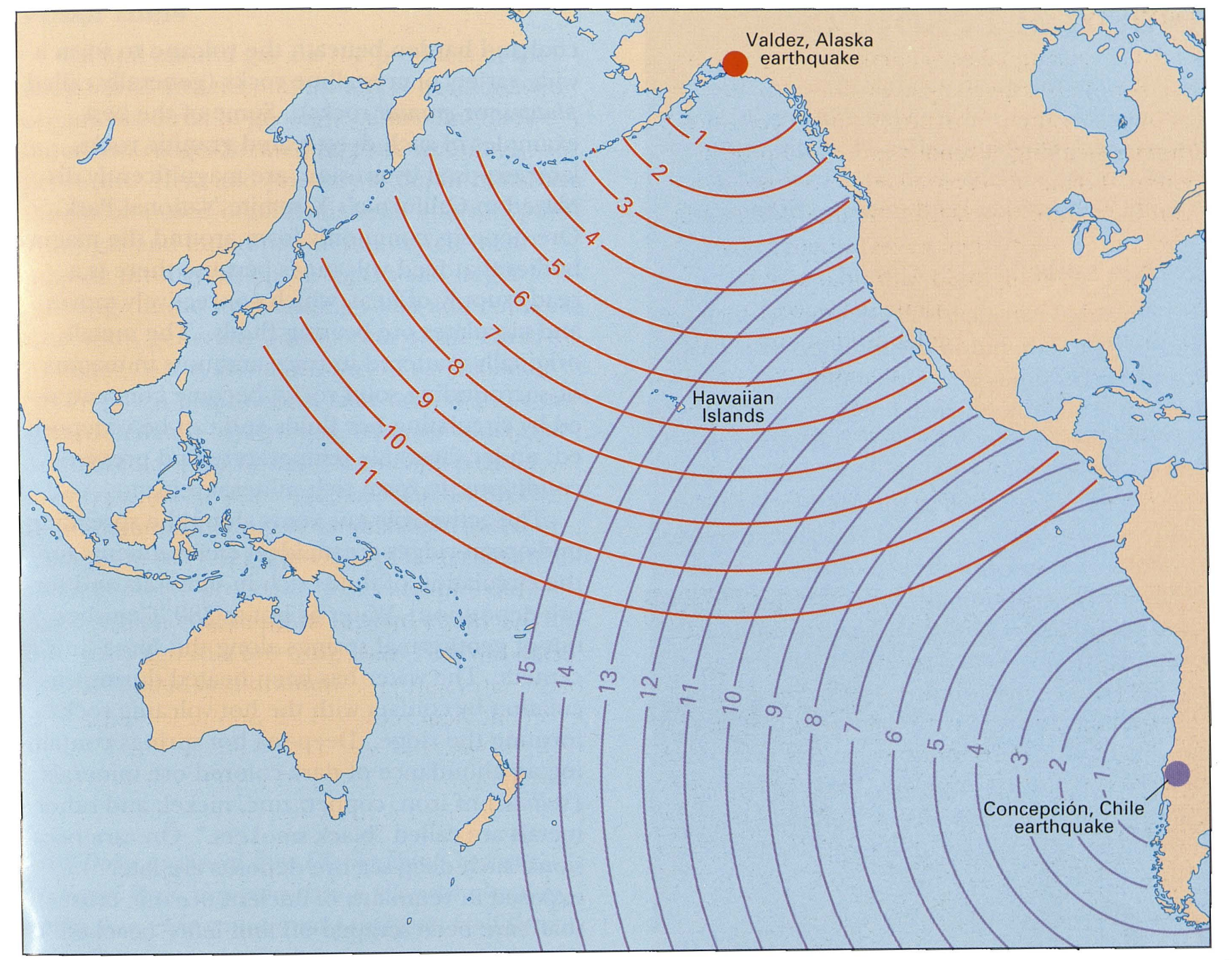

The Hawaiian Islands are especially vulnerable to destructive tsunamis generated by major earthquakes in the circum-Pacific Ring of Fire. Travel times (in hours) are shown for the tsunamis produced by the 1960 Concepcion, Chile, earthquake (purple curves) and by the 1964 Good Friday, Valdez (Anchorage), Alaska earthquake (red curves). The 1960 tsunamis killed 61 people and caused about $\$ 24$ million in damage. 


\section{Natural resources}

Many of the Earth's natural resources of energy, minerals, and soil are concentrated near past or present plate boundaries. The utilization of these readily available resources have sustained human civilizations, both now and in the past.

\section{Fertile soils}

Volcanoes can clearly cause much damage and destruction, but in the long term they also have benefited people. Over thousands to millions of years, the physical breakdown and chemical weathering of volcanic rocks have formed some of the most fertile soils on Earth. In tropical, rainy regions, such as the windward (northeastern) side of the Island of Hawaii, the formation of fertile soil and growth of lush vegetation following an eruption can be as fast as a few hundred years. Some of the earliest civilizations (for example, Greek, Etruscan, and Roman) settled on the rich, fertile volcanic soils in the Mediterranean-Aegean region. Some of the best ricegrowing regions of Indonesia are in the shadow of active volcanoes. Similarly, many prime agricultural regions in the western United States have fertile soils wholly or largely of volcanic origin.

\section{Ore deposits}

Most of the metallic minerals mined in the world, such as copper, gold, silver, lead, and zinc, are associated with magmas found deep within the roots of extinct volcanoes located above subduction zones. Rising magma does not always reach the surface to erupt; instead it may slowly cool and harden beneath the volcano to form a wide variety of crystalline rocks (generally called plutonic or granitic rocks). Some of the best examples of such deep-seated granitic rocks, later exposed by erosion, are magnificently displayed in California's Yosemite National Park. Ore deposits commonly form around the magma bodies that feed volcanoes because there is a ready supply of heat, which convectively moves and circulates ore-bearing fluids. The metals, originally scattered in trace amounts in magma or surrounding solid rocks, become concentrated by circulating hot fluids and can be redeposited, under favorable temperature and pressure conditions, to form rich mineral veins.

The active volcanic vents along the spreading mid-ocean ridges create ideal environments for the circulation of fluids rich in minerals and for ore deposition. Water as hot as $380^{\circ} \mathrm{C}$ gushes out of geothermal springs along the spreading centers. The water has been heated during circulation by contact with the hot volcanic rocks forming the ridge. Deep-sea hot springs containing an abundance of dark-colored ore minerals (sulfides) of iron, copper, zinc, nickel, and other metals are called "black smokers." On rare occasions, such deep-sea ore deposits are later exposed in remnants of ancient oceanic crust that have been scraped off and left ("beached") on top of continental crust during past subduction processes. The Troodos Massif on the Island of Cyprus is perhaps the best known example of such ancient oceanic crust. Cyprus was an important source of copper in the ancient world, and Romans called copper the "Cyprian metal"; the Latin word for copper is cyprium. 


\section{Fossil fuels}

Oil and natural gas are the products of the deep burial and decomposition of accumulated organic material in geologic basins that flank mountain ranges formed by plate-tectonic processes. Heat and pressure at depth transform the decomposed organic material into tiny pockets of gas and liquid petroleum, which then migrate through the pore spaces and larger openings in the surrounding rocks and collect in reservoirs, generally within $5 \mathrm{~km}$ of the Earth's surface. Coal is also a product of accumulated decomposed plant debris, later buried and compacted beneath overlying sediments. Most coal originated as peat in ancient swamps created many millions of years ago, associated with the draining and flooding of landmasses caused by changes in sea level related to plate tectonics and other geologic processes. For example, the Appalachian coal deposits formed about 300 million years ago in a low-lying basin that was alternately flooded and drained.

Half Dome as viewed from Glacier Point, Yosemite National Park, rises more than a kilometer above the valley floor. The granitic rocks that form Half Dome and other spectacular Park features represent unerupted magma later exposed by deep erosion and glaciation. (Photograph by Carroll Ann Hodges, USGS.)

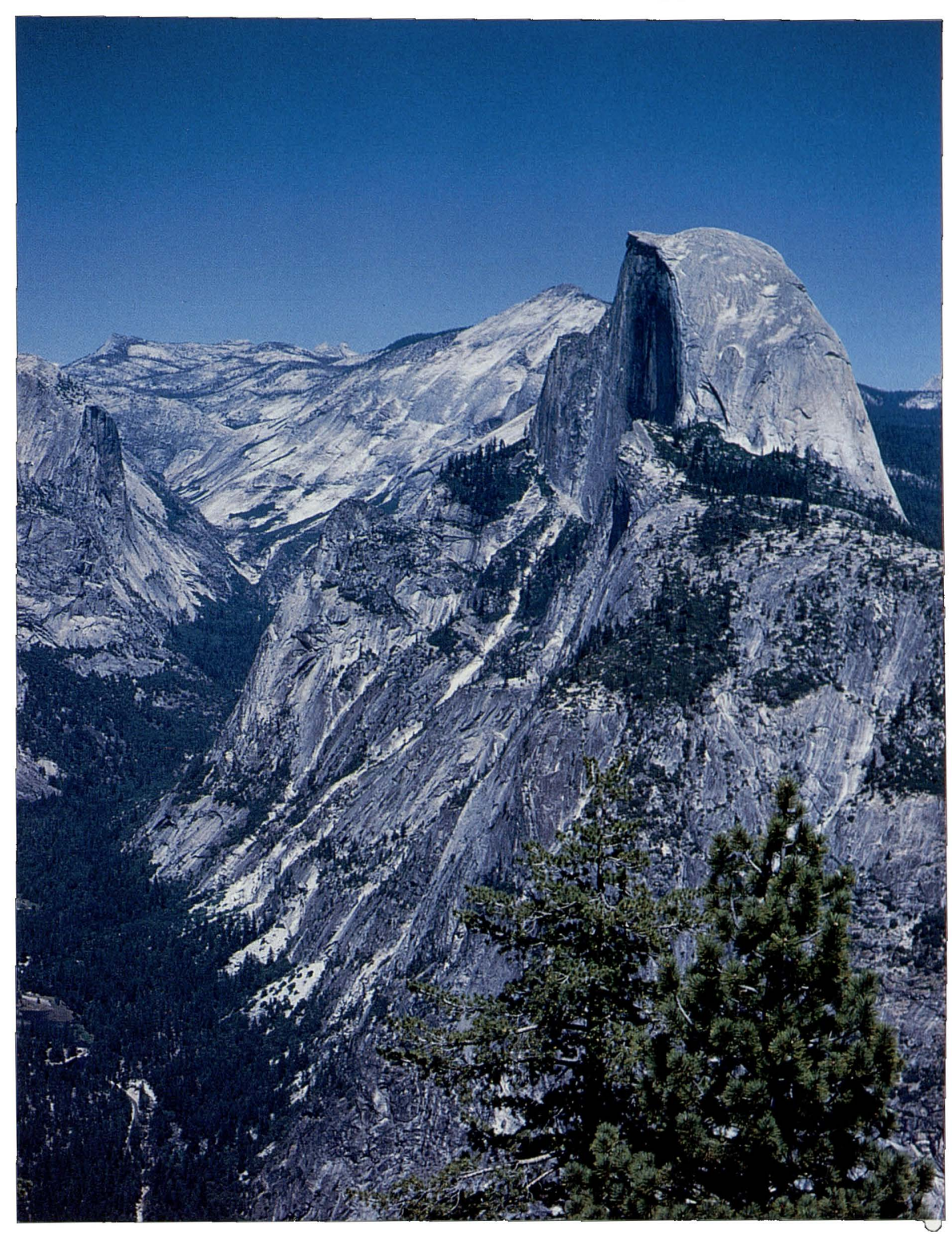


Geothermal powerplant at The Geysers near the city of Santa Rosa in northern California. The Geysers area is the largest geothermal development in the world. (Photograph by Julie DonnellyNolan, USGS.)

$\sqrt{1}$

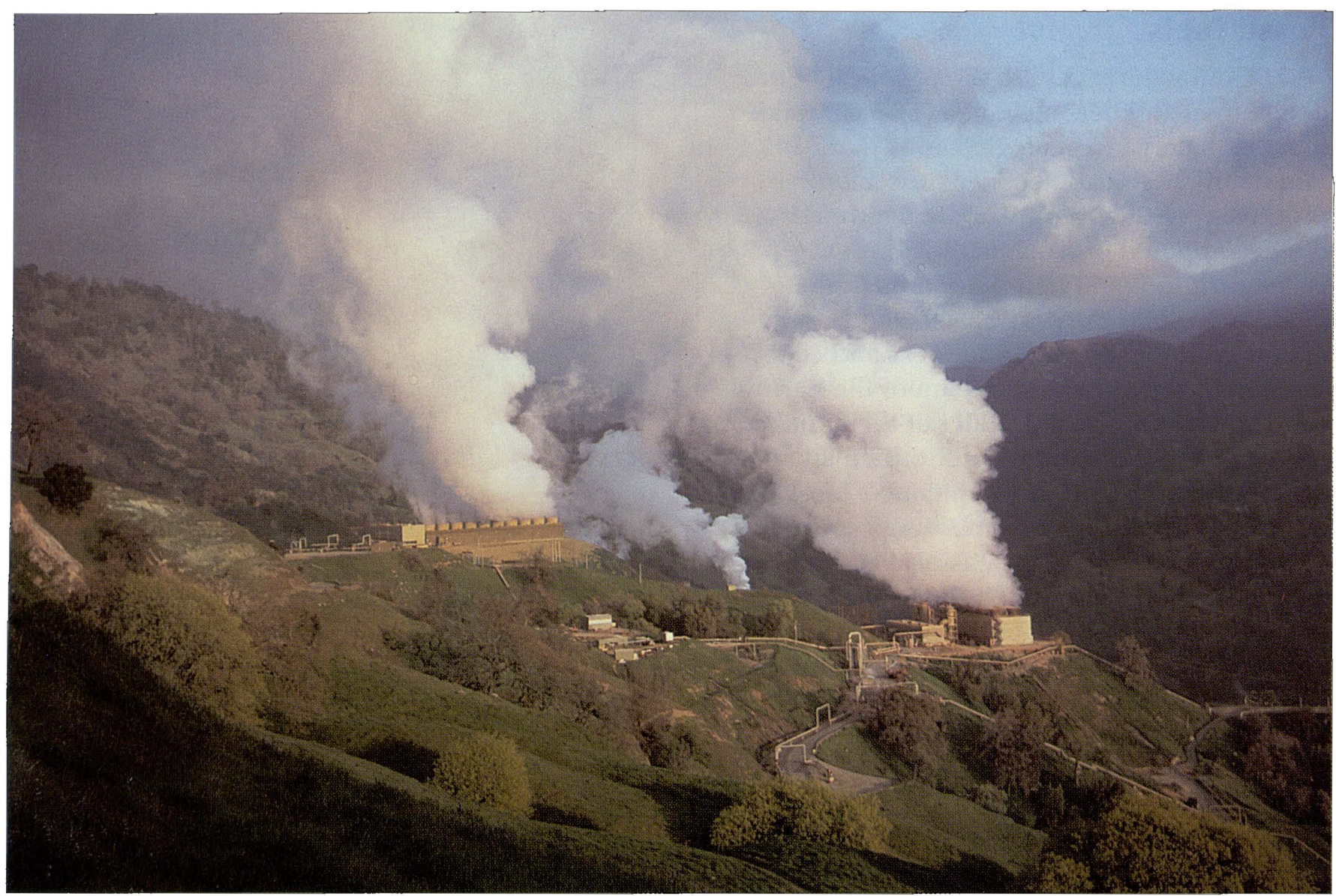

\section{Geothermal energy}

Geothermal energy can be harnessed from the Earth's natural heat associated with active volcanoes or geologically young inactive volcanoes still giving off heat at depth. Steam from high-temperature geothermal fluids can be used to drive turbines and generate electrical power, while lower temperature fluids provide hot water for space-heating purposes, heat for greenhouses and industrial uses, and hot or warm springs at resort spas. For example, geothermal heat warms more than 70 percent of the homes in Iceland, and The Geysers geothermal field in Northern California produces enough electricity to meet the power demands of San Francisco. In addition to being an energy resource, some geothermal waters also contain sulfur, gold, silver, and mercury that can be recovered as a byproduct of energy production. 


\section{A formidable challenge}

As global population increases and more countries become industrialized, the world demand for mineral and energy resources will continue to grow. Because people have been using natural resources for millennia, most of the easily located mineral, fossil-fuel, and geothermal resources have already been tapped. By necessity, the world's focus has turned to the more remote and inaccessible regions of the world, such as the ocean floor, the polar continents, and the resources that lie deeper in the Earth's crust. Finding and developing such resources without damage to the environment will present a formidable challenge in the coming decades. An improved knowledge of the relationship between plate tectonics and natural resources is essential to meeting this challenge.

The long-term benefits of plate tectonics should serve as a constant reminder to us that the planet Earth occupies a unique niche in our solar system. Appreciation of the concept of plate tectonics and its consequences has reinforced the notion that the Earth is an integrated whole, not a random collection of isolated parts. The global effort to better understand this revolutionary concept has helped to unite the earthsciences community and to underscore the linka ses between the many different scientific discivines. As we enter the 21st century, when the Earth's finite resources will be further strained by explosive population growth, earth scientists must strive to better understand our dynamic planet. We must become more resourceful in reaping the long-term benefits of plate tectonics, while coping with its short-term adverse impacts, such as earthquakes and volcanic eruptions.
Farmer plowing a lush rice paddy in central Java, Indonesia; Sundoro Volcano looms in the background. The most highly prized rice-growing areas have fertile soils formed from the breakdown of young volcanic deposits. (Photograph by Robert I. Tilling, USGS.)

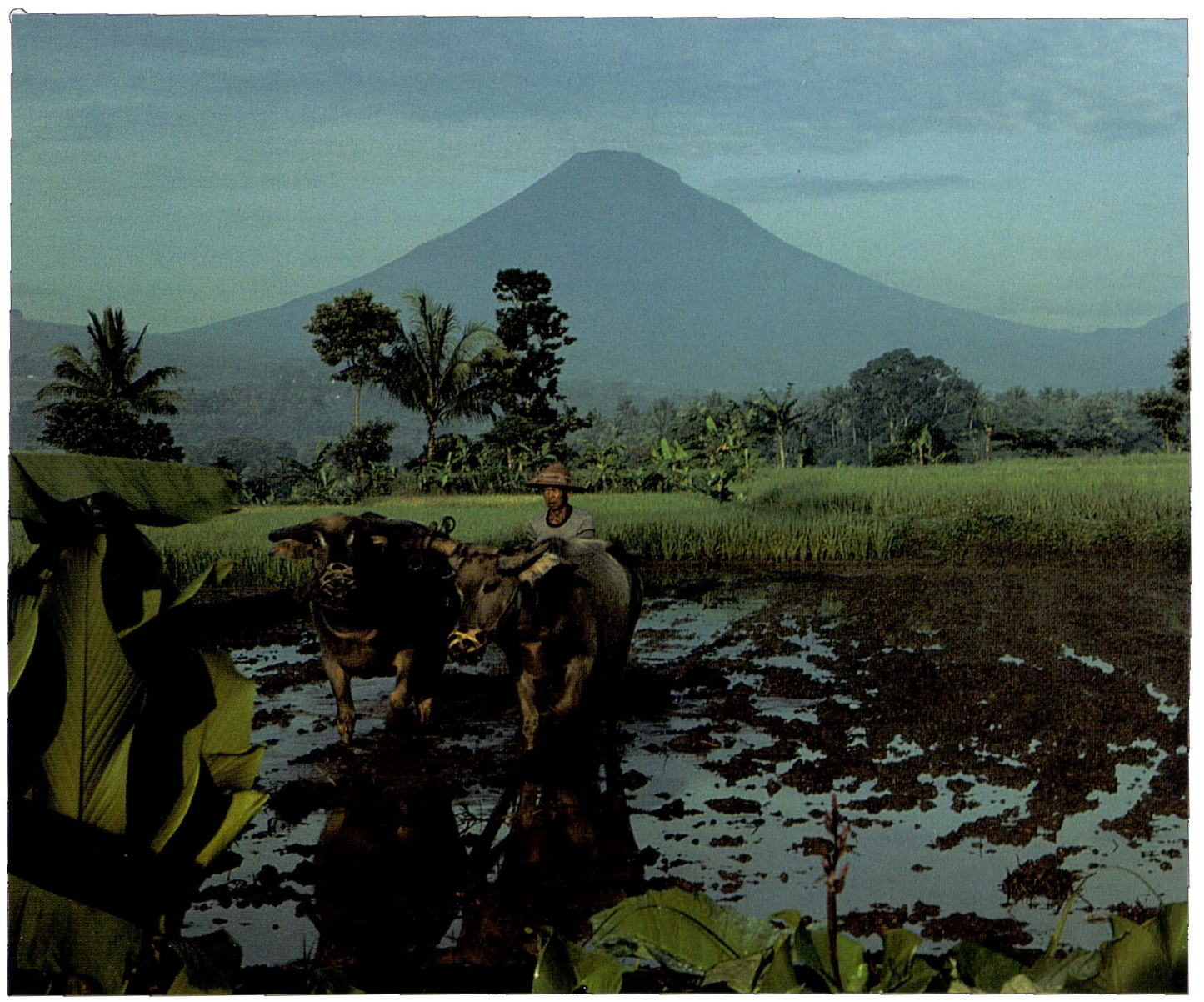




\section{Further reading}

These works listed furnish additional information on topics not covered, or only briefly discussed, in the booklet.

Attenborough, David, 1986, The Living Planet: British Broadcasting Corporation, 320 p. (An informative, narrative version of the highly successful television series about how the Earth works.)

Coch, N.K., and Ludman, Allan, 1991, Physical

Geology: Macmillan Publishing Company, New York, $678 \mathrm{p}$. (Well-illustrated college textbook that contains excellent chapters on topics related to Earth dynamics and plate tectonics.)

Cone, Joseph, 1991, Fire Under the Sea: William Morrow and Company, Inc., New York, 285 p. (paperback). (A readable summary of oceanographic exploration and the discovery of volcanic hot springs on the ocean floor.)

Decker, Robert, and Decker, Barbara, 1989, Volcanoes: W.H. Freeman and Company, New York, 285 p. (paperback). (An excellent introduction to the study of volcanoes written in an easy-toread style.)

Duffield, W.A., Sass, J.H., and Sorey, M.L., 1994, Tapping the Earth's Natural Heat: U.S. Geological Survey Circular 1125, 63 p. (A full-color book that describes, in non-technical terms, USGS studies of geothermal resources-one of the benefits of plate tectonics-as a sustainable and relatively nonpolluting energy source.)

Ernst, W.G., 1990, The Dynamic Planet: Columbia University Press, New York, 280 p. (A comprehensive college-level textbook that includes good chapters on plate tectonics and related topics.)
Heliker, Christina, 1990, Volcanic and seismic hazards of the Island of Hawaii: U.S. Geological Survey general-interest publication, $48 \mathrm{p}$. (A full-color booklet summarizing the volcanic, seismic, and tsunami hazards.)

Krafft, Maurice, 1993, Volcanoes: Fire from the Earth: Harry N. Abrams, New York, 207 p. (paperback). (A well-illustrated, non-technical primer on volcanoes; Maurice Krafft and his wife Katia were the world's foremost photographers of volcanoes before they were killed during the June 1991 eruption of Unzen Volcano, Japan.)

Lindh, A.G., 1990, Earthquake prediction comes of age: Technology Review, Feb/March, p. 42-51. (A good introduction to the basis and techniques used by scientists in attempting to predict earthquakes.)

McNutt, Steve, 1990, Loma Prieta earthquake, October 17, 1989: An overview: California Geology, v. 43, no. 1, p. 3-7. (Along with the companion article by D.D. Montgomery, gives the essential information about this destructive earthquake along the San Andreas Fault.)

McPhee, John, 1993, Assembling California: Farrar, Straus, \& Giroux, New York, 303 p. (A fascinating account of the role of plate tectonics in the geology of California, told in the typical McPhee style of conversations with scientists.)

Montgomery, D.D., 1990, Effects of the Loma Prieta earthquake, October 17, 1989: California Geology, v. 43 , no. 1, p. 8-13. (Along with the companion article by Steve McNutt, gives the essential information about this destructive earthquake along the San Andreas Fault.)

Ritchie, David, 1981, The Ring of Fire: New American Library, New York, 204 p. (paperback). (A popularized account of earthquakes, volcanoes, and tsunamis that frequently strike the circumPacific regions.) 
Schulz, S.S., and Wallace, R.E., 1989, The San Andreas Fault: U.S. Geological Survey generalinterest publication, $16 \mathrm{p}$. (This little booklet provides the basic information about the San Andreas Fault Zone, including a good discussion of earthquakes that occur frequently along it.)

Simkin, Tom, Unger, J.D., Tilling, R.I., Vogt, P.R., and Spall, Henry, compilers, 1994, This Dynamic Planet: World map of volcanoes, earthquakes, impact craters and plate tectonics: 1 sheet, U.S. Geological Survey (USGS). (In addition to the map's visually obvious physiographic features that relate to plate tectonics, the explanatory text gives a concise summary of how plate tectonics work.)

Sullivan, Water, 1991, Continents'in Motion: McGrawHill Book Co., New York, 430 p. (A comprehensive review of the developments that culminated in the plate tectonics theory. Science Editor of the New York Times, Sullivan is widely regarded as the "dean" of America's science writers.)

Tarbuck, Edward, and Lutgens, Frederick, 1985, Earth Science: Charles E. Merrill Publishing Co., Columbus, Ohio, 561 p. (A college-level geology textbook that contains good chapters on plate tectonics and related topics.)

Tilling, R.I., 1991, Born of fire: Volcanoes and igneous rocks: Enslow Publishers, Inc., Hillside, New Jersey, 64 p. (An introductory text about the kinds of volcanoes and their products and hazardous impacts-aimed at approximately junior high- to high-school level.)

Tilling, R.I., Heliker, C., and Wright, T.L., 1987, Eruptions of Hawaiian Volcanoes: Past, present, and future: U.S. Geological Survey general-interest publication, 54 p. (A nontechnical summary, illustrated by many color photographs, of the abundant data on Hawaiian volcanism; similar in format to this book.)
Tilling, R.I., Topinka, Lyn, and Swanson, D.A., 1990, Eruptions of Mount St. Helens: Past, present, and future: U.S. Geological Survey general-interest publication, 56 p. (A nontechnical summary, illustrated by many color photographs and diagrams, of the abundant scientific data available for the volcano, with emphasis on the catastrophic eruption of 18 May 1980; similar in format to this book.)

Time-Life Books Inc., 1982, Volcano: 1983,

Continents in Collision, in Planet Earth Series: Alexandria, Virginia, Time-Life Books, 176 p. each. (Informative and general surveys of volcanism and plate tectonics.)

Wright, T.L., and Pierson, T.C., 1992, Living with vol canoes: U.S. Geological Survey Circular 1073, 57 p. (A non-technical summary of the USGS' Volcano Hazards Program, highlighting the scientific studies used in forecasting eruptions and assessing volcanic hazards, in the United States and abroad.)

This publication is one of a series of general interest publications prepared by the U.S. Geological Survey to provide information about the earth sciences, natural resources, and the environment. To obtain a catalog of additional titles in the series "General Interest Publications of the U.S. Geological Survey," write:

$$
\text { U.S. Geological Survey }
$$

Branch of Information Services

Denver, CO 80225 


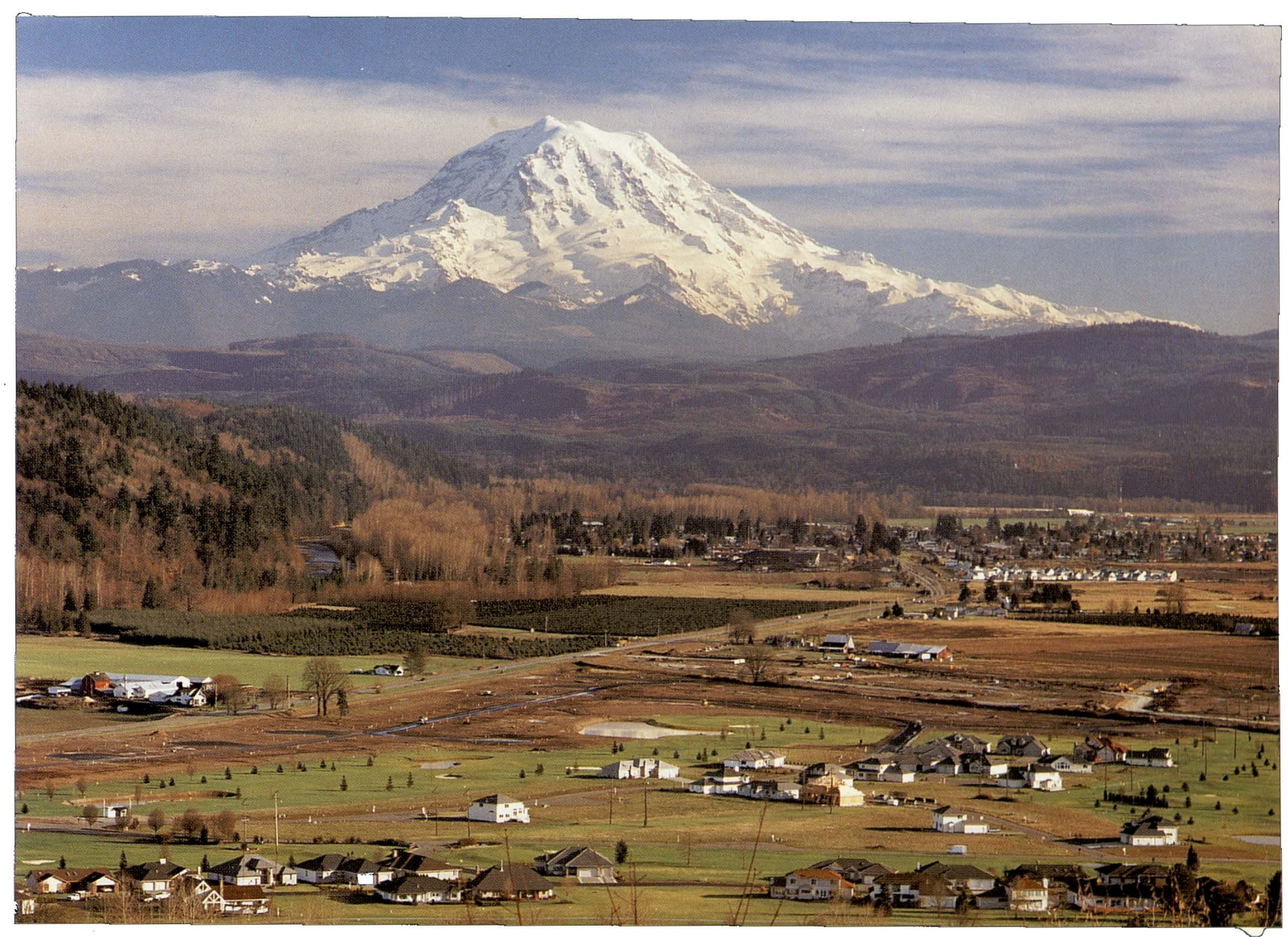

Snow-clad Mt. Rainier, a 4,392 m-high volcano built by plate-tectonic processes, dominates the pastoral scene around Orting, Washington. This valley is an inviting place for people to live, work, and play, but it is also highly vulnerable to destructive mudflows that could be generated by renewed eruptive activity at Mt. Rainier. Society must learn to "co-exist" intelligently with active volcanoes. (Photograph by David E. Wieprecht, USGS.)

For sale by the U.S. Government Printing Office

Superintendent of Documents, Mail Stop: SSOP, Washington, DC 20402-9328

ISBN $0-16-048220-8$ 


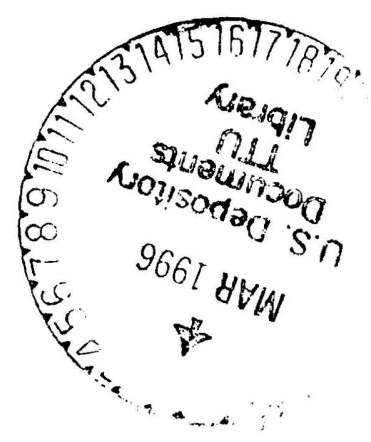

As the Nation's principal conservation agency, the Department of the Interior has responsibility for most of our nationally owned public lands and natural and cultural resources. This includes fostering sound use of our land and water resources; protecting our fish, wildlife, and biological diversity; preserving the environmental and cultural values of our national parks and historical places; and providing for the enjoyment of life through outdoor recreation. The Department assesses our energy and mineral resources and works to ensure that their development is in the best interests of all our people by encouraging stewardship and citizen participation in their care. The Department also has a major responsibility for American Indian reservation communities and for people who live in island territories under U.S. administration.

ISBN $0-16-048220-8$

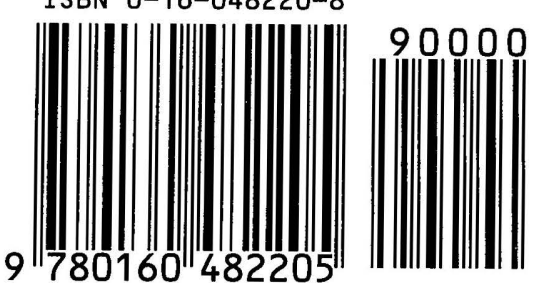

